\title{
Battery Test Manual for Plug-In Hybrid Electric Vehicles
}

\author{
March 2008
}

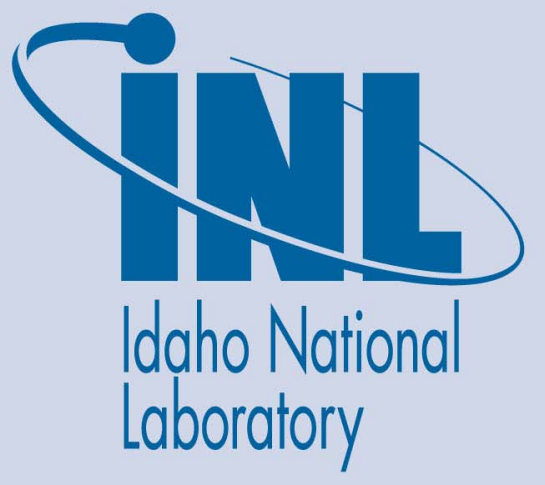

The INL is a U.S. Department of Energy National Laboratory operated by Battelle Energy Alliance 
INL/EXT-07-12536

\title{
Battery Test Manual for Plug-In Hybrid Electric Vehicles
}

March 2008

\begin{abstract}
Idaho National Laboratory
Idaho Falls, Idaho 83415
\end{abstract}

Prepared for the

U.S. Department of Energy

Assistant Secretary for Energy Efficiency and Renewable Energy Under DOE Idaho Operations Office

Contract DE-AC07-05ID14517 
INL/EXT-07-12536

\title{
U.S. Department of Energy \\ Vehicle Technologies Program
}

\author{
Battery Test Manual \\ For Plug-In Hybrid Electric Vehicles
}

\author{
REVISION 0
}

MARCH 2008

The Idaho National Laboratory is a U.S. Department of Energy National

Laboratory

Operated by Battelle Energy Alliance 


\section{Disclaimer}

This manual was prepared as an account of work sponsored by an agency of the United States Government. Neither the United States Government nor any agency thereof, nor any of their employees, makes any warranty, express or implied, or assumes any legal liability or responsibility for the accuracy, completeness, or usefulness of any information, apparatus, product, or process disclosed, or represents that its use would not infringe privately owned rights. References herein to any specific commercial product, process or service by trade name, trademark, manufacturer, or otherwise does not necessarily constitute or imply its endorsement, recommendation, or favoring by the United States Government or any agency thereof. The views and opinions of authors expressed herein do not necessarily state or reflect those of the United States Government or any agency thereof. 


\section{FOREWORD}

This battery test procedure manual was prepared for the United States Department of Energy (DOE), Office of Energy Efficiency and Renewable Energy (EERE), Vehicle Technologies Program. It is based on technical targets established for energy storage development projects aimed at meeting system level DOE goals for Plug-in Hybrid Electric Vehicles (PHEV). The specific procedures defined in this manual support the performance and life characterization of advanced battery devices under development for PHEV's. However, it does share some methods described in the previously published battery test manual for power-assist hybrid electric vehicles.

Due to the complexity of some of the procedures and supporting analysis, a revision including some modifications and clarifications of these procedures is expected. As in previous battery and capacitor test manuals, this version of the manual defines testing methods for full-size battery systems, along with provisions for scaling these tests for modules, cells or other subscale level devices.

The DOE-United States Advanced Battery Consortium, Electrochemical Energy Storage Technical Team supported the development of the manual. Technical Team points of contact responsible for its development and revision are Harshad Tataria of General Motors Corporation and Jeffrey R. Belt of the Idaho National Laboratory.

The development of this manual was funded by the Unites States Department of Energy, Office of Energy Efficiency and Renewable Energy, Vehicle Technologies Program. Technical direction from DOE was provided by David Howell, Energy Storage R\&D Manager, and Tien Duong, Hybrid Electric Systems Team Leader.

Comments and questions regarding the manual should be directed to Jeffrey R. Belt at the Idaho National Laboratory. (jeffrey.belt@inl.gov). 


\section{CONTENTS}

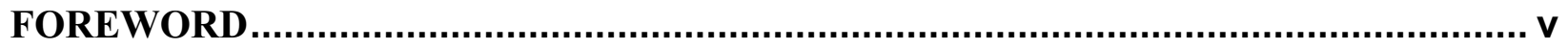

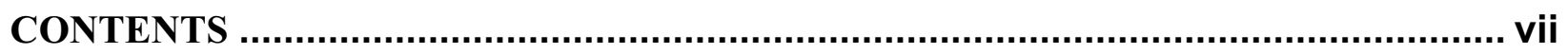

FIGURES

TABLES

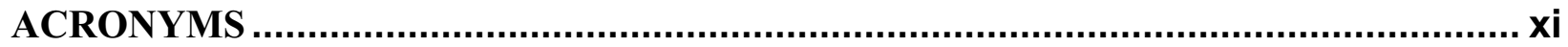

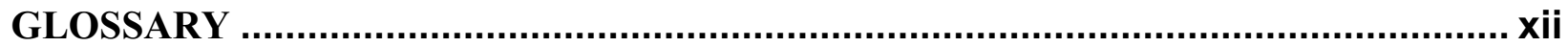

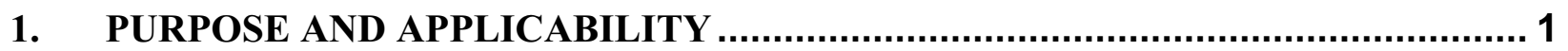

1.1 Energy Storage Targets For Plug-In Hybrid Electric Vehicles .................................................. 1

2. TEST PROFILES DERIVED FROM TARGETS …......................................... 2

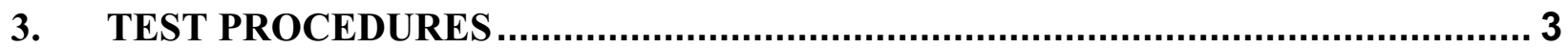

3.1 General Test Conditions and Scaling ............................................................................ 3

3.1.1 Temperature Control................................................................................

3.1.2 Scaling of Performance and Cycle Life Test Profile .............................................. 3

3.1.3 Scaling of HPPC-Current........................................................................... 4

3.1.4 Charging Procedure ……………………………………………………… 4

3.2 Static Capacity Test …………………………………………………………….... 4

3.3 Constant Power Discharge Tests............................................................................... 5

3.4 Hybrid Pulse Power Characterization Test ……………………………………………….... 5

3.4.1 Hybrid Pulse Power Characterization Test Profile …………………………….... 5

3.4.2 Test Procedure Description............................................................................. 6

3.4.3 Charge-Sustaining Available Energy Verification Test.......................................... 8

3.4.4 Charge-Depleting Available Energy Verification Test......................................... 9

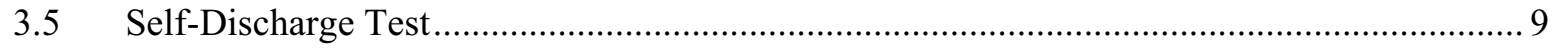

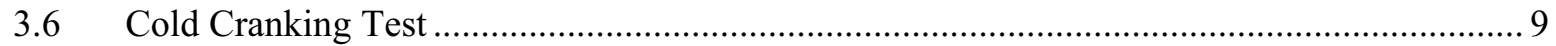

3.6.1 Cold Cranking Test Profile .............................................................................. 10

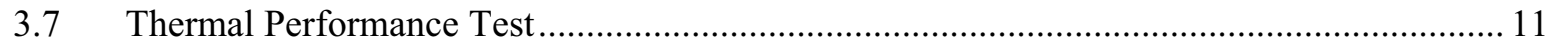

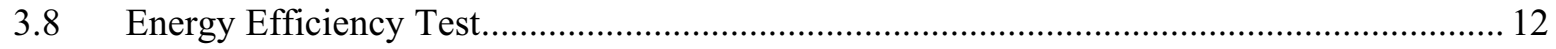

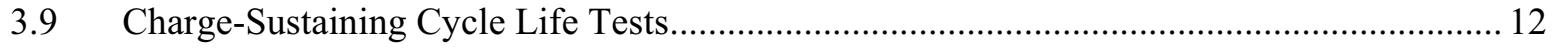

3.9.1 Cycle Life Test Procedure Outline ………………………………………..... 12

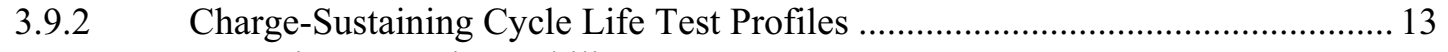

3.9.3 Operating Set Point Stability Test................................................................... 15

3.10 Charge-Depleting Cycle Life Tests................................................................................. 16

3.10.1 Cycle Life Test Procedure Outline …………………………………………..... 16

3.10.2 Charge-Depleting Cycle Life Test Profile ………………………………………1 17

3.10.3 Combined Cycle Life Test............................................................................ 19

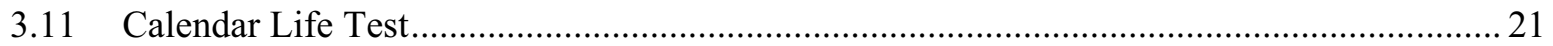

3.11.1 Calendar Life Test Planning ……………………………………………22

3.11.2 Calendar Life Test Procedure ………………………………………………. 22 


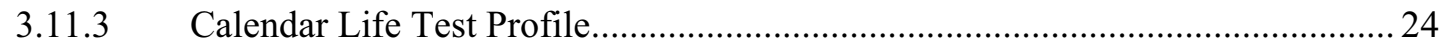

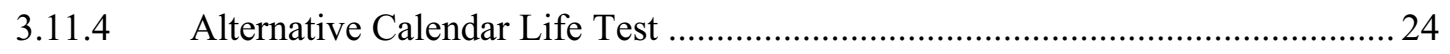

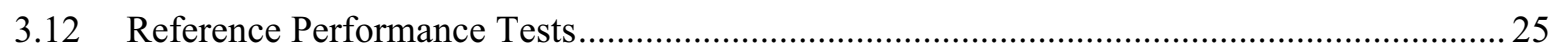

4. ANALYSIS AND REPORTING OF TEST RESULTS .................................. 27

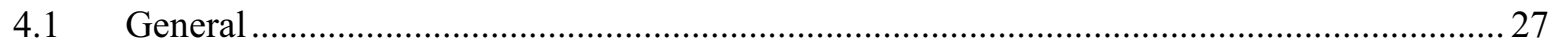

4.2 Static Capacity Test and Constant Power Discharge Test ............................................... 27

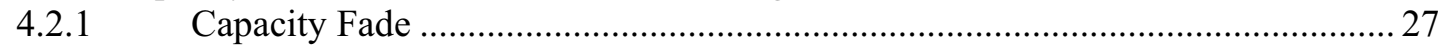

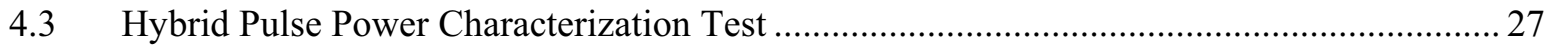

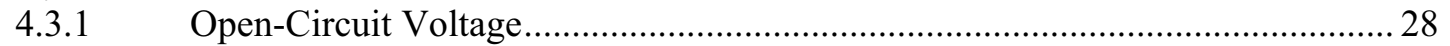

4.3.2 Calculated Resistance Characteristics as a Function of Depth-of-Discharge ...... 28

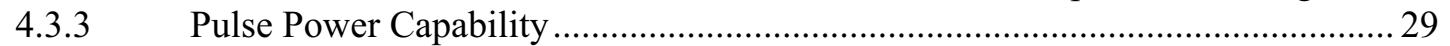

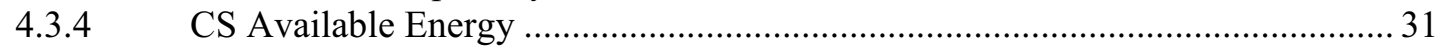

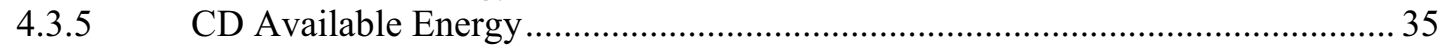

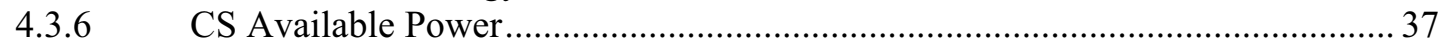

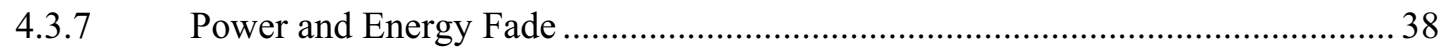

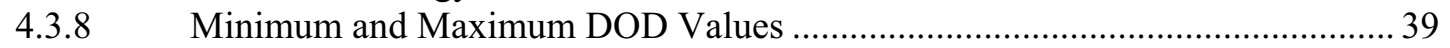

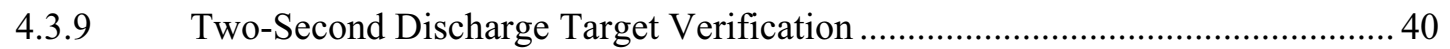

4.3.10 Pulse Power Characterization Profile Voltage Response ...................................... 40

4.3.11 Other Laboratory Cell Performance Characteristics........................................... 40

4.3.12 Determining Battery Size Factor When Not Supplied By Manufacturer ............ 41

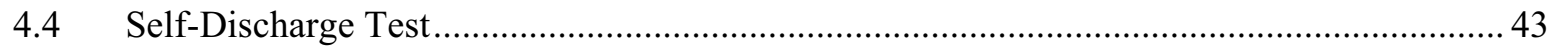

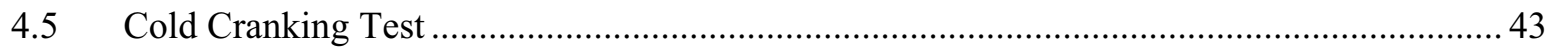

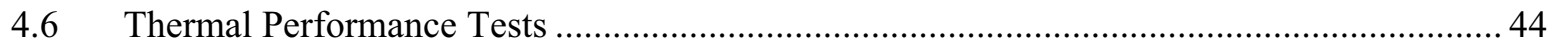

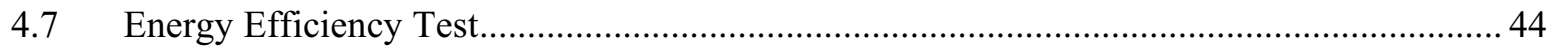

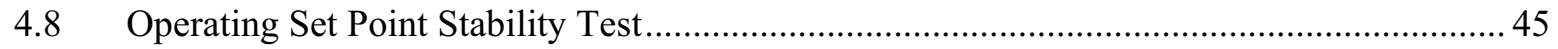

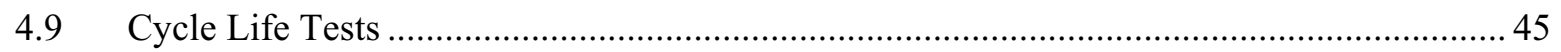

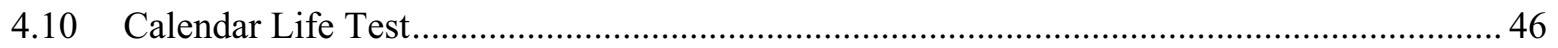

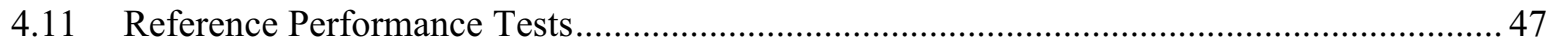

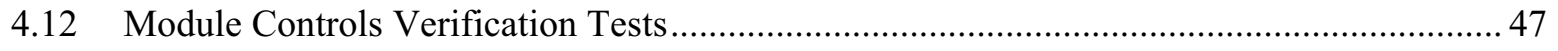

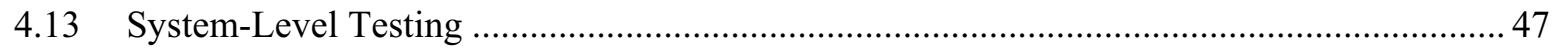

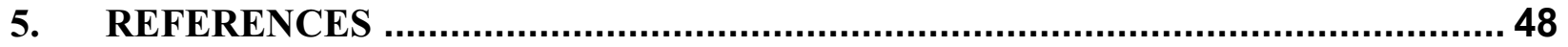

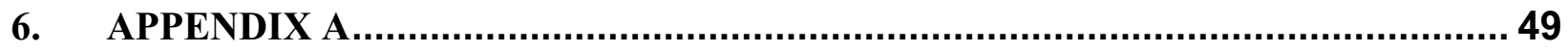

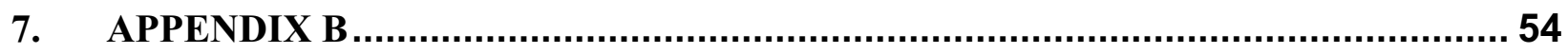




\section{FIGURES}

Figure 1. Hybrid Pulse Power Characterization Test Profile................................................................ 6

Figure 2. Hybrid Pulse Power Characterization Test (start of test sequence) ......................................... 7

Figure 3. Hybrid Pulse Power Characterization Test (complete HPPC sequence).................................. 7

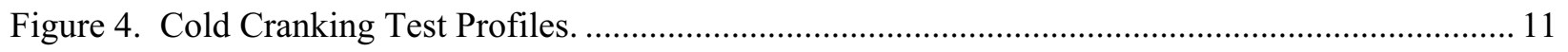

Figure 5. Charge-Sustaining Minimum PHEV Battery (50 Wh) Cycle Life Test Profile. ........................ 14

Figure 6. Charge-Sustaining Maximum PHEV Battery (50 Wh) Cycle Life Test Profile........................ 15

Figure 7. Charge-Depleting Cycle Life Test Profile for the Minimum PHEV Battery........................... 19

Figure 8. Charge-Depleting Cycle Life Test Profile for the Maximum PHEV Battery ...........................2 21

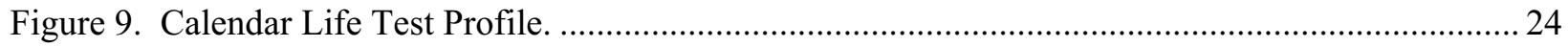

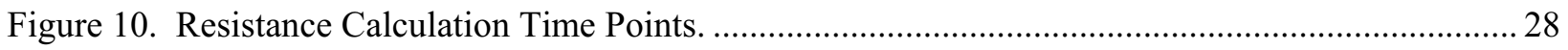

Figure 11. Open-Circuit Voltage and Pulse Resistances versus Depth-of-Discharge. ............................29

Figure 12. Pulse Power Capability vs. Depth-of-Discharge. ............................................................... 30

Figure 13. Relationship Between Energy and DOD in a 10-kW Discharge........................................ 32

Figure 14. Unscaled HPPC Cell Power Capability vs. Energy Removed.............................................. 33

Figure 15. HPPC Power vs. HPPC-Current Discharge Energy Scaled by the Battery Size Factor........... 34

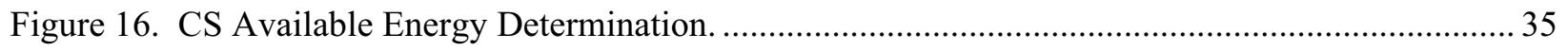

Figure 17. Charge-Depleting and Sustaining Available Energy Determination...................................... 36

Figure 18. CD and CS Available Energy Margins Over Life............................................................ 37

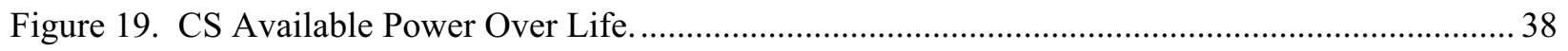

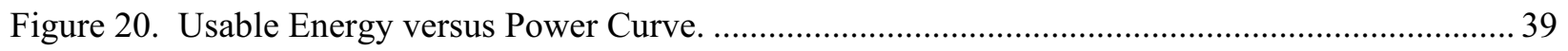

Figure 21. Minimum and Maximum DOD Values Where Targets Are Met. ........................................ 40

Figure 22. Finding a Battery Size Factor Using Device-Level Results. .............................................. 42

Figure 23. Cold Cranking Test Resistance Calculation Points. ............................................................ 44 


\section{TABLES}

Table 1. Energy Storage System Performance Targets for Plug-In Hybrid Electric Vehicles (January 2007)

Table 2. Hybrid Pulse Power Characterization Test Profile. …............................................................... 6

Table 3. Cold Cranking Test Profiles for Plug-In Hybrid Targets....................................................... 10

Table 4. Charge-Sustaining Minimum PHEV Battery (50 Wh) Cycle Life Test Profile.......................... 14

Table 5. Charge-Sustaining Maximum PHEV Battery (50 Wh) Cycle Life Test Profile......................... 15

Table 6. Charge-Depleting Cycle Life Test Profile for the Minimum PHEV Battery ............................ 18

Table 7. Charge-Depleting Cycle Life Test Profile for the Maximum PHEV Battery...........................20

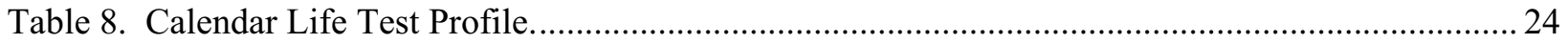

Table 9. Reference Performance Tests and Test Intervals for Life Testing..........................................25

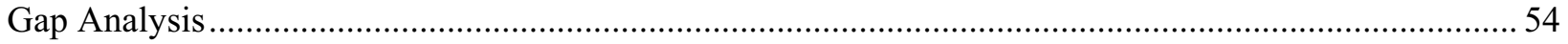




\title{
ACRONYMS
}

\author{
ASI area-specific impedance \\ BSF battery size factor \\ BOL beginning-of-life \\ CD charge-depleting \\ CS charge-sustaining \\ DOD depth-of-discharge \\ EOL end-of-life \\ EV electric vehicle \\ HEV hybrid electric vehicle \\ HPPC hybrid pulse power characterization \\ OCV open-circuit voltage \\ OSPS operating set point stability \\ PHEV plug-in hybrid electric vehicle \\ PNGV Partnership for a New Generation of Vehicles \\ RPT reference performance test \\ SOC state-of-charge \\ TLVT technology life verification tests \\ USABC United States Advanced Battery Consortium
}




\section{GLOSSARY}

CS Available Power -the discharge pulse power at which the usable energy is equal to the Charge-Sustaining Available Energy target for a given mode (Minimum or Maximum PHEV).

Battery Size Factor (BSF) - for a particular cell or module design, an integer which is the minimum number of cells or modules expected to be required to meet all the performance and life targets. If this value cannot be determined prior to testing, the Battery Size Factor is chosen as the minimum number of cells or modules that can both satisfy the CS energy target with a $30 \%$ power margin and provide a $30 \%$ energy margin for Charge Depleting Available Energy at beginning-of-life . Battery Size Factor is determined separately for each mode.

Beginning-of-Life $(B O L)$ - the point at which life testing begins. A distinction is made in this manual between the performance of a battery at this point and its initial performance, because some degradation may take place during early testing prior to the start of life testing. Analysis of the effects of life testing is based on changes from the BOL performance.

$C_{I} / 1$ Rate - a current corresponding to the manufacturer's rated capacity (in ampere-hours) for a one-hour discharge at $30^{\circ} \mathrm{C}$. For example, if the battery's rated one-hour capacity is $40 \mathrm{Ah}$, then $\mathrm{C}_{1} / 1$ is $40 \mathrm{~A}$.

Charge - any condition in which energy is supplied to the device rather than removed from the device. Charge includes both recharge and regen conditions. Charge is indicated in this manual as a negative value (from the perspective of the battery)

Charge-Depleting Available Energy -the discharge energy available at a 10-kW constant power discharge rate between an arbitrarily defined upper limit (nominally $10 \%$ DOD) and the minimum DOD. (See Section 4.3.5)

Charge-Sustaining Available Energy - the discharge energy available over the DOD range where both the discharge and regen pulse power targets for a given mode (Minimum or Maximum PHEV) are precisely met. This energy is measured using a $10-\mathrm{kW}$ discharge rate, and the limiting power conditions are calculated using the procedure defined in this manual (section 4.3.4).

Depth-of-Discharge (DOD) - the percentage of a device's rated capacity removed by discharge relative to a fully charged condition, normally referenced to a constant current discharge at the HPPC-Current rate.

Device - a cell, module, sub-battery or battery pack, depending on the context. The generic term "device" is normally used in test procedures except where a specific type of device is meant. (Most test procedures are intended to apply to any of these types).

Discharge - any condition in which energy is removed from the device rather than supplied to the device. Discharge is indicated in this manual as a positive value (from the perspective of the battery)

End-of-Life (EOL) - a condition reached when the device under test is no longer capable of meeting the targets. This is normally determined from HPPC Test results scaled using the Battery Size Factor, and it may not coincide exactly with the ability to perform the life test profile (especially if cycling is done at elevated temperatures). The number of test profiles executed at end of test is not necessarily equal to the cycle life per the targets. 
End of Test - a condition where life testing is halted, either because criteria specified in the test plan are reached, or because it is not possible to continue testing.

Energy Margin - for a given HPPC Test data set, the difference between either the CS or the CD Available Energy and the energy target for a given application and operating mode.

Fully Charged - The condition reached by a device when it is subjected to the manufacturer's recommended recharge algorithm. This state is defined as $100 \%$ state-of-charge, or $0 \%$ depth-of-discharge.

HPPC-Current rate - the constant current equivalent of a BSF-scaled $10-\mathrm{kW}$ rate (see Section 3.1.3).

Hybrid Pulse Power Characterization (HPPC) Test - a test procedure whose results are used to calculate pulse power and energy capability under operating conditions.

Maximum Rated Current (Imax) - the maximum discharge current that a manufacturer will permit to be sustained by a device for 10 seconds. (This value need not be achievable at all DOD values).

Power Fade - the change in CS Available Power from the beginning-of-life value to the value determined at some later time, expressed as a percentage of the BOL value. (Similar definitions apply to Capacity Fade and CS or CD Available Energy Fade, although these are not included in this glossary).

Power Margin - for a given HPPC Test data set, the difference between the maximum power at which the applicable energy target can be met and the power target for a given application.

Profile - a connected sequence of pulses used as the basic 'building block' of many test procedures. A test profile normally includes discharge, rest and charge steps in a specific order, and each step is normally defined as having a fixed time duration and a particular (fixed) value of current or power.

Recharge - any device charge interval corresponding to the sustained replenishment of energy by a continuous power source (such as an engine-generator or off-board charger).

Regen - any device charge interval corresponding to the return of vehicle kinetic energy to a device (typically from braking). Because of physical limitations, high rates of regen can only persist for a few seconds at a time.

State- of-Charge (SOC) - the available capacity in a battery expressed as a percentage of rated capacity (Handbook of Batteries, $3^{\text {rd }}$ Edition).

Usable Energy - a value (calculated from HPPC Test results) that represents the discharge energy available over a DOD range corresponding to any pair of discharge and regen power values whose ratio is that of the corresponding power targets. ChargeSustaining Available Energy is the value of usable energy at the actual power target values. (Usable energy has been frequently but inaccurately called "Available Energy"). 


\section{Battery Test Manual For Plug-In Hybrid Electric Vehicles \\ 1. PURPOSE AND APPLICABILITY}

This manual defines a series of tests to characterize aspects of the performance or life behavior of batteries for plug-in hybrid electric vehicle (PHEV) applications. Tests are defined based on the Vehicle Technologies Program targets for plug-in hybrid electric vehicles, though it is anticipated these tests may be generally useful for testing energy storage devices for plug-in hybrid vehicles. The test procedures in this manual are directly applicable to complete battery systems. However, most can also be applied with appropriate scaling to the testing of modules, cells or sub-scale cells. Much of the rationale for the test procedures and analytical methodologies utilized in this manual evolved from the USABC Electric Vehicle Battery Test Procedure Manual (Reference 1), the PNGV Battery Test Manual (Reference 2) and the FreedomCAR Battery Test Manual for Power-Assist Hybrid Electric Vehicles (Reference 3).

\subsection{Energy Storage Targets For Plug-In Hybrid Electric Vehicles}

Vehicle Technologies Program Energy Storage Targets are the primary driving force for the test procedures and methods defined in this manual. These targets are outlined in Table 1 for a Minimum PHEV Battery and a Maximum PHEV Battery performance specified for the Vehicle Technologies Program. Note that this table of targets is presented as the primary basis for this test manual. Establishing or verifying battery performance in comparison to these targets is a principal objective of the test procedures defined in this document. The intended vehicle platform for the Minimum PHEV Battery target is a sport utility vehicle with a vehicular mass of $2000 \mathrm{~kg}$ with an equivalent electric range of 10 miles, while the Maximum PHEV Battery target is a car with a vehicular mass of $1500 \mathrm{~kg}$ with an equivalent electric range of 40 miles. Unless otherwise stated, these targets all pertain to devices operating at $30^{\circ} \mathrm{C}$.

This manual defines two operational modes for plug-in hybrid electric vehicles, Charge-Depleting (CD) and Charge-Sustaining (CS). The Charge-Depleting mode is intended to allow the vehicle to operate in hybrid mode (propulsion and accessories are powered by the electric drive and/or engine) and electric mode (propulsion and accessories powered by the electric drive and onboard electric energy storage), with a net decrease in battery state-of-charge (SOC). The Charge-Sustaining mode only allows the vehicle to operate in hybrid mode with a relatively constant battery state-of-charge. 
Table 1. Energy Storage System Performance Targets for Plug-In Hybrid Electric Vehicles (January 2007).

\begin{tabular}{|c|c|c|c|}
\hline Characteristics at EOL (End-of-Life) & Unit & $\begin{array}{l}\text { Minimum PHEV } \\
\text { Battery }\end{array}$ & $\begin{array}{c}\text { Maximum PHEV } \\
\text { Battery }\end{array}$ \\
\hline Reference Equivalent Electric Range & miles & 10 & 40 \\
\hline $\begin{array}{l}\text { Peak Discharge Pulse Power ( } 2 \mathrm{sec} / 10 \\
\mathrm{sec})^{1}\end{array}$ & $\mathrm{~kW}$ & $50 / 45$ & $46 / 38$ \\
\hline Peak Regen Pulse Power $(10 \mathrm{sec})$ & $\mathrm{kW}$ & 30 & 25 \\
\hline Max. Current (10 sec pulse) & A & 300 & 300 \\
\hline $\begin{array}{l}\text { Available Energy for CD (Charge- } \\
\text { Depleting) Mode, } 10-\mathrm{kW} \text { Rate }\end{array}$ & $\mathrm{kWh}$ & 3.4 & 11.6 \\
\hline $\begin{array}{l}\text { Available Energy for CS (Charge- } \\
\text { Sustaining) Mode, } 10-\mathrm{kW} \text { Rate }{ }^{2}\end{array}$ & $\mathrm{kWh}$ & 0.5 & 0.3 \\
\hline $\begin{array}{l}\text { Minimum Round-trip Energy Efficiency } \\
\text { (CS } 50 \mathrm{Wh} \text { profile) }\end{array}$ & $\%$ & 90 & 90 \\
\hline $\begin{array}{l}\text { Cold cranking power at }-30^{\circ} \mathrm{C}, 2 \mathrm{sec}, 3 \\
\text { Pulses }\end{array}$ & $\mathrm{kW}$ & 7 & 7 \\
\hline CD Life / Discharge Throughput & Cycles/MWh & $5,000 / 17$ & $5,000 / 58$ \\
\hline CS HEV Cycle Life, 50 Wh Profile & Cycles & 300,000 & 300,000 \\
\hline Calendar Life, $35^{\circ} \mathrm{C}$ & year & 15 & 15 \\
\hline Maximum System Weight & $\mathrm{kg}$ & 60 & 120 \\
\hline Maximum System Volume & Liter & 40 & 80 \\
\hline Maximum Operating Voltage & Vdc & 400 & 400 \\
\hline Minimum Operating Voltage & Vdc & $>0.55 \times \mathrm{Vmax}^{3}$ & $>0.55 \times \operatorname{Vmax}^{3}$ \\
\hline Maximum Self-discharge & $\mathrm{Wh} / \mathrm{day}$ & 50 & 50 \\
\hline $\begin{array}{l}\text { Maximum System Recharge Rate at } \\
30^{\circ} \mathrm{C}\end{array}$ & $\mathrm{kW}$ & $1.4(120 \mathrm{~V} / 15 \mathrm{~A})^{4}$ & $1.4(120 \mathrm{~V} / 15 \mathrm{~A})^{4}$ \\
\hline 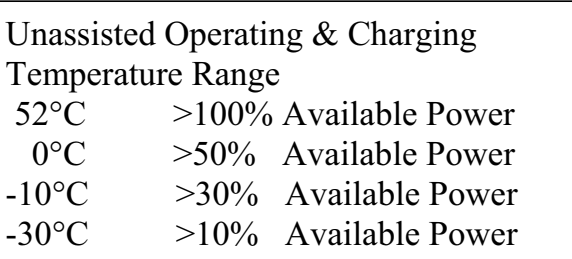 & ${ }^{\circ} \mathrm{C}$ & -30 to +52 & -30 to +52 \\
\hline Survival Temperature Range & ${ }^{\circ} \mathrm{C}$ & -46 to +66 & -46 to +66 \\
\hline $\begin{array}{l}\text { Maximum System Production Price @ } \\
100 \mathrm{k} \text { units/yr }\end{array}$ & $\$$ & $\$ 1,700$ & $\$ 3,400$ \\
\hline
\end{tabular}

\section{TEST PROFILES DERIVED FROM TARGETS}

The test procedures described in this manual are intended for use over a broad range of devices at various stages of developmental maturity. Application of the procedures is further complicated by the

1 The Peak Discharge Pulse Power and Peak Regen Pulse Power targets are applicable for the Charge-Sustaining mode.

2 The HPPC-Current rate is used to approximate the required 10-kW rate during the HPPC Test and the Static Capacity test.

3 This value can be reduced to $45 \%$ of Vmax for temperatures lower than $0^{\circ} \mathrm{C}$.

4 With the battery manufacturer's concurrence, an increase recharge rate can be used to accelerate life testing. 
existence of two different sets of performance targets. The approach taken for these procedures is to define a small set of test profiles based on the overall vehicle characteristics, independent of the size or capability of the device to be tested. These profiles are specified in terms of the characteristics of vehicle power demand. They can be used in various combinations, with the appropriate scaling factors, to define specific performance or cycle life tests for cells, modules or battery systems. Each profile is defined within the respective procedure described, because there is essentially a one-to-one relationship between test profiles and test procedures.

\section{TEST PROCEDURES}

\subsection{General Test Conditions and Scaling}

In general, testing is divided into three broad phases, i.e., characterization, life, and reference performance testing. Characterization testing establishes the baseline performance and includes static capacity, hybrid pulse power characterization, self-discharge, cold cranking, thermal performance, and efficiency tests. ${ }^{5}$ Life testing establishes behavior over time at various temperatures, states of charge and other stress conditions and includes both cycle life and calendar life testing. Reference Performance Tests establish changes in the baseline performance and are performed periodically during life testing, as well as at the start- and end-of-life testing. A generic test plan for testing is outlined in Appendix A; this outline can be used as a starting point for device-specific test plans.

\subsubsection{Temperature Control}

Unless otherwise specified in a device-specific test plan, the ambient temperature for all tests should be controlled at a default nominal temperature of $30^{\circ} \mathrm{C}$. Also, to the extent possible, all testing should be conducted using environmental chambers. As a general practice, a rest of 60 minutes (or more if required) should be observed after each charge and each discharge prior to proceeding with further testing, to allow devices to reach stable voltage and temperature conditions.

\subsubsection{Scaling of Performance and Cycle Life Test Profile}

With the exception of the Hybrid Pulse Power Characterization Test (HPPC) and Calendar Life Test, all performance and cycle life test profiles are defined in terms of required power levels at the system (i.e., full-size vehicle battery) level. Testing any device smaller than a full-size system requires a method for scaling these test profiles to a level appropriate to the size of the device (cell, module, or sub-battery) under test. This is done by using a battery size factor. For purposes of this manual, the Battery Size Factor (BSF) is defined as the minimum number of units (cells, modules or subbatteries) of a given design required for a device to meet all targets, including cycle life and calendar life. Wherever possible, the Battery Size Factor will be specified by the manufacturer, based on the manufacturer's testing and best estimates of any allowances needed for system burdens and degradation over life.

5 In this manual, unless specifically stated otherwise, the desired state-of-charge for a test is established as a depth-ofdischarge (DOD) value, which is always reached by removing the appropriate fraction of the rated capacity from a fully charged device (normally at a constant HPPC current discharge rate.) Also, the term "fully charged" means "charged in accordance with the manufacturer's recommended procedure". 
If insufficient data exist to allow the manufacturer to determine a meaningful value, the Battery Size Factor will be determined from the beginning-of-life Low Current HPPC Test results using a $\mathrm{C}_{1} / 1$ rate for the HPPC-Current rate by applying the larger BSF from either a nominal power margin of $30 \%$ or a nominal CD Energy Margin of 30\% to allow for degradation resulting from cycle life and calendar life effects. See Section 4.3.12 for details of this determination. ${ }^{6}$

Once the Battery Size Factor is determined, it becomes a constant (i.e., fixed over life) scaling factor for all subsequent performance and cycle life tests. Any test profile (except HPPC or calendar life) is then scaled by dividing the nominal profile power levels by the Battery Size Factor. For example, if the Battery Size Factor is 100 for a particular cell design, the 7-kW Cold Cranking Test would then be performed at a pulse power level of $7000 / 100=70 \mathrm{~W}$ for such cells. Note that there is a different mode-specific Battery Size Factor for Minimum and Maximum PHEV Battery operation.

\subsubsection{Scaling of HPPC-Current}

The HPPC-Current is a constant current that will closely resemble the steady state current during the $10-\mathrm{kW}$ Constant Power Discharge Test. In order to relate the energy removed at the $10-\mathrm{kW}$ rate and the energy removed during the HPPC Test, the "HPPC current" will be used for the $10 \%$ DOD (depth-of-discharge) constant current discharge segments.

The HPPC-Current is calculated using the formula below.

$\mathrm{I}_{\mathrm{HPPC}}=\mathrm{P}_{\mathrm{CPDT}} /\left(\mathrm{V}_{\mathrm{avg}} * \mathrm{BSF}\right)$

where $\mathrm{I}_{\mathrm{HPPC}}$ is the HPPC discharge current between pulses, $\mathrm{P}_{\mathrm{CPDT}}$ is the Constant Power Discharge Test power, and $\mathrm{V}_{\text {avg }}$ is the average voltage between $\mathrm{V}_{\max }$ and $\mathrm{V}_{\min }$. For example, if $\mathrm{V}_{\max }=4 \mathrm{~V}$ and $\mathrm{V}_{\text {min }}=3 \mathrm{~V}$, and $\mathrm{V}_{\text {avg }}=\left(\mathrm{V}_{\max }-\mathrm{V}_{\min }\right) / 2=3.5 \mathrm{~V}$, and the $\mathrm{BSF}=100$, and where $\mathrm{P}_{\mathrm{CPDT}}=10-\mathrm{kW}$, then $\mathrm{I}_{\mathrm{HPPC}}$ $=10,000 \mathrm{~W} /(3.5 \mathrm{~V} * 100)=28.6 \mathrm{~A}$. Note that if the Battery Size Factor has not been determined, a $\mathrm{C}_{1} / 1$ rate can be used as an approximate rate for the HPPC-Current during the first iteration of the HPPC Test to determine an appropriate Battery Size Factor. This value is used extensively once the BSF is determined for the Static Capacity and HPPC tests.

\subsubsection{Charging Procedure}

The manufacturer is responsible for defining a reasonable charging procedure with the assistance of the Program Manager. In order to speed up testing and avoid the degradation that may accompany the fully charged condition, the manufacturer may specify a charging procedure to charge up to the manufacturer's specified DOD $_{\text {min }}$ during life testing and Reference Performance Tests. This charging procedure should specify rest periods required before and after (1 hour recommended) charging is performed.

\subsection{Static Capacity Test}

This test measures device capacity in ampere-hours at a constant current discharge rate corresponding to the HPPC Current (See Section 3.1.3). Discharge begins following a one-hour rest from a fullycharged state and is terminated on a manufacturer-specified discharge voltage limit, followed by a one-hour rest at open-circuit voltage. If the manufacturer does not provide a discharge voltage limit,

6 In some cases, this value and/or the associated voltage limits may require modification to ensure that the round-trip efficiency targets are also met. 
or if the provided limit is unrealistically low, either an appropriate value is determined from the literature or $55 \%$ of the maximum charge voltage is used. (This will automatically become the lowest possible value for full-size battery tests in any event because of the operating voltage ratio limits). The HPPC-Current rate is used as the reference for static capacity and energy measurement and as a 'standard' constant current rate for module and system-level testing. The slower rates more commonly used for electric vehicle (EV) batteries are unrealistically low for hybrid applications.

\subsection{Constant Power Discharge Tests}

This test measures device capacity in ampere-hours and energy in watt-hours at a constant power discharge rate corresponding to a BSF-scaled 10-kW rate. Discharge begins following a one-hour rest from a fully-charged state and is terminated on a manufacturer-specified discharge voltage limit, followed by a one-hour rest at open-circuit voltage.

\subsection{Hybrid Pulse Power Characterization Test}

The Hybrid Pulse Power Characterization (HPPC) Test is intended to determine dynamic power capability over the device's useable voltage range using a test profile that incorporates both discharge and regen pulses. The primary objective of this test is to establish, as a function of depth-ofdischarge, (a) the $\mathrm{V}_{\text {MIN }}$ discharge power capability at the end of a 10-s discharge current pulse and (b) the $\mathrm{V}_{\text {MAX }}$ regen power capability at the end of a 10-s regen current pulse. ${ }^{7}$ These power and energy capabilities are then used to derive other performance characteristics such as Charge-Sustaining Available Energy and Available Power as well as the Charge-Depleting Available Energy.

Secondary objectives when used for cell testing are to derive from the voltage response curves the fixed (ohmic) cell resistance and cell polarization resistance as a function of state-of-charge with sufficient resolution to reliably establish cell voltage response time constants during discharge, rest, and regen operating regimes. The resistance measurements will be used to evaluate resistance degradation during subsequent life testing and to develop hybrid battery performance models for vehicle systems analysis.

\subsubsection{Hybrid Pulse Power Characterization Test Profile}

The objective of this test is to determine the 10-second discharge-pulse and the 10-second regen-pulse power capabilities at each 10\% depth-of-discharge (DOD) increment for both the Minimum PHEV Battery and the Maximum PHEV Battery Targets. Between each pair of discharge and regen pulses, the device is discharged to the next 10\% DOD increment using the HPPC-Current as determined in Section 3.1.3. The pulse profile is shown in Table 2 and Figure 1.

Note that the current values are relative, not absolute. The actual current values are determined as defined at the end of Section 3.4.2. Also, note that this manual uses positive values for discharge current and power, whereas charge or regen values are negative.

\footnotetext{
$7 \quad \mathrm{~V}_{\mathrm{MIN}}$ and $\mathrm{V}_{\mathrm{MAX}}$ refer to the device minimum and maximum voltages that correspond to the operating voltage range as defined in Table 1. For cells, the specific voltages can be any values appropriate to the technology as long as they fall within the BSF-scaled limits in Table 1.
} 
Table 2. Hybrid Pulse Power Characterization Test Profile.

\begin{tabular}{ccc}
\hline $\begin{array}{c}\text { Time Increment } \\
(\mathrm{s})\end{array}$ & $\begin{array}{c}\text { Cumulative Time } \\
(\mathrm{s})\end{array}$ & Relative Currents \\
\hline 10 & 10 & 1.00 \\
40 & 50 & 0 \\
10 & 60 & -0.75 \\
\hline
\end{tabular}

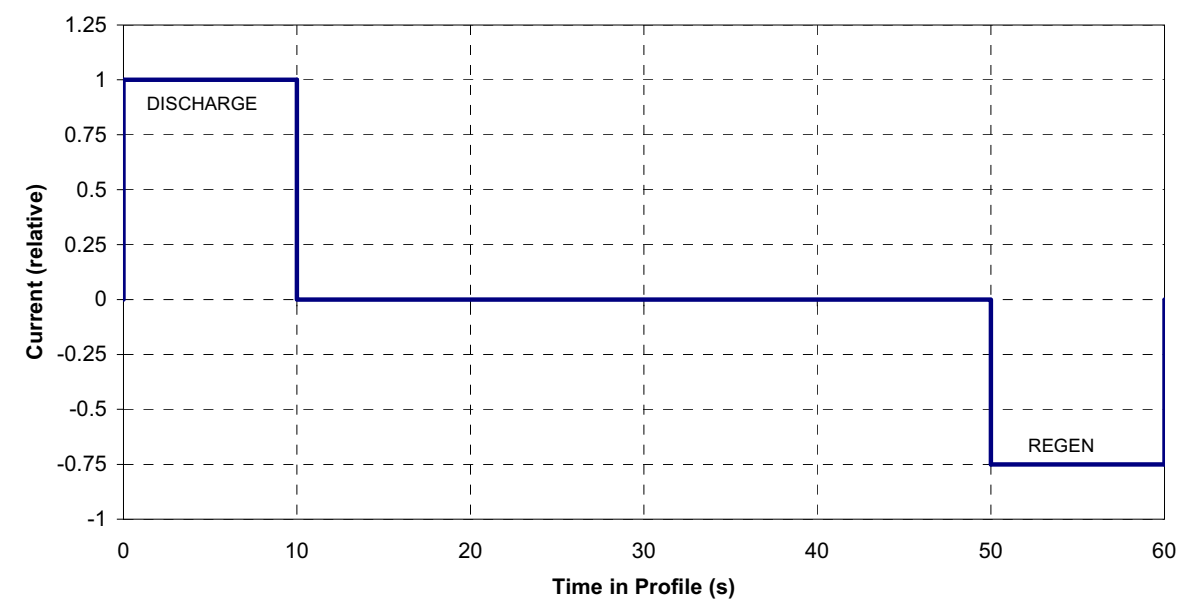

Figure 1. Hybrid Pulse Power Characterization Test Profile.

\subsubsection{Test Procedure Description}

The HPPC Test incorporates the pulse power characterization profile as defined in Section 3.4.1. Constant current steps are used in the ratios listed in Table 2. The test is made up of single repetitions of this profile, separated by 10\% DOD (depth-of-discharge) constant current discharge segments (performed using the HPPC Current defined in Section 3.1.3), ${ }^{8}$ each followed by a 1-hr rest period to allow the cell to return to an electrochemical and thermal equilibrium condition before applying the next profile. The constant current used during these segments i.e., between the pairs of discharge and regen pulses is the HPPC-Current as determined in Section 3.1.3. The test begins with a fully charged device after a 1-hr rest and terminates after completing the final profile at $90 \% \mathrm{DOD}$, a discharge of the cell at the HPPC-Current rate to $100 \%$ DOD, and a final 1-hr rest. The voltages during each rest period are recorded to establish the cell's OCV (open-circuit voltage) behavior. The sequence of rest periods, pulse profiles, and discharge segments is illustrated in Figures 2 and 3. These figures also illustrate a $10-\mathrm{kW}$ discharge to be executed just prior to each HPPC Test. ${ }^{9}$

$8 \quad$ Note that the energy of the pulse profile must be accounted for in determining the actual state-of-charge at which the profile was performed. The profile in Table 2 may remove several percent of the capacity from a typical device. The test should be programmed such that $10 \%$ of the rated capacity is removed in each test segment, including that removed by the pulse profile itself.

9 This HPPC current discharge is required because the HPPC results will eventually be reported as power capability versus energy removed at a $10-\mathrm{kW}$ rate. The availability of linked HPPC current data facilitates this analysis and reporting; see Section 4.3. 


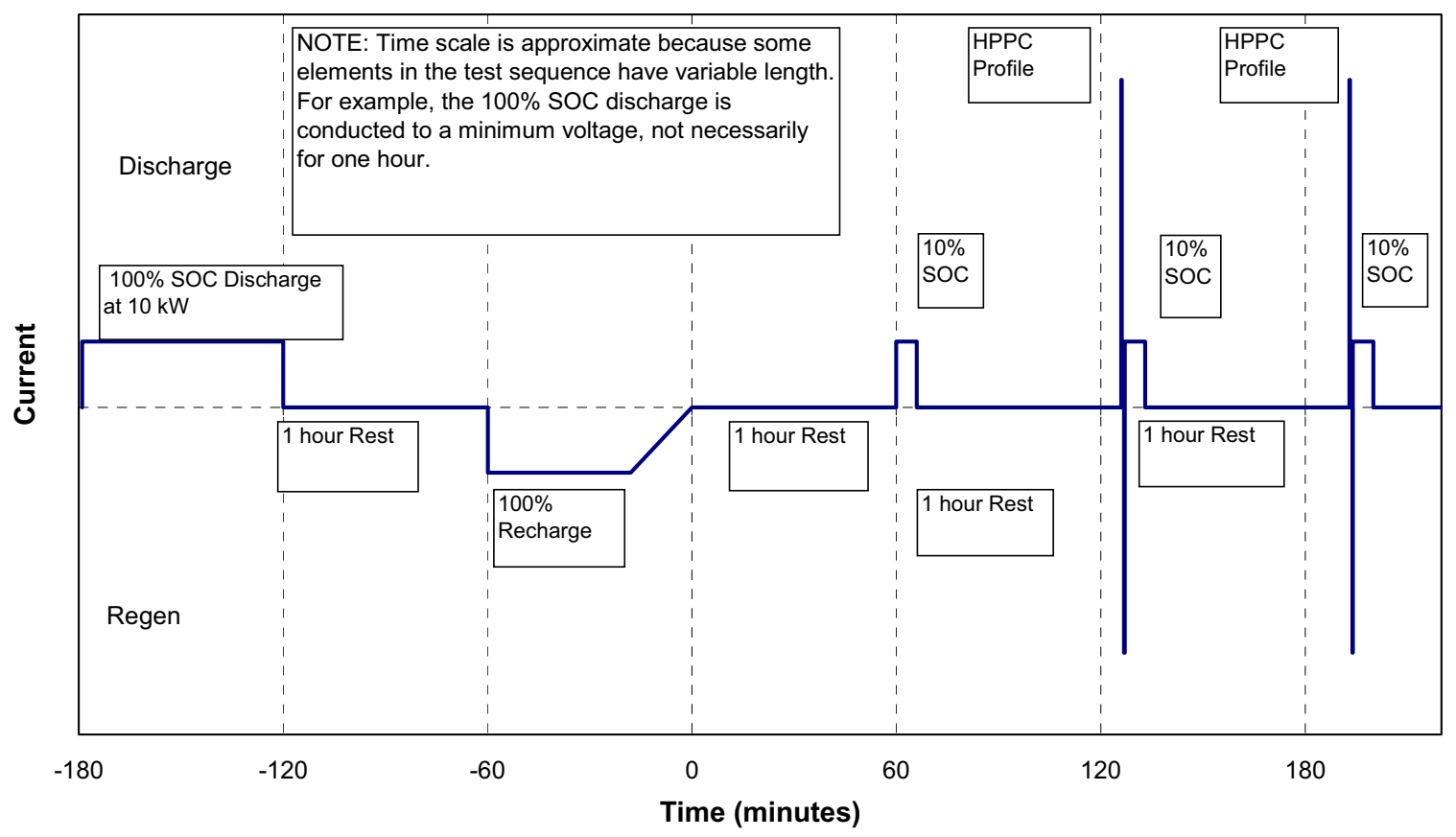

Figure 2. Hybrid Pulse Power Characterization Test (start of test sequence).

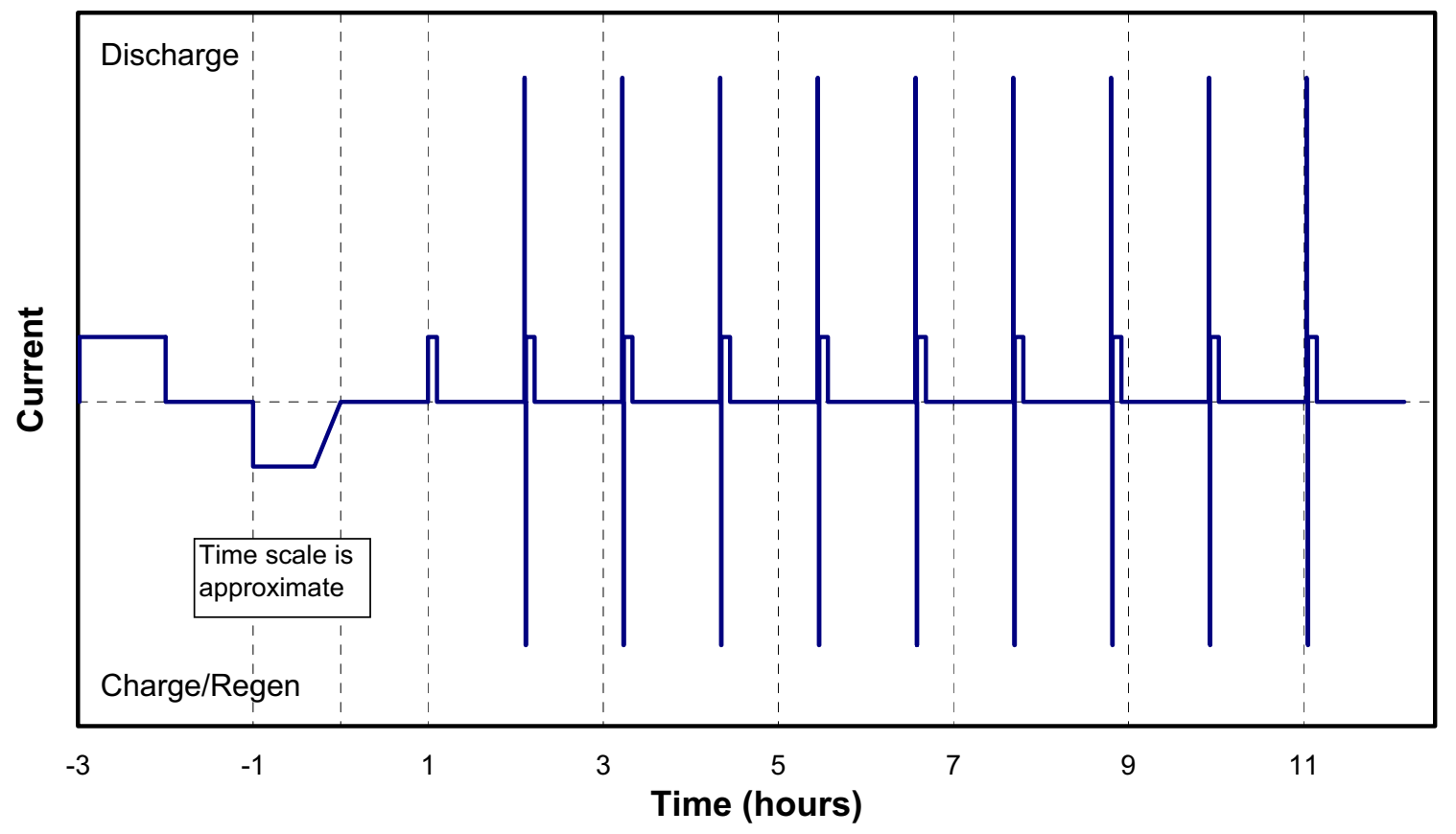

Figure 3. Hybrid Pulse Power Characterization Test (complete HPPC sequence). 
The HPPC Test may be performed at the low-current level, the high-current level, or both. Each HPPC Test sequence is performed using peak currents scaled to one of the levels. Scaling of the levels is determined by the following criteria.

LOW CURRENT HPPC TEST - The pulse profile discharge current is equal to 2.5 times the HPPCCurrent rating. If the $\mathrm{BSF}$ is unknown at the time of first testing, a $5 \mathrm{C}_{1} / 1$ rate can be used to determine the BSF.

HIGH CURRENT HPPC TEST - The pulse profile discharge current is selected as $75 \%$ of $\mathrm{I}_{\max }$ (the manufacturer's absolute maximum allowable pulse discharge current for $10 \mathrm{~s}$ at some state-of-charge, which needs not be specified).

\subsubsection{Charge-Sustaining Available Energy Verification Test}

In general the HPPC Test produces slightly conservative results, because it is normally performed at power levels that are less than the target values. (At higher test currents, internal heating lowers the battery resistance and gives higher power capability). In some cases (e.g. when a new technology, a new cell design or a full-size battery design is tested for the first time), it may be desirable to verify the extent of this conservatism by performing a test at the actual target values. This is done using a special test sequence as follows:

1. From HPPC Test results, calculate (a) the minimum DOD value $\left(\mathrm{DOD}_{\mathrm{MIN}}\right)$ at which the regen pulse power target can be met and (b) the maximum DOD value (DOD MAX $_{\text {) }}$ at which the discharge pulse power target can be met. The Available Energy for Charge-Sustaining Mode should equal the energy discharged at the $10-\mathrm{kW}$ rate between $\mathrm{DOD}_{\mathrm{MIN}}$ and DOD $_{\text {MAX. }}$ These values are calculated using Section 4.3.4 and 4.3.8 and graphically shown in Figure 21 of this manual.

2. Starting with a fully-charged battery, discharge to DOD $_{\text {MIN }}$ at a constant $10-\mathrm{kW}$ rate, and then rest for one-hour at open-circuit conditions.

3. Perform a (10-s) regen pulse at the BSF-scaled Peak Regen Pulse Power target from Table 1. Remove the energy added to the battery from the regen pulse at the $10-\mathrm{kW}$ rate.

4. Remove the Available Energy for Charge-Sustaining Mode from Table 1 by discharging the battery at a constant $10-\mathrm{kW}$ rate, and then rest for one-hour at open-circuit conditions.

5. Perform a 10-s discharge pulse at the BSF-scaled Peak Discharge Pulse Power 10-s ${ }^{10}$ target from Table 1 .

The results of this test can be used to verify that the HPPC-predicted power capabilities and energy values are actually achievable and that they are not excessively conservative.

10 This same procedure can be used to verify the 2-second target by using a 2-second pulse at the associated power level for comparison with the target. 


\subsubsection{Charge-Depleting Available Energy Verification Test}

This test will verify the Available Energy for the Charge-Depleting mode by direct measurement; secondarily, it will determine the charge range to be used for the Charge-Sustaining mode tests (i.e. that region where Charge-Sustaining operation will take place after Charge-Depleting energy is used). This test is performed in two steps.

1. Starting at $10 \%$ DOD or manufacturer's specified DOD, remove $3.4 \mathrm{kWh}$ at the $10-\mathrm{kW}$ rate.

2. Verify that the DOD is less than DOD $_{\max }$ if established in Section 3.4.3, or perform a 10 -second, $45 \mathrm{~kW}$ discharge pulse without violating the minimum voltage requirements.

\subsection{Self-Discharge Test}

This test is intended to determine the temporary capacity loss that results from a cell or battery standing (i.e., at rest) for a predetermined period of time (i.e. 7 days at $30^{\circ} \mathrm{C}$ ).

The test consists of the following sequence of activities:

1. Measure the actual cell capacity from full charge to the discharge voltage limit using a constant $10-\mathrm{kW}$ discharge rate, and recharge it using the manufacturer's recommended charge algorithm.

2. Remove the Available Energy for Charge-Depleting Mode at the scaled 10-kW rate. Allow it to stand in an open-circuit condition for a nominal interval of 7 days. ${ }^{11}$ (The actual stand period should be selected based on the expected stand loss rate, with the value chosen to yield an expected capacity loss of $5 \%$ or more over the interval). All measurement equipment may need to be disconnected from the cell during this period to reduce parasitic losses.

3. Discharge the cell for its remaining (residual) capacity at the $10-\mathrm{kW}$ discharge rate.

4. Recharge the cell and fully discharge it again at the $10-\mathrm{kW}$ discharge rate. If a loss of capacity is observed between (1) and (4), additional recharge/discharge cycles may be performed to return the cell to its nominal capacity.

\subsection{Cold Cranking Test}

The Cold Cranking Test is intended to measure 2-s power capability at low temperature (normally $-30^{\circ} \mathrm{C}$ ) for comparison with the Cold Cranking Power target(s) in Table 1. The test is conducted at the maximum DOD (minimum state-of-charge) where CS and CD Available Energy targets are just

11. Although the end of the CD Available Energy Target is the default nominal condition for this test, the actual value to be used is commonly defined in a device-specific test plan. The DOD value that will be used for cycle life or calendar life testing is a typical value. 
met, i.e., after removal of the energy required by both targets, based on the most recent L-HPPC data. ${ }^{12}$ The test consists of the following sequence of activities:

1. At normal ambient temperature, discharge the fully charged device at a $10-\mathrm{kW}$ discharge rate to the maximum DOD value (minimum state-of-charge) determined as above.

2. Reduce the ambient temperature to $-30^{\circ} \mathrm{C}$, and soak the device for a period of time adequate to ensure it has reached thermal equilibrium at this temperature (nominally 4 to 8 hours).

3. Perform the Cold Cranking Test profile defined in Section 3.6.1. The pulse power level to be used is $7 \mathrm{~kW}$ divided by the Battery Size Factor as determined in Sections 3.1.2 and 4.3.12. Note that the manufacturer may specify a different minimum discharge voltage for cold cranking testing. This voltage, if specified, will be used for both test control and the subsequent calculation of cold cranking power capability, but it may not exceed the voltage ratio limits in Table 1. Note also that the profile pulses must be performed for the full 2-s duration (even if the test power has to be limited to stay within the minimum discharge voltage) to permit the later calculation of Cold Cranking power capability.

\subsubsection{Cold Cranking Test Profile}

The Cold Cranking Test Profile is a literal implementation of the Cold Cranking Power targets, which require the ability to provide $7 \mathrm{~kW}$ of discharge power for three 2-s pulses at 12-s intervals (i.e., 10 seconds between pulses). The profile is defined in Table 3 and illustrated in Figure 4 for the Plug-In Hybrid Battery targets.

Table 3. Cold Cranking Test Profiles for Plug-In Hybrid Targets.

\begin{tabular}{ccc}
\hline $\begin{array}{c}\text { Time Increment } \\
(\mathrm{s})\end{array}$ & $\begin{array}{c}\text { Cumulative Time } \\
(\mathrm{s})\end{array}$ & $\begin{array}{c}\text { System Power } \\
(\mathrm{kW})\end{array}$ \\
\hline 2 & 2 & 7 \\
10 & 12 & 0 \\
2 & 14 & 7 \\
10 & 24 & 0 \\
2 & 26 & 7 \\
\hline
\end{tabular}




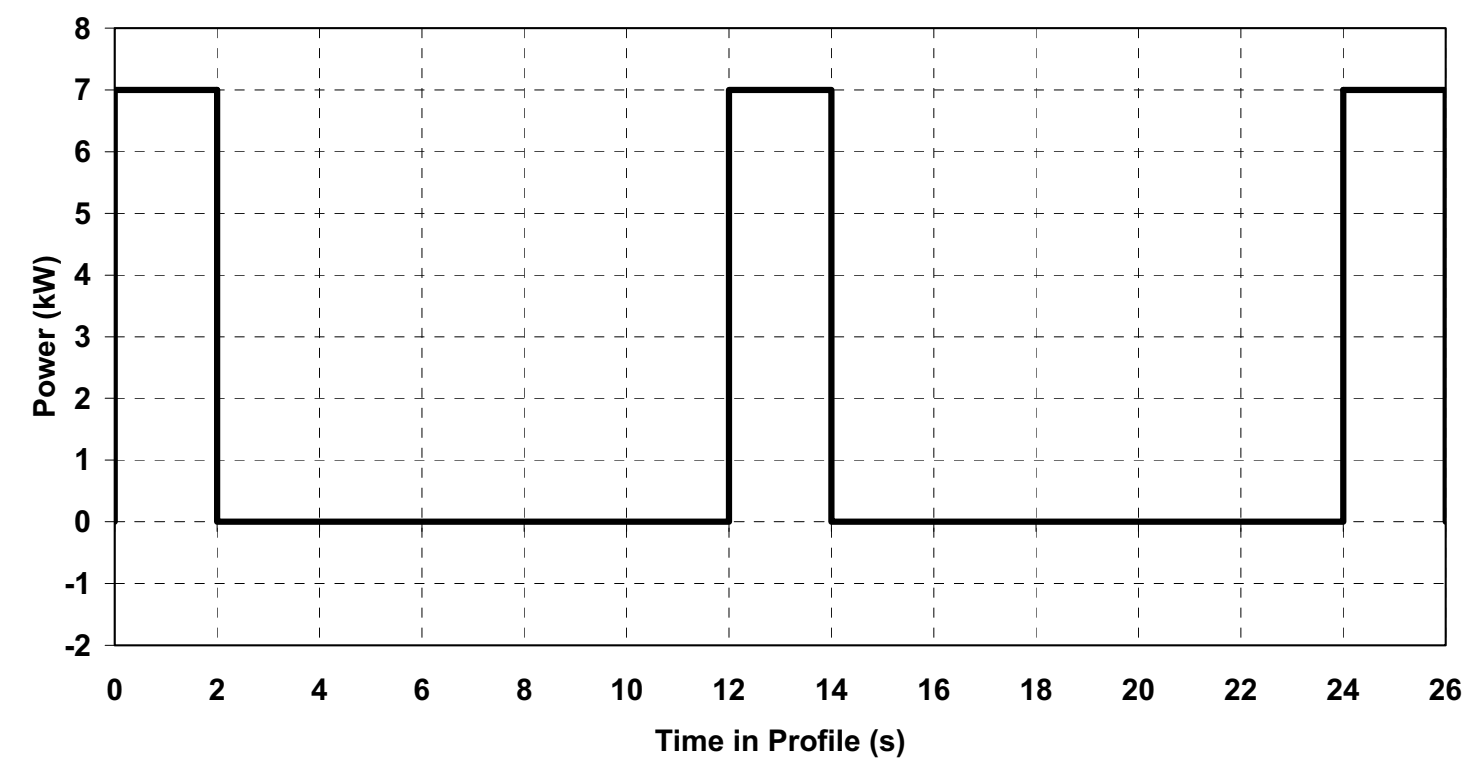

Figure 4. Cold Cranking Test Profiles.

\subsection{Thermal Performance Test}

A primary objective of the thermal performance testing is to demonstrate the ability to meet some fraction of the CS Available Power target at various temperatures. The effects of environment (ambient temperature) on device performance will be measured as required by performing the Static Capacity Test, Low-Current Hybrid Pulse Power Characterization Test, and/or Cold Cranking Test at various temperatures within the operating temperature target range $\left(-30\right.$ to $\left.+52^{\circ} \mathrm{C}\right)$. At the laboratory cell level, such testing has two targets: to characterize the performance of the technology as a function of temperature and to bound the likely constraints on thermal management of full-size cells or batteries. At the module and system level, the emphasis of thermal performance testing is increasingly on thermal management system design and behavior.

Unless otherwise specified in a device-specific test plan, initial charging should be performed at $30^{\circ} \mathrm{C}$ during thermal performance testing. This implies a test sequence as follows: (1) fully charge the device at $30^{\circ} \mathrm{C}$; (2) raise or lower the device ambient temperature to the target value; (3) wait a suitable soak period for thermal equalization, typically 4 to $8 \mathrm{hr}$; and (4) execute the desired performance test. If self-discharge is a major concern during the soak period, the device can be clamped at a voltage during this period; however, this requires knowledge of the device OCV versus temperature behavior to ensure that the SOC is not changed inadvertently.

It may be necessary to adjust the rest intervals in the HPPC Test to ensure that thermal stability as well as voltage equilibrium is reached before each repetition of the pulse power characterization profile. 


\subsection{Energy Efficiency Test}

Round-trip efficiency is determined at the cell level by calculation from a charge-balanced pulse profile. These profiles have been constructed for use in both efficiency and CS hybrid cycle life testing. This test is performed similarly to the Operating Set Point Stability (OSPS) Test, as follows:

1. With the cell at $30^{\circ} \mathrm{C}$, discharge at the HPPC current (See Section 3.1.3) to the specified target state-of-charge value and then bring the cell to the specified test temperature.

2. Perform 100 efficiency test profiles.

3. Determine the change (if any) in the state-of-charge before and after the 100 profiles. Allow a 1-hr rest period before and after the 100 profiles are performed to determine any change in open-circuit voltage.

4. If the initial and final SOC values are different (by $5 \%$ or more), or the data indicate that stable cycling was not achieved by the completion of 100 profiles, repeat the test with different SOC control values or additional profiles, as appropriate.

The Charge-Sustaining Test Profiles are used for the efficiency tests and are 90-s in duration, nominally charge-neutral pulse profile scaled to a level appropriate to verify the round trip energy efficiency target of $90 \%$ with a 50 -Wh energy swing. ${ }^{13}$ The test profile for the Minimum PHEV Battery is defined in Table 4 and illustrated in Figure 5 and the profile for the Maximum PHEV Battery is defined in Table 5 and Figure 6.

\subsection{Charge-Sustaining Cycle Life Tests}

Charge-Sustaining Cycle life testing is performed using one of the $50 \mathrm{Wh}$ Hybrid Cycle Life Test Profiles defined in Section 3.9.2 for Plug-In Hybrid operation. Cycle life testing is performed by repeating the selected test profile at a fixed state-of-charge (i.e., the profile is charge-neutral).

\subsubsection{Cycle Life Test Procedure Outline}

The cycle life testing process consists of the following steps:

1. Scale the selected test profile (Table 4 for the Minimum PHEV Battery or Table 5 for the Maximum PHEV Battery) by dividing the nominal profile power values by the Battery Size Factor as described in Section 3.1.2.

2. Determine end-of-test criteria for cycle life testing. These are normally specified in a device-specific test plan. A default (and generally mandatory) end-of-test condition is reached when the test profile cannot be executed within the discharge and regen voltage limits. ${ }^{14}$

13 These profiles are calculated to be charge-neutral for a device that is about $90 \%$ efficient. Note that the Efficiency Test may also serve as the OSPS Test if the same SOC value and temperature are used.

14 At this point, the cell has insufficient available energy and capacity at the test conditions to execute the test, i.e. its capability is less than that required by the test profile. 
Another default end-of-test condition also occurs if performance degrades to a point where the HPPC Reference Test yields insufficient information to show further degradation. ${ }^{15}$

End of test is normally chosen to occur when one of the following conditions exists: (a) cycle life meeting the targets has been attained (i.e., the number of properly scaled test cycles exceeds the applicable target); or (b) CS or CD Available Energy drops below the target value. In case (a) the battery may not have reached end-of-life when testing stops, but further testing is not usually considered cost-effective. In case (b), end-of-life has occurred at some prior time. ${ }^{16}$

3. Bring the cell to the desired operating state-of-charge and test temperature for cycle life testing and perform the Operating Set Point Stability Test (Section 3.9.3) to verify stable operation at the selected SOC point. Make any needed adjustments to the test profile or test operating conditions.

4. Repeat the selected test profile(s) at the desired operating conditions the number of times specified in Table 9 or a device-specific test plan.

5. After the specified number of repetitions, suspend cycling. If cycling is being done at other than $30^{\circ} \mathrm{C}$, return the cell to $30^{\circ} \mathrm{C}$. Observe the open-circuit voltage after a 1-hr rest. Remove the residual capacity at a constant HPPC-Current rate to verify the cycling depthof-discharge, and perform one or more Reference Performance Tests to determine the extent of degradation in capacity and/or power capability. The reference tests are listed in Table 9. The intervals between repetitions of these reference tests are also specified in Table 9, though these may be adjusted somewhat if required for time synchronization of cells being tested under different test regimes.

6. If the residual capacity measured in Step 5 indicates an unacceptable drift in DOD during cycling, repeat Step 3 to re-establish the target cycling condition.

7. Repeat Steps 4 and 5 until an end-of-test condition is reached.

\subsubsection{Charge-Sustaining Cycle Life Test Profiles}

The objective of these test profiles is to demonstrate device life in the Charge-Sustaining mode when subjected to different energy use levels and patterns appropriate to the targets.

Each profile is a 90-s pulse profile intended to demonstrate the ability to meet the cycle life target of 300,000 cycles with a 50-Wh swing. The profile families transfer about 15 million watt-hours (MWh) respectively in and out of the device over 300,000 cycles.

The test profiles are all defined at the battery pack level. They are scaled to the appropriate power levels for testing laboratory cells, full-size cells and module designs using the Battery Size Factor as described in Section 3.1.2.

15 This would normally be the point where valid discharge and regen data are obtained at less than three DOD values using the Low-Current HPPC test.

16 Note that end-of-test and end-of-life are not the same, and they may not even be related. See the glossary for more information on this distinction. The determination of End-of-Life and Cycle Life is discussed in Section 4.9. 
Table 4. Charge-Sustaining Minimum PHEV Battery (50 Wh) Cycle Life Test Profile.

\begin{tabular}{ccccc}
\hline $\begin{array}{c}\text { Time } \\
\text { Increment } \\
(\mathrm{s})\end{array}$ & $\begin{array}{c}\text { Cumulative } \\
\text { Time } \\
(\mathrm{s})\end{array}$ & $\begin{array}{c}\text { System } \\
\text { Power } \\
(\mathrm{kW})\end{array}$ & $\begin{array}{c}\text { Energy } \\
\text { Increment } \\
(\mathrm{Wh})\end{array}$ & $\begin{array}{c}\text { Cumulative } \\
\text { Energy } \\
(\mathrm{Wh})\end{array}$ \\
\hline 33 & 33 & 3.00 & 27.5 & 27.5 \\
3 & 36 & 27.00 & 22.5 & 50 \\
52 & 88 & -3.2 & -46.2 & 3.8 \\
2 & 90 & -18.00 & -10 & -6.2
\end{tabular}

Each of the Charge-Sustaining (50Wh) Cycle Life Test Profiles removes $50 \mathrm{Wh}$ on discharge and is nominally charge-balanced for a device that just satisfies the $90 \%$ efficiency target. The Minimum PHEV Battery profile is defined here as Table 4 and is illustrated in Figure 5, and the Maximum PHEV Battery profile is defined in Table 5 and illustrated in Figure 6.

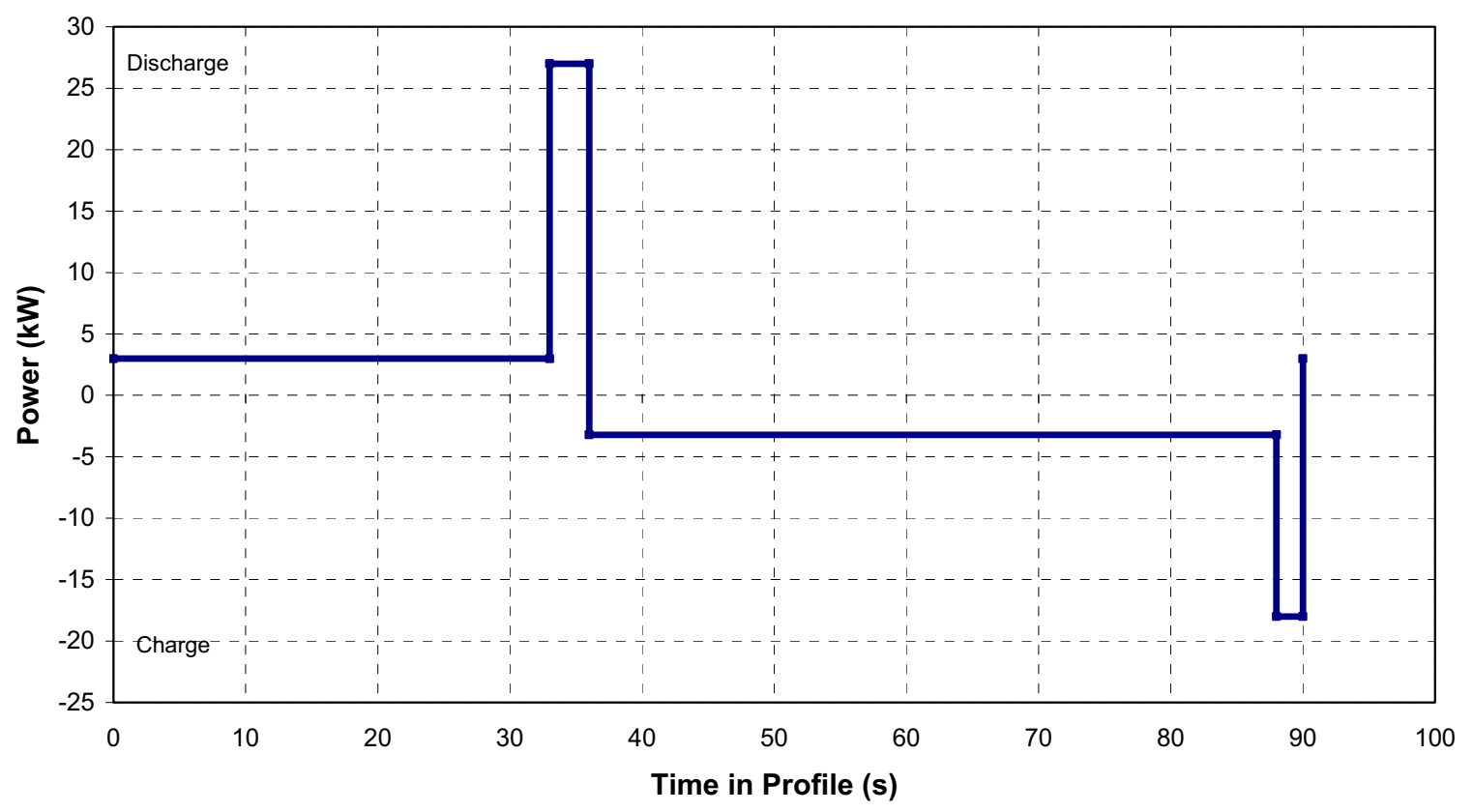

Figure 5. Charge-Sustaining Minimum PHEV Battery (50 Wh) Cycle Life Test Profile. 
Table 5. Charge-Sustaining Maximum PHEV Battery (50 Wh) Cycle Life Test Profile.

\begin{tabular}{|c|c|c|c|c|}
\hline $\begin{array}{c}\text { Time } \\
\text { Increment }\end{array}$ & $\begin{array}{c}\text { Cumulative } \\
\text { Time }\end{array}$ & $\begin{array}{c}\text { System } \\
\text { Power }\end{array}$ & $\begin{array}{c}\text { Energy } \\
\text { Increment }\end{array}$ & $\begin{array}{c}\text { Cumulative } \\
\text { Energy }\end{array}$ \\
\hline (s) & (s) & $(\mathrm{kW})$ & $(\mathrm{Wh})$ & (Wh) \\
\hline 37 & 37 & 3 & 30.8 & 30.8 \\
\hline 3 & 40 & 23 & 19.2 & 50.0 \\
\hline 48 & 88 & -3.6 & -48.0 & 2.0 \\
\hline 2 & 90 & -15 & -8.3 & -6.3 \\
\hline
\end{tabular}

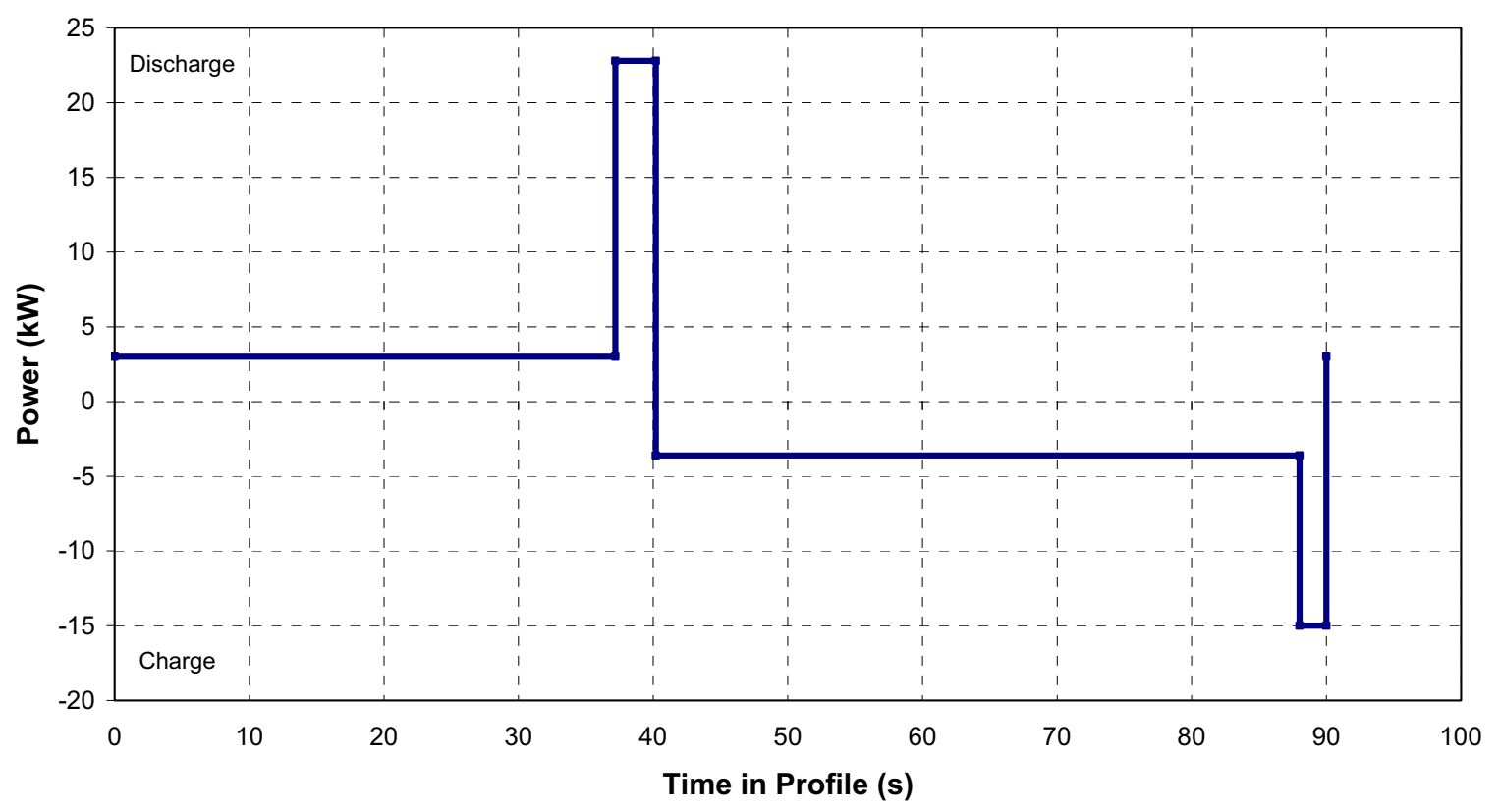

Figure 6. Charge-Sustaining Maximum PHEV Battery (50 Wh) Cycle Life Test Profile.

\subsubsection{Operating Set Point Stability Test}

This test is a special case of the cycle life testing regime to be applied to a given cell or battery. Since cycle life testing is normally done at an intermediate state-of-charge, it is necessary to determine that stable cycling will occur at the target SOC, and to adjust test conditions if necessary to ensure that this will be the case. The target state-of-charge for the cycle life test(s) defined in Section 3.9 is 
normally specified in a device-specific test plan based on projected use of the device. ${ }^{17}$ This test should be performed immediately before the beginning of cycle life testing.

With the cell at the selected state-of-charge value and all other conditions (e.g., operating temperature) as required for life cycling, apply the selected Cycle Life Test Profile for a period long enough to reach thermal equilibrium and to return to the target SOC. ${ }^{18}$ Determine the change (if any) in the state-of-charge before and after the cycling interval. Allow a 1-hr rest before and after this cycling is performed to determine any change in open-circuit voltage. The residual capacity can also be removed at a constant HPPC-Current rate to verify the depth-of-discharge at the end of the cycling interval.

\subsubsection{Adjusting the Operating Set Point}

If the device does not reach a voltage and temperature equilibrium during the cycling interval, upper or lower voltage constraints or other limits may be adjusted (within manufacturer limits) to provide stable cycling conditions, and this test may be repeated or extended if necessary. The test may also be repeated at the beginning of any cycle life testing interval if the device condition has changed significantly.

\subsubsection{Controlling the State-of-Charge during the OSPS Test}

The preferred approach to maintaining a target state-of-charge during the OSPS test and later cycle life testing depends on the test profile used and on test equipment capabilities. Guidelines for accomplishing can be called out in a device-specific test plan.

Note that achieving the target SOC and a stable cycling condition are related but have separate constraints. The maximum and minimum pulse voltages from profile to profile are usually the most sensitive indicators of stable cycling (unless the device resistance is changing appreciably during the cycling period), while the SOC during cycling must actually be measured after cycling stops. The intent of this test is to establish control parameter values, and if necessary to fine-tune the test profile, such that life cycling can be performed continuously over the intervals between reference tests specified in Table 9.

\subsection{Charge-Depleting Cycle Life Tests}

Charge-Depleting Cycle life testing is performed using one of the Charge-Depleting Cycle Life Test Profiles. Cycle life testing is performed by repeating the test profile(s) until the Target Energy for the Charge-Depleting mode is reached. The device is recharged at the Maximum System Recharge Rate listed in Table 1, unless otherwise specified by the manufacturer.

\subsubsection{Cycle Life Test Procedure Outline}

The cycle life testing process consists of the following steps:

17 There is no "default nominal" state-of-charge for life cycling. However, if the appropriate value is not known in advance of the start of testing, the range of usable target SOC values can be determined from the HPPC test results (see Section 4.3) based on the peak discharge and regen powers planned for cycle life testing.

18 This typically requires approximately 100 complete pulse profiles. 
1 Scale the selected test profile by dividing the nominal profile power values by the Battery Size Factor as described in Section 3.1.2.

2 Determine end-of-test criteria for cycle life testing. These are normally specified in a device-specific test plan. A default (and generally mandatory) end-of-test condition is reached when the test profile cannot be executed within the discharge and regen voltage limits. ${ }^{19}$

3 The initial state-of-charge is either the minimum operating DOD specified by the manufacturer or $10 \%$ DOD.

$4 \quad$ Bring the cell to the desired DOD and temperature. (If testing is to be performed at a temperature other than $30^{\circ} \mathrm{C}$, then charging should occur at the same temperature.) Repeat the selected test profile(s) at the desired operating conditions five times for the Minimum PHEV battery or 20 times for the Maximum PHEV battery.

5 Recharge the device using the Maximum System Recharge Rate unless otherwise specified by the manufacturer. (For accelerated testing, this may be performed at temperatures other than $30^{\circ} \mathrm{C}$ ). Steps 4 and 5 will be the equivalent of one Charge-Depleting Cycle.

6 Repeat the cycle (from steps 4 and 5) at the desired operating conditions the number of times specified in Table 9 or a device-specific test plan.

7 After the specified number of repetitions, suspend cycling. If cycling is being done at other than $30^{\circ} \mathrm{C}$, return the device to $30^{\circ} \mathrm{C}$. Observe the open-circuit voltage after a 1-hr rest. Perform the Reference Performance Tests to determine the extent of degradation in capacity and/or power capability. The reference tests are listed in Table 9 . The intervals between repetitions of these reference tests are also specified in Table 9, though these may be adjusted somewhat if required for time synchronization of cells being tested under different test regimes.

8 Repeat Steps 4 through 6 until an end-of-test condition is reached.

\subsubsection{Charge-Depleting Cycle Life Test Profile}

The objective of these test profiles is to demonstrate device life in the Charge-Depleting mode when subjected to energy use levels and patterns appropriate to the targets.

Each profile is a series of constant power discharge/charge steps with a total duration of 360 seconds. The profile for the Minimum PHEV Battery is intended to demonstrate the ability to meet the ChargeDepleting cycle life target of 5,000 cycles (in sets of five profiles per cycle) with a 687-Wh of energy throughput (i.e. energy discharged) per full profile. The profile transfers about 17.2 million watthours (MWh) respectively in and out of the device over 5,000 cycles. The profile for the Maximum PHEV Battery is intended to demonstrate the ability to meet the Charge-Depleting cycle life target of 5,000 cycles (in sets of 20 profiles per cycle) with a 582-Wh of energy throughput per full profile. The profile transfers about 58 million watt-hours (MWh) respectively in and out of the device over 5,000 cycles.

19 At this point, the cell has insufficient useable energy and capacity at the test conditions to execute the test, i.e. its capability is less than that required by the test profile. 
Table 6. Charge-Depleting Cycle Life Test Profile for the Minimum PHEV Battery.

\begin{tabular}{|c|c|c|c|c|c|}
\hline $\begin{array}{c}\text { Step } \\
\text { No }\end{array}$ & $\begin{array}{l}\text { Step } \\
\text { Time } \\
\text { (sec) } \\
\end{array}$ & $\begin{array}{l}\text { Cum } \\
\text { Time } \\
\text { (sec) } \\
\end{array}$ & $\begin{array}{c}\% \\
\text { Power } \\
(\%) \\
\end{array}$ & $\begin{array}{c}\text { Power } \\
\text { (W) }\end{array}$ & $\begin{array}{c}\text { Cum } \\
\text { Energy } \\
\text { (Wh) }\end{array}$ \\
\hline 1 & 16 & 16 & 0 & 0 & 0 \\
\hline 2 & 28 & 44 & 12.5 & 5625 & 43.75 \\
\hline 3 & 12 & 56 & 25 & 11250 & 81.25 \\
\hline 4 & 8 & 64 & -12.5 & -5625 & 68.75 \\
\hline 5 & 16 & 80 & 2 & 900 & 72.75 \\
\hline 6 & 24 & 104 & 12.5 & 5625 & 110.25 \\
\hline 7 & 12 & 116 & 25 & 11250 & 147.75 \\
\hline 8 & 8 & 124 & -12.5 & -5625 & 135.25 \\
\hline 9 & 16 & 140 & 2 & 900 & 139.25 \\
\hline 10 & 24 & 164 & 12.5 & 5625 & 176.75 \\
\hline 11 & 12 & 176 & 25 & 11250 & 214.25 \\
\hline 12 & 8 & 184 & -25 & -11250 & 189.25 \\
\hline 13 & 16 & 200 & 2 & 900 & 193.25 \\
\hline 14 & 36 & 236 & 12.5 & 5625 & 249.5 \\
\hline 15 & 2 & 238 & 100 & 45000 & 274.5 \\
\hline 16 & 6 & 244 & 50 & 22500 & 312 \\
\hline 17 & 24 & 268 & 62.5 & 28125 & 499.5 \\
\hline 18 & 8 & 276 & -25 & -11250 & 474.5 \\
\hline 19 & 32 & 308 & 25 & 11250 & 574.5 \\
\hline 20 & 8 & 316 & -50 & -22500 & 524.5 \\
\hline 21 & 12 & 328 & 2 & 900 & 527.5 \\
\hline 22 & 2 & 330 & 111 & 50000 & 555.28 \\
\hline 23 & 5 & 335 & 2 & 900 & 556.53 \\
\hline 24 & 2 & 337 & -66.7 & -30000 & 539.86 \\
\hline 25 & 23 & 360 & 2 & 900 & 545.61 \\
\hline
\end{tabular}




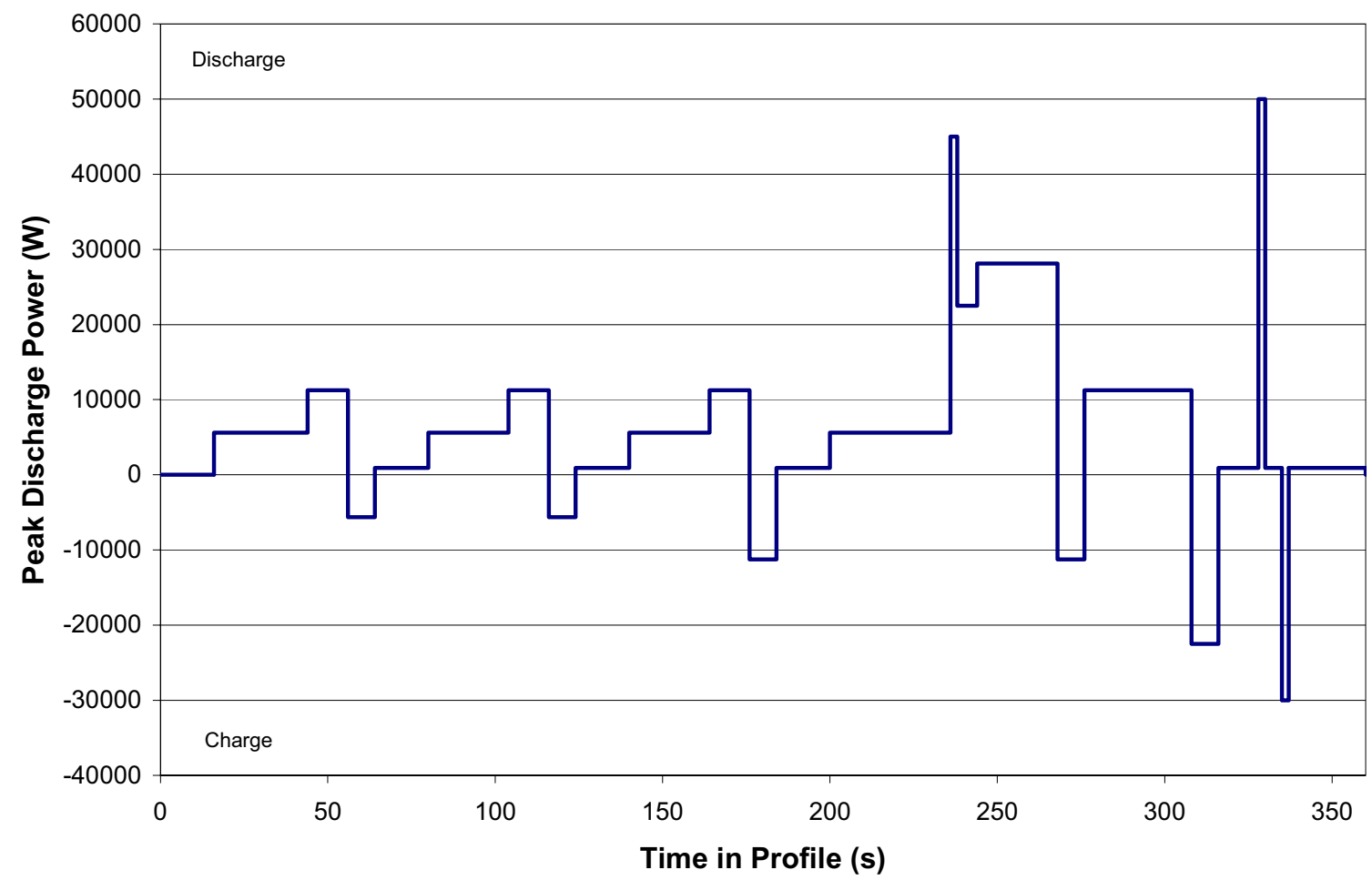

Figure 7. Charge-Depleting Cycle Life Test Profile for the Minimum PHEV Battery.

\subsubsection{Combined Cycle Life Test}

The purpose of the combined cycle life test is to combine the appropriate number of ChargeDepleting Cycle Life Profiles with Charge-Sustaining Cycle Life Profiles such that both sets of cycle life targets are met at the end of testing.

1. Scale the selected test profile by dividing the nominal profile power values by the Battery Size Factor as described in Section 3.1.2.

2. The initial state-of-charge is either the Minimum operating DOD specified by the manufacturer or $10 \%$ DOD.

3. Perform five successive Charge-Depleting Cycle Life Test Profiles for the Min PHEV Battery (or 20 successive Charge-Depleting Cycle Life Test Profiles for the Max PHEV Battery).

4. Perform 60 successive Charge-Sustaining Cycle Life Test Profiles for the Min PHEV Battery (or 60 successive Charge-Sustaining Cycle Life Test Profiles for the Max PHEV Battery). 
5. Recharge the device using the Maximum System Recharge Rate unless otherwise specified by the manufacturer. (For accelerated testing, this may be performed at temperatures other than $30^{\circ} \mathrm{C}$ ).

6. Repeat Steps 3-5, 500 times.

7. Perform the Reference Performance Tests from Table 9.

8. Repeat Steps 1-7, ten times. (Note: Steps 6 and 8 can be modified to provide longer or shorter intervals between Reference Performance Testing).

Table 7. Charge-Depleting Cycle Life Test Profile for the Maximum PHEV Battery.

\begin{tabular}{|c|c|c|c|c|c|}
\hline $\begin{array}{c}\text { Step } \\
\text { No }\end{array}$ & $\begin{array}{l}\text { Step } \\
\text { Time } \\
\text { (sec) }\end{array}$ & $\begin{array}{l}\text { Cum } \\
\text { Time } \\
\text { (sec) }\end{array}$ & $\begin{array}{c}\% \\
\text { Power } \\
(\%) \\
\end{array}$ & $\begin{array}{c}\text { Power } \\
\text { (W) }\end{array}$ & $\begin{array}{c}\text { Cum } \\
\text { Energy } \\
\text { (Wh) } \\
\end{array}$ \\
\hline 1 & 16 & 16 & 0 & 0 & 0.00 \\
\hline 2 & 28 & 44 & 12.5 & 4750 & 36.94 \\
\hline 3 & 12 & 56 & 25 & 9500 & 68.61 \\
\hline 4 & 8 & 64 & -12.5 & -4750 & 58.06 \\
\hline 5 & 16 & 80 & 2 & 760 & 61.43 \\
\hline 6 & 24 & 104 & 12.5 & 4750 & 93.10 \\
\hline 7 & 12 & 116 & 25 & 9500 & 124.77 \\
\hline 8 & 8 & 124 & -12.5 & -4750 & 114.21 \\
\hline 9 & 16 & 140 & 2 & 760 & 117.59 \\
\hline 10 & 24 & 164 & 12.5 & 4750 & 149.26 \\
\hline 11 & 12 & 176 & 25 & 9500 & 180.92 \\
\hline 12 & 8 & 184 & -25 & -9500 & 159.81 \\
\hline 13 & 16 & 200 & 2 & 760 & 163.19 \\
\hline 14 & 36 & 236 & 12.5 & 4750 & 210.69 \\
\hline 15 & 2 & 238 & 100 & 38000 & 231.80 \\
\hline 16 & 6 & 244 & 50 & 19000 & 263.47 \\
\hline 17 & 24 & 268 & 62.5 & 23750 & 421.80 \\
\hline 18 & 8 & 276 & -25 & -9500 & 400.69 \\
\hline 19 & 32 & 308 & 25 & 9500 & 485.13 \\
\hline 20 & 8 & 316 & -50 & -19000 & 442.91 \\
\hline 21 & 12 & 328 & 2 & 760 & 445.44 \\
\hline 22 & 2 & 330 & 121 & 46000 & 471.00 \\
\hline 23 & 5 & 335 & 2 & 760 & 472.06 \\
\hline 24 & 2 & 337 & -65.8 & -25000 & 458.17 \\
\hline 25 & 23 & 360 & 2 & 760 & 463.02 \\
\hline
\end{tabular}




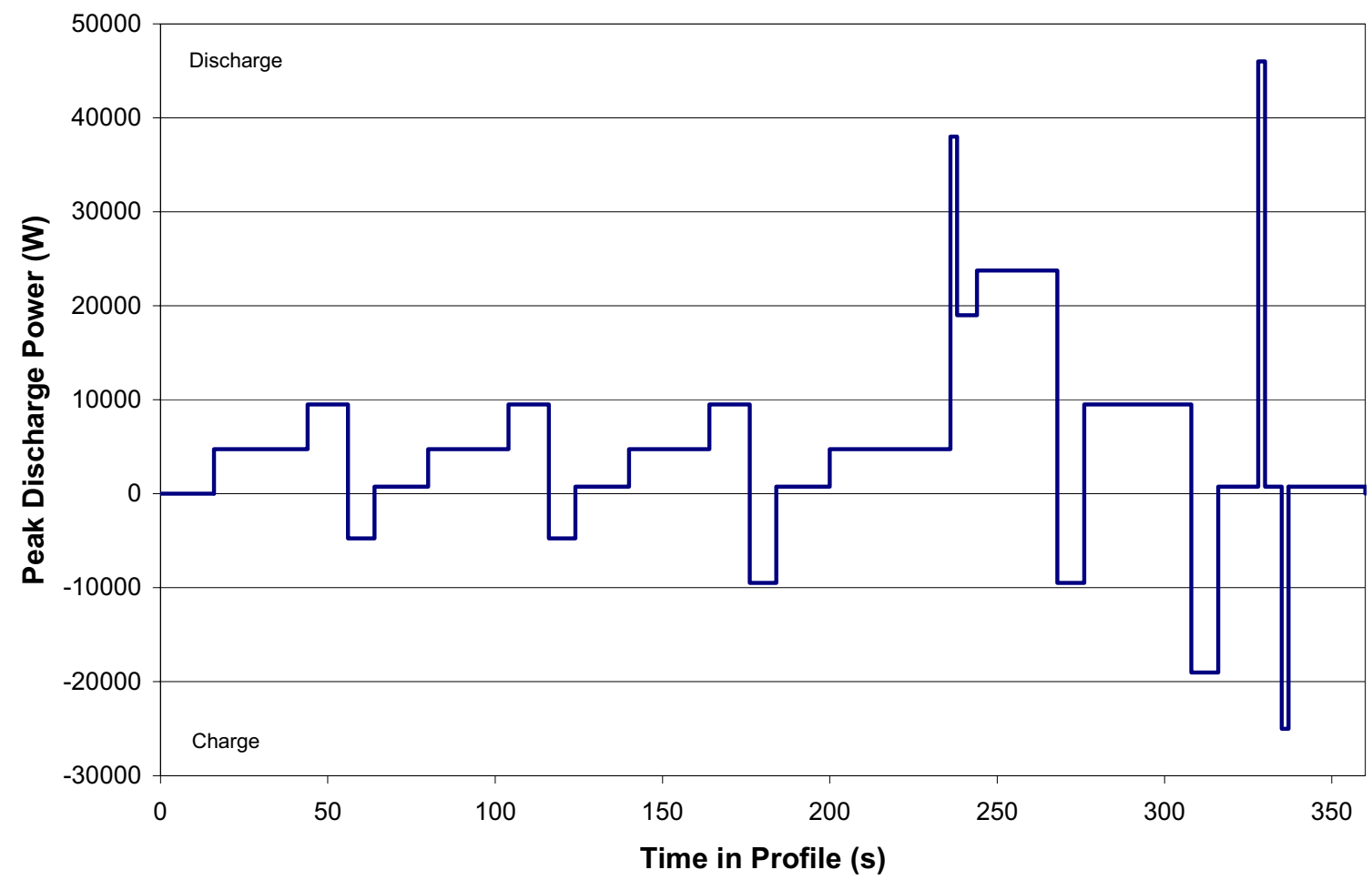

Figure 8. Charge-Depleting Cycle Life Test Profile for the Maximum PHEV Battery.

\subsection{Calendar Life Test}

This test is designed to permit the evaluation of cell or battery degradation as a result of the passage of time with minimal usage. It is not a pure shelf life test, because the devices under test are maintained at or near a target state-of-charge during the test. They must also be periodically subjected to reference discharges to determine the changes (if any) in their performance characteristics.

In general, calendar life testing is performed using multiple cells over a range of test conditions. ${ }^{20}$ It is commonly done at elevated temperatures in order to shorten the time required for obtaining useful results. Cells to be tested may be included in a matrix of test variables such as temperature and stateof-charge. This matrix may in turn be part of a larger cycle life test matrix where calendar life testing is considered a limiting cycle life test, i.e., one in which the state-of-charge swing during cycling is zero. Reference 4 provides more guidance on this subject. The calendar life test procedure assumes that the target test conditions for each cell or group of cells have been defined, typically in a devicespecific test plan.

20 The cell terminology in this section is not intended to prevent the calendar life testing of modules or complete batteries. It reflects only the fact that the vast majority of such testing is done at the cell level. 


\subsubsection{Calendar Life Test Planning}

Careful planning and analysis of calendar life tests are critical to estimation of battery life with high confidence. Accurate life estimates are, in turn, essential for assessing battery warranty risks and costs. Calendar life estimates are necessarily based on accelerated test methods. The general approach is to store cells or batteries under open-circuit conditions at elevated temperatures to artificially increase their rates of performance deterioration. The key tradeoff in the selection of storage temperatures is to avoid introducing irrelevant failure modes at too high a temperature, while achieving high rates of deterioration to minimize test time and cost.

At a minimum, three temperatures should be selected. Optimally, five to seven elevated temperatures should be selected. The lowest temperature should be the baseline temperature for calendar life, while the highest temperature should result in an end-of-life condition at the desired test duration (e.g., two years). Other temperatures should be equally spaced between these extremes. At least two cells should be tested at each temperature, but for improved statistical results, additional cells should be used, especially at the lower temperatures. The cells under test should be stored in an open-circuit condition, but with voltage monitoring using sensing circuits that present negligible loads to the devices under test. Periodically, based on criteria for acceptable decay in open-circuit voltages (and the corresponding SOC), the cells should be brought back to nominal operating temperature (i.e., $30^{\circ}$ C) and their performance measured. Such performance tests should be done at least monthly on each cell. Additionally, a 5-minute voltage clamp after each daily pulse will help maintain the appropriate SOC.

Key parameters, e.g., CD and CS Available Energy and Power, and minimum voltage (or voltage margin) in the Cold Cranking Test, should be monitored by periodic execution of Reference Performance Tests. The corresponding end-of-life criteria for these parameters are: (1) CD and CS Available Energy or Power < target energy or power; and (2) inability to complete the Cold Cranking Test within voltage limits. The test-to-test repeatability of these parameters should be no worse than one percent of the target values (to one standard deviation).

Other guidelines to improve test consistency for multiple cell tests include the following:

- Wherever possible, cells subjected to the same test conditions should be contained in the same test chamber or other environment, preferably using identical test channels, and test intervals should be time-synchronized.

- $\quad$ All cells that are part of a common test matrix should be subjected to reference testing at the same intervals if possible. Minimizing the fraction of time not spent at target temperatures is important for testing at elevated temperatures. However, in some cases rapid degradation may take place at very high temperatures; in such cases, the use of uniform test intervals will lead to a reduced number of data points for predicting trends over life. The reference test intervals have been selected to balance these conflicting needs but may need adjustment in special cases.

\subsubsection{Calendar Life Test Procedure}

The outline of this test procedure for a particular cell is as follows:

1. Characterize the cell using the Static Capacity Test (Section 3.2), the Constant Power Discharge Test (Section 3.3) and the Hybrid Pulse Power Characterization Test (Section 3.4) and other reference tests as appropriate. 
2. Discharge the fully charged cell to the target $\mathrm{DOD} / \mathrm{SOC}$ value at $30^{\circ} \mathrm{C}$. This can be done in one of two ways: (1) [default] remove the appropriate fraction of the cell's rated capacity at a HPPC-Current rate, or (b) if the open-circuit voltage corresponding to the target $\mathrm{DOD} / \mathrm{SOC}$ is known, clamp the cell at this voltage while limiting discharge current to a HPPC-Current rate and then wait for the voltage and current to stabilize. ${ }^{21}$ Note that the default method will typically reach the target DOD more quickly. However, in some cases it may be desirable to use voltage (rather than fractional discharge) as the measure of SOC.

3. Apply a single iteration of the Calendar Life Test Profile defined in Section 3.11.3. The nominal discharge current to be used for this profile is equal to the peak discharge current for the Low-Current HPPC Test.

4. Bring the cell to the target temperature at open-circuit condition and wait for the ambient temperature and voltage to stabilize (i.e. 4 to 8 hours).

5. Apply a single iteration of the Calendar Life Test Profile defined in Section 3.11.3 at the same current level defined in Step 3. The device is then placed in an open-circuit state and the test continues at the target conditions.

6. Once every 24-hours, and immediately before beginning Step 7, repeat Step 5. Note that data acquisition requirements during this pulse profile execution will be similar to those for HPPC Tests, even though other data may be required only infrequently during the 24-hour intervals. ${ }^{22}$

7. At intervals as specified in Table 9 or a device-specific test plan, return the cell to nominal temperature (e.g., $30^{\circ} \mathrm{C}$ ), observe its open-circuit voltage after a 1-hr rest, and apply a single iteration of the Calendar Life Test Profile before discharging its remaining capacity at the HPPC-Current rate. Conduct a single iteration of the required periodic Reference Performance Tests, and then return the cells to their test temperatures.

8. Repeat this test sequence until the cell reaches an end-of-test condition. Default end-of-test conditions are generally analogous to those for cycle life testing in Section 3.9.1: (a) the Calendar Life Test Profile cannot be performed within the voltage limits; (b) the HPPC Reference Test yields insufficient information to show further degradation; (c) calculated CD or CS Available Energy is less than the target; or (d) sufficient data is acquired to project calendar life at $35^{\circ} \mathrm{C}$ with a predetermined degree of confidence. Note that condition (d) may take precedence over condition (c) in some cases.

This test profile is intended for once-per-day execution during calendar life testing at the target temperature and state-of-charge. Additionally, this test profile is performed again at the target SOC but at $30^{\circ} \mathrm{C}$, immediately before and immediately after each calendar life testing interval. The data provide daily information regarding the extent and rate of cell degradation during the intervals between periodic reference tests. This test profile differs from Cycle Life Test Profile in that it is not

21 A value less than $1 \%$ of the HPPC current is probably adequate to meet this criterion, provided this is within the measurement capability of the test equipment.

22 Intermittent charge increments may be required to compensate for self-discharge to keep the state-of-charge within an acceptable range until the next reference test. The method to be employed for doing this should be specified in a devicespecific test plan. The suggested method is to clamp each device after the once-per-24-hours profile at its elevatedtemperature OCV (as measured in Step 4) for a specified duration sufficient to compensate for increased self-discharge at the target temperature. 
intended for continuous execution; instead, it is executed once during each 24 -hr period while the cell under test is maintained at a given temperature and state-of-charge. The pulse profile is shown in Table 8 and illustrated in Figure 9. Note that although not shown in the figure, the pulse extends to 380 seconds just as specified in Table 8 .

\subsubsection{Calendar Life Test Profile}

Table 8. Calendar Life Test Profile.

\begin{tabular}{ccc}
$\begin{array}{c}\text { Step Time } \\
(\mathrm{s})\end{array}$ & $\begin{array}{c}\text { Cumulative Time } \\
(\mathrm{s})\end{array}$ & $\begin{array}{c}\text { Relative Current } \\
\text { (Ratio) }\end{array}$ \\
\hline 10 & 10 & 1.0 \\
60 & 70 & 0 \\
10 & 80 & -0.75 \\
300 & 380 & Voltage Clamp \\
\hline
\end{tabular}

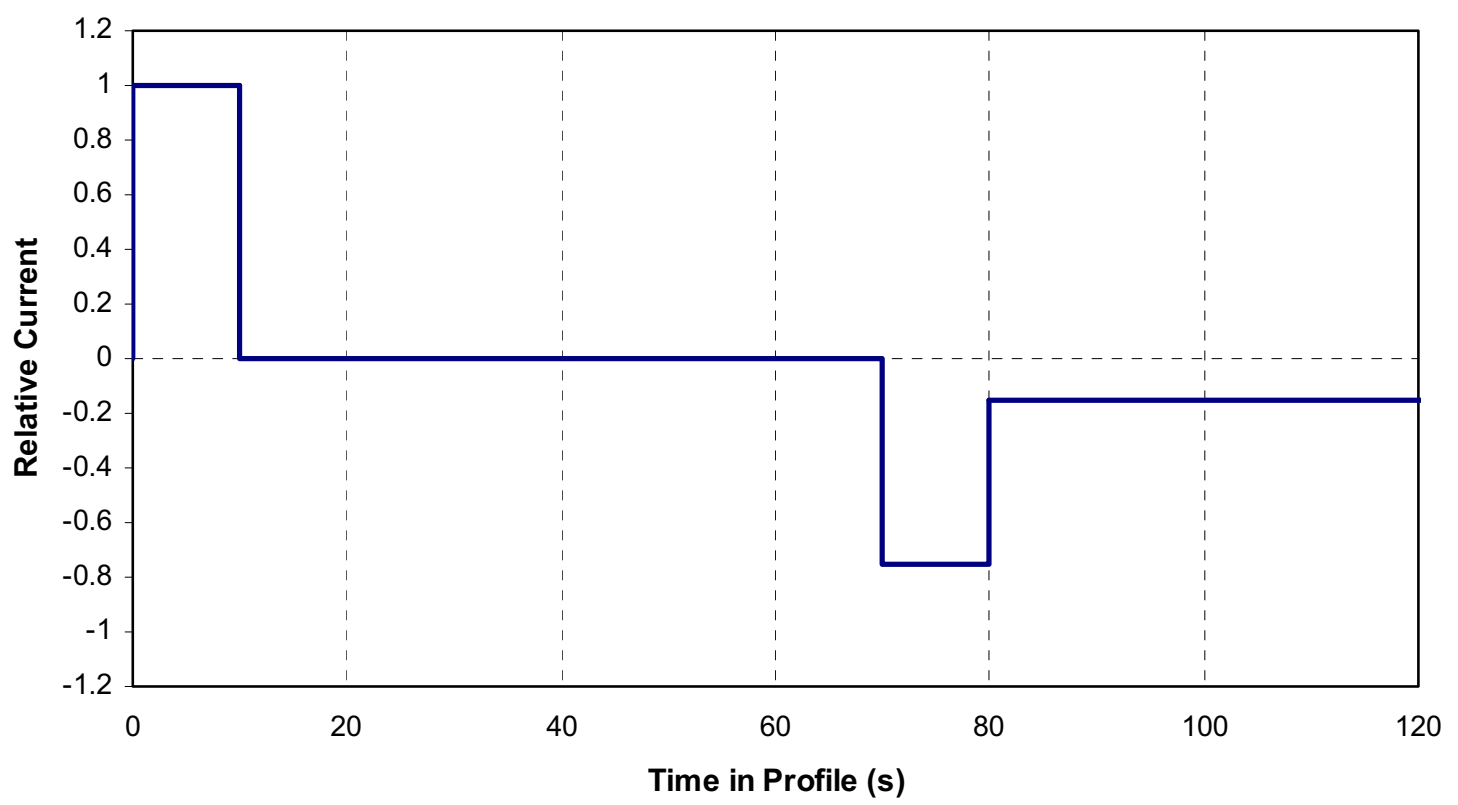

Figure 9. Calendar Life Test Profile.

\subsubsection{Alternative Calendar Life Test}

In some cases calendar life testing may be conducted without using the once-per-24-hr Calendar Life Test Profile. The most likely reason for this is a shortage of continuously available test channels for the number of devices to be tested. (If the 24-hr pulse profile is not performed, a test channel is required only for the periodic Reference Performance Tests and possibly for occasional charge 
increments). The earlier procedure can be used in this fashion by omitting the daily performance of the test profile specified in Step 6 in the preceding section. If testing is performed in this fashion, the device open-circuit voltage should be checked every 24 to 48 -hours to verify that the state-of-charge remains in an acceptable region.

\subsection{Reference Performance Tests}

Reference Performance Tests (RPTs) are a set of tests performed at periodic intervals during life testing to establish the condition and rate of performance degradation of devices under test. Except as modified by a device-specific test plan, these tests should be performed (a) prior to the start of life testing; (b) at defined periodic intervals; and (c) at end of testing, for all devices undergoing either cycle life testing or calendar life testing. ${ }^{23}$

Table 9. Reference Performance Tests and Test Intervals for Life Testing.

\begin{tabular}{|c|c|c|}
\hline Type of Life Testing & Interval Between RPTs & Reference Performance Tests \\
\hline $\begin{array}{c}\text { Charge-Sustaining Cycle } \\
\text { Life Testing }\end{array}$ & $\begin{array}{c}30,000 \text { cycle life profiles } \\
\text { (50 Wh profile) }\end{array}$ & \multirow{7}{*}{$\begin{array}{c}\text { 10-kW Constant Power Discharge Test } \\
\text { (This test is to precede the HPPC Test } \\
\text { and generally included in the same } \\
\text { data file as the HPPC Test for analysis } \\
\text { purposes) } \\
\text { Low-Current HPPC Test }\end{array}$} \\
\hline Charge-Depleting Cycle & & \\
\hline & $\begin{array}{l}\text { (2,500 Min PHEV Profiles or } \\
\text { 10,000 Max PHEV Profiles) }\end{array}$ & \\
\hline Calendar Life Testing & $\begin{array}{c}\text { Approximately } 32 \text { days } \\
\text { (consistent with CS cycle life } \\
\text { RPTs) }\end{array}$ & \\
\hline \multirow[t]{2}{*}{$\begin{array}{c}\text { Combined Cycle Life } \\
\text { Testing }\end{array}$} & $\begin{array}{c}\text { Min PHEV (2,500 CD Profiles } \\
\text { and 30,000 CS Profiles) }\end{array}$ & \\
\hline & $\begin{array}{c}\text { Max PHEV }(10,000 \mathrm{CD} \\
\text { Profiles and 30,000 CS } \\
\text { Profiles })^{24}\end{array}$ & \\
\hline Other Life Tests TBD & $10 \%$ of expected life & \\
\hline
\end{tabular}

23 For battery chemistries that have a strong dependence of performance on temperature, it may be desirable to measure accurately the actual (ambient) temperature of the test article during the RPTs and adjust the performance results using the data from the Thermal Performance Tests (Section 3.7) to estimate the present performance at the nominal $30^{\circ} \mathrm{C}$ temperature. Performing such an adjustment is necessarily limited to those cases where the following conditions are satisfied: temperature data is available with accuracy better than the variations to be corrected $\left(2^{\circ} \mathrm{C}\right.$ or less); Thermal Performance Test data is available "near" the normal testing range, e.g., within $\pm 5^{\circ} \mathrm{C}$ on either side of the nominal temperature; and the test whose data is to be adjusted is conducted within this limited range "near" the nominal temperature.

24 These values can be modified as long as the ratio between CD Profiles and CS Profiles remains the same to allow a shorter or longer RPT interval. 
A Reference Performance Test iteration consists of one repetition of each test listed in Table 9. It is recommended that these tests be performed in the order listed. ${ }^{25}$ These tests are performed for all PHEV testing modes.

Table 9 also lists typical intervals for reference tests during cycle life and calendar life testing. In practice, these intervals may have to be adjusted somewhat to synchronize reference testing for groups of multiple cells, especially where calendar life and cycle life cells are being tested in the same temperature chamber.

25 The Cold Cranking Test is not included in the list of Reference Performance Tests, because it will not routinely be performed at the intervals specified in Table 9. However, it should typically be performed along with the Reference Performance Tests at each of three times over the life of a device: (1) as part of initial characterization testing, (2) about halfway through the projected life, and (3) at the end-of-life testing. 


\section{ANALYSIS AND REPORTING OF TEST RESULTS}

\subsection{General}

For purposes of consistency in test reporting (particularly between multiple testing organizations), a required minimum subset of information, based on the procedures in this manual, has been compiled for testing and is tabulated in Appendix B for the Minimum PHEV battery. Corresponding data should also be reported for the Maximum PHEV battery, when appropriate. This is not intended to limit the reporting of other test results where appropriate; the intent is rather to ensure that important test results are reported in a fashion that allows them to be compared to test results on hybrid energy storage devices performed at various locations and stages of development.

\subsection{Static Capacity Test and Constant Power Discharge Test}

Capacity in ampere-hours and energy in watt-hours at the specified discharge rates are reported based on manufacturer-specified discharge termination conditions. The Static Capacity Test is performed at a constant current discharge rate corresponding to the HPPC-Current and the Constant Power Discharge Test is performed at a constant power discharge rate corresponding to a BSF-scaled 10-kW rate. (Note that all of this capacity will not generally be useable within operating conditions, and thus it does not reflect conformance to the Plug-In CS or CD Available Energy targets. However, it is still considered a useful measure of capacity at the laboratory cell stage).

Ampere-hours and watt-hours returned (and the corresponding overall charge/discharge efficiencies) are also reported for the manufacturer-specified charge algorithm. Energy removed (watt-hours) is reported as a function of depth-of-discharge (in percent of rated capacity). These data are used for the later calculation of CS and CD Available Energy.

\subsubsection{Capacity Fade}

For devices subjected to life testing, the change in static capacity and constant power discharge capacity from the beginning-of-life values (measured just prior to the start of life testing) to some later point in time are to be reported periodically for each test as Capacity Fade, expressed as a percentage of the original (BOL) capacity as shown in Equation (2).

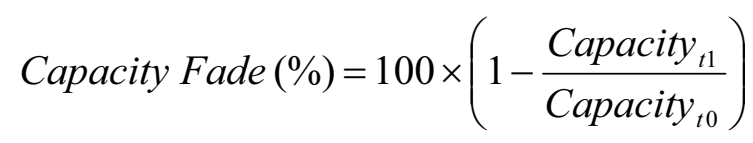

where $t 0$ refers to the time of the initial Beginning-of-Life (BOL) RPT and $t 1$ refers to the time of the later RPT where capacity fade is to be determined.

\subsection{Hybrid Pulse Power Characterization Test}

Analysis and reporting of the results of the HPPC Test are generally aimed at comparing the present performance of a cell to the targets. Since the targets are all expressed at the system level, most results must be scaled using the Battery Size Factor before such comparisons can be made (See Section 3.1.2). The Battery Size Factor for a cell is necessarily specific to either the Minimum PHEV 
Battery or the Maximum PHEV Battery targets and most likely will be different for each set of targets.

\subsubsection{Open-Circuit Voltage}

Open-circuit voltage (OCV) is measured and plotted as a function of depth-of-discharge (DOD) at the end of each HPPC rest period, as shown in Figure 11. From these data, OCV at other DOD values can be estimated by straight-line interpolation or by fitting a curve through the measured data.

\subsubsection{Calculated Resistance Characteristics as a Function of Depth-of-Discharge}

Calculated resistance characteristics as a function of depth-of-discharge are derived from the pulse profile test data as follows:

1. Discharge resistance $10 \mathrm{sec}$ after start of discharge pulse

2. Regen resistance $10 \mathrm{sec}$ after start of regen pulse.

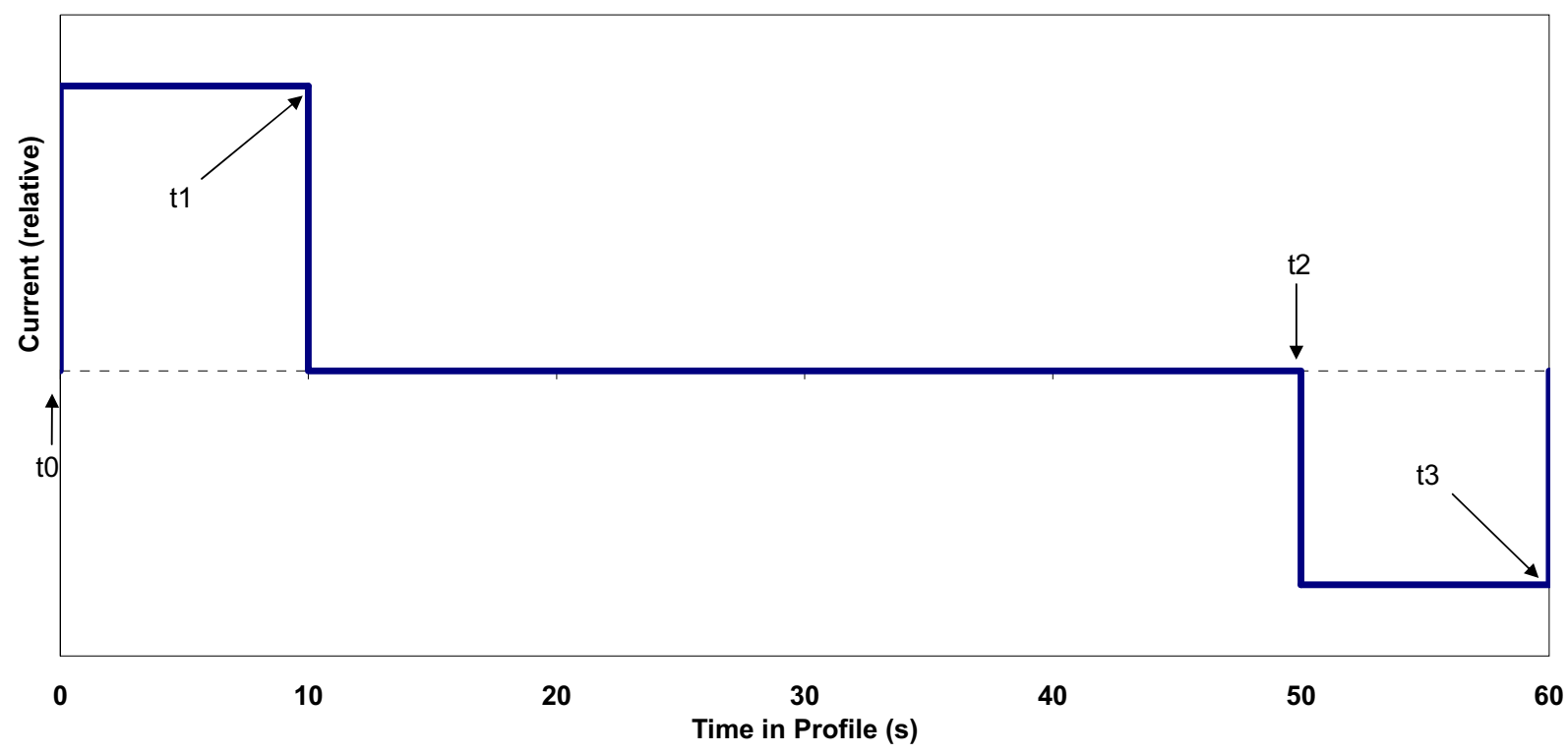

Figure 10. Resistance Calculation Time Points.

Discharge and regen resistances are determined using a $\Delta \mathrm{V} / \Delta \mathrm{I}$ calculation for each iteration of the test profile, in accordance with Equations 3 and 4 and Figure 10. Resistances are normally only calculated for completely unabated test profile pulses, i.e., those with full duration and amplitude. ${ }^{26}$

The signs of all terms in these equations have been chosen to agree with the manual convention that discharge current is positive and regen current is negative, thus assuring that the calculated resistance is always a positive quantity. These discharge and regen resistances are plotted as a function of

26 Because the HPPC test is required to continue to 100\% DOD (or until the constant current discharge rate cannot be sustained), some data may be acquired during pulses where current limiting was encountered. Tests conducted by INL indicate that pulse resistances calculated using such data will be somewhat different (probably higher) than the values calculated for pulses where limiting does not occur. While this current limited data may be useful as an indication of device behavior, it should not be used for direct comparisons to the targets. 
depth-of-discharge, as shown in Figure 11. Also it may be informative to plot open-circuit voltage on this same figure as shown here. (Resistance and voltage values are shown for illustration only).

$$
\begin{aligned}
& \text { Discharge Resistance }=\frac{\Delta V_{\text {discharge }}}{\Delta I_{\text {disch arge }}}=\left|\frac{V_{t 1}-V_{t 0}}{I_{t 1}-I_{t 0}}\right| \\
& \text { Regen Resistance }=\frac{\Delta V_{\text {regen }}}{\Delta I_{\text {regen }}}=\left|\frac{V_{t 3}-V_{t 2}}{I_{t 3}-I_{t 2}}\right|
\end{aligned}
$$

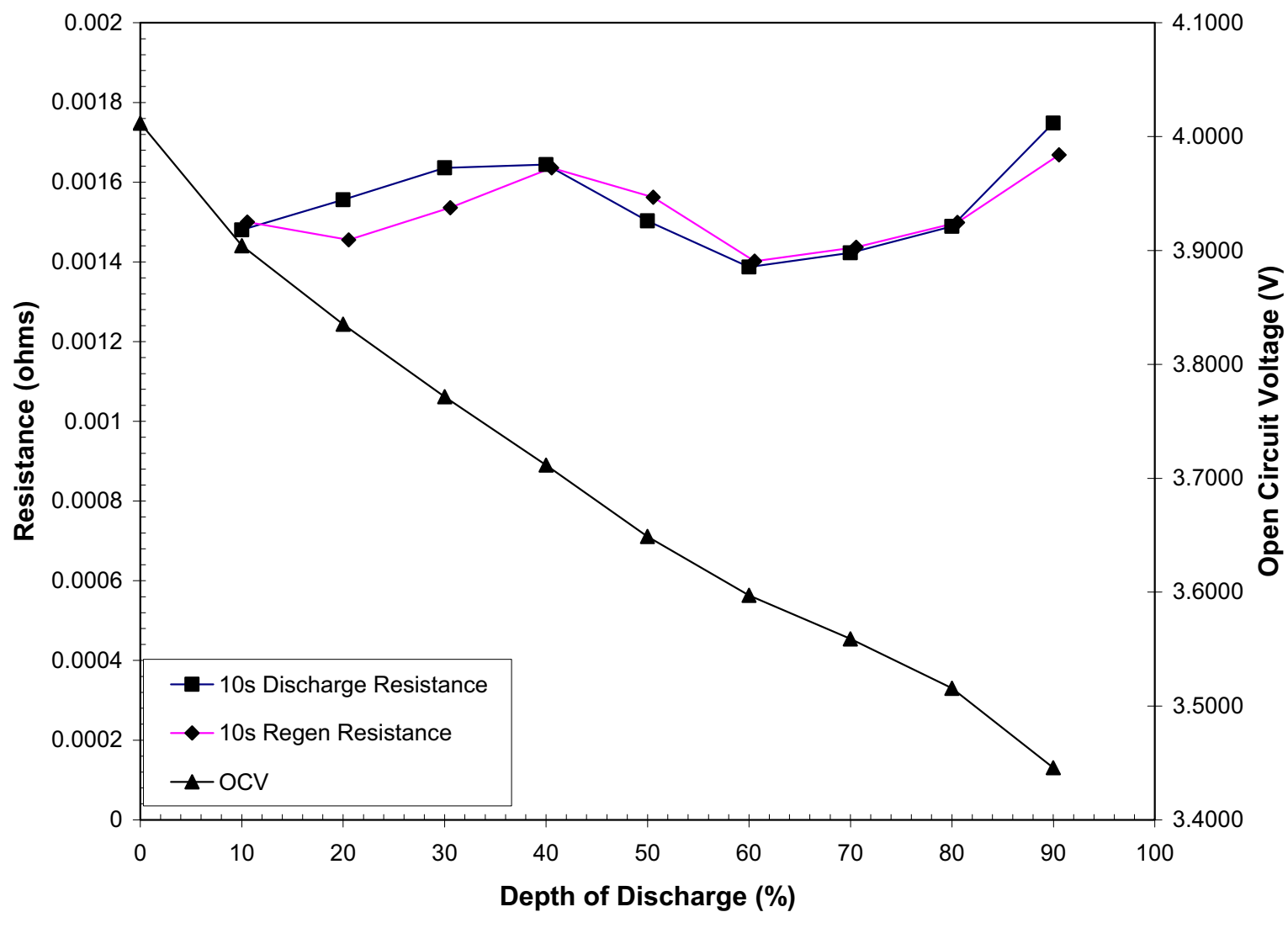

Figure 11. Open-Circuit Voltage and Pulse Resistances versus Depth-of-Discharge.

\subsubsection{Pulse Power Capability}

Pulse power capability is defined and plotted from the voltage and resistance characteristics, showing the $\mathrm{V}_{\text {MIN }}$ discharge capability and $\mathrm{V}_{\mathrm{MAX}}$ regen capability at each DOD tested. (See Footnote [7] in Section 3.4 regarding allowable values for $\mathrm{V}_{\mathrm{MAX}}$ and $\mathrm{V}_{\mathrm{MIN}}$ ).

Discharge and regen pulse power capability is calculated at each available DOD increment from the open-circuit voltage and resistance determined for that DOD (as shown in Figure 11), using Equations 5 and 6. 


$$
\text { Discharge Pulse Power Capability }=\mathrm{V}_{\mathrm{MIN}} \bullet\left(\mathrm{OCV}_{\text {dis }}-\mathrm{V}_{\mathrm{MIN}}\right) \div \mathrm{R}_{\text {discharge }}
$$

and

$$
\text { Regen Pulse Power Capability }=\mathrm{V}_{\mathrm{MAX}} \bullet\left(\mathrm{V}_{\mathrm{MAX}}-\mathrm{OCV}_{\text {regen }}\right) \div \mathrm{R}_{\text {regen }}{ }^{27}
$$

These power capability values are used to determine the total available depth-of-discharge and energy swing that can be used (within the operating voltage limits) for specified discharge and regen power levels. Note that profile charge removal has to be accounted for in determining DOD. ${ }^{28}$ An example of the power capability versus DOD plot is shown in Figure 12. (Power values shown are for illustration only).

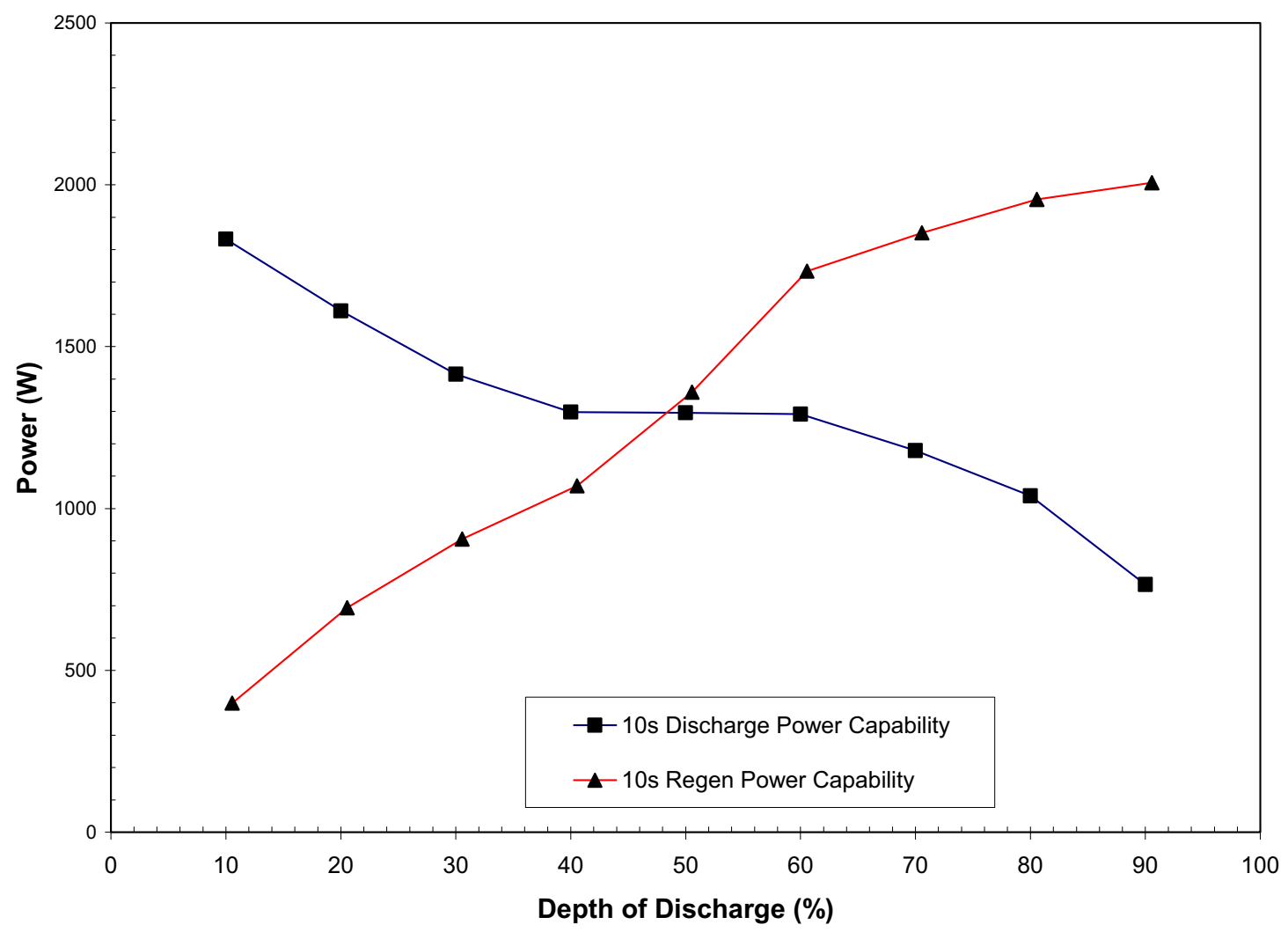

Figure 12. Pulse Power Capability vs. Depth-of-Discharge.

27 Note that OCV at the start of each regen pulse must be interpolated from the OCV curve derived from the rest periods before each discharge pulse, accounting for the percent DOD removed by the discharge pulse (i.e., this is not the same OCV used for discharge calculations.) For example, if the discharge pulse starting at $10 \%$ DOD removes $3 \%$ of the device capacity, the subsequent regen pulse OCV is interpolated starting at $13 \%$ DOD.

28 In this manual, plotted DOD values always represent the beginnings of their respective discharge or regen pulses. 


\subsubsection{CS Available Energy}

The Plug-In Hybrid Electric Vehicle (PHEV) targets include two power targets (Peak Discharge Pulse Power and Peak Regen Pulse Power) plus two energy targets (CD Energy and CS Energy) for each mode (i.e., the Minimum PHEV Battery and the Maximum PHEV Battery) which must be satisfied in several combinations of these parameters. The Electrochemical Energy Storage Technical Team has decided that for PHEVs, the CD energy can be regen limited (unable to accept complete regen at the upper end of the SOC range) and is to be measured starting from the $10 \%$ DOD point. (However, a manufacturer may specify a different minimum operating DOD that may be more suitable for their technology).

With this in mind, CS Available Energy is defined as the energy removed during a 10-kW discharge over the DOD range for which the discharge and regen pulse power targets for a given mode are precisely met. As will be described in the following discussions, CS Available Energy generally includes a portion of the CD energy, all of the CS energy, and any energy margin that may exist. Determining CS Available Energy is done by the following sequence of steps:

1. From the HPPC Test results, establish the relationship between HPPC power and 10-kW discharge energy as a function of DOD.

2. Scale both the energy and power results using the Battery Size Factor.

3. Determine the minimum and maximum DOD values over which the power targets can be met.

4. Calculate the available (10-kW equivalent) energy over the discharge region where the targets are precisely met. 


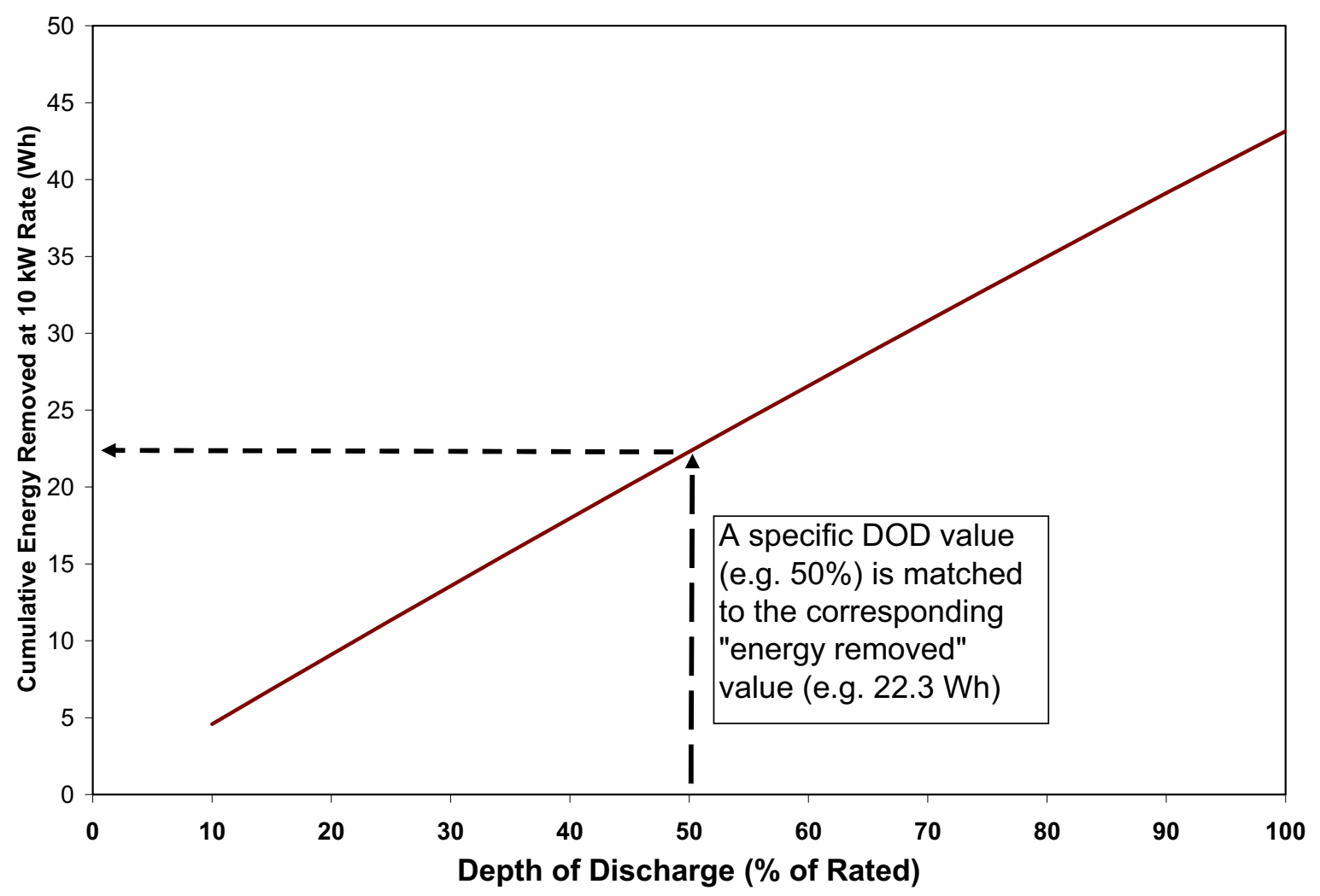

Figure 13. Relationship Between Energy and DOD in a 10-kW Discharge.

HPPC power capability and 10-kW discharge energy values are related by assuming that the corresponding measured DOD values in a pair of such tests are equivalent. ${ }^{29}$ With this assumption, Figure 12 can be transformed to a power-versus-energy plot by replacing each DOD value from the HPPC data with the energy value at that DOD from a corresponding 10-kW discharge test. Figure 13 shows a 10-kW equivalence, and Figure 14 illustrates the resulting HPPC power versus 10-kW equivalent energy plot for cell-level data. ${ }^{30}$ (Power and energy values are illustrative only).

29 This equivalence is not exact, because part of each $10 \%$ capacity increment removed in the HPPC test is due to the pulse profile. However, for high-power batteries the corresponding DOD values are assumed to represent the same state-ofcharge in both tests. 


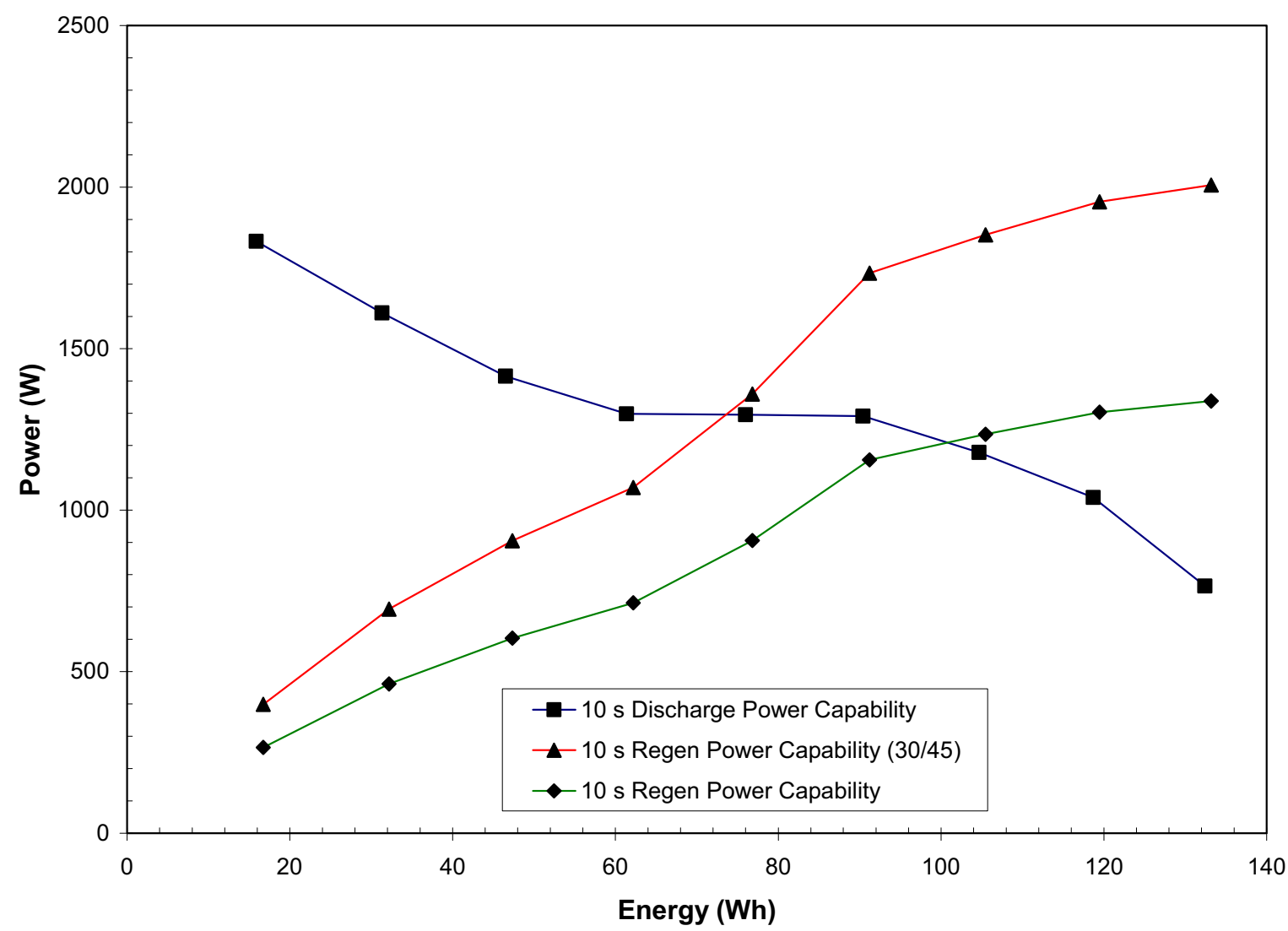

Figure 14. Unscaled HPPC Cell Power Capability vs. Energy Removed.

The power-versus-energy data plot can now be scaled by the Battery Size Factor for comparison with the targets. This is performed by multiplying all cell-level power and energy values by the Battery Size Factor (for Minimum PHEV or Maximum PHEV Battery as applicable). To simplify the targets comparison, the regen power results are plotted on a second y-axis scaled by the ratio of required regen to discharge power, e.g., $30-\mathrm{kW}$ regen and $45-\mathrm{kW}$ discharge for the Minimum PHEV Battery targets. Figure 15 illustrates the result of this scaling applied to Figure 14, for a Battery Size Factor of 44 with the Regen Power now plotted on a secondary y-axis. 


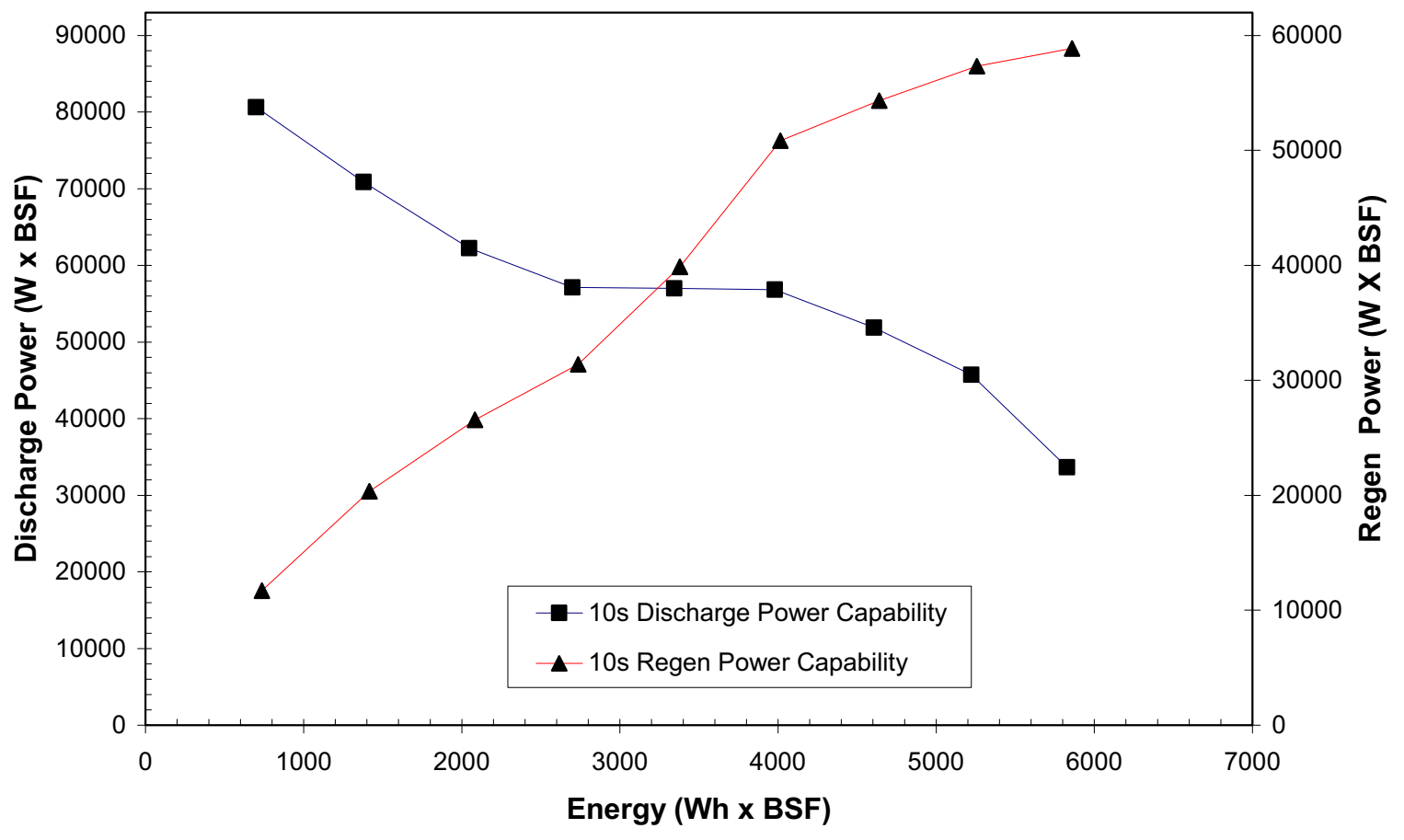

Figure 15. HPPC Power vs. HPPC-Current Discharge Energy Scaled by the Battery Size Factor.

Note that in Figure 14, the crossover point of the two power capability curves shifts when the axes are scaled in proportion to the discharge and regen pulse power targets. Because of the way these pulse power values are calculated in Equations 5 and 6, changing the operating voltage limits $V_{M A X}$ and/or $V_{M I N}$ will also cause the curves to shift relative to each other. Thus the location of the usable energy range can be varied if desired by altering the operating voltage range (within the allowable voltage limits).

The comparison of these results to the targets can be performed graphically in several steps by first adding a horizontal line representing the power targets and determining the CS Available Energy based on the intersection of this target line and the discharge and regen power capability curves, as shown in Figure 16. (This horizontal line represents both the discharge and regen targets because the two vertical axes are scaled in proportion to these targets). Figure 16 shows that the calculated CS Available Energy is that energy that extends from the Pulse Discharge Power curve to the Pulse Regen Power curve. Reading the values from Figure 16, it can be seen that the CS Available Energy is approximately equal to the difference between $5260 \mathrm{Wh}$ and $2560 \mathrm{Wh}$, or $2700 \mathrm{Wh}^{31}$ 


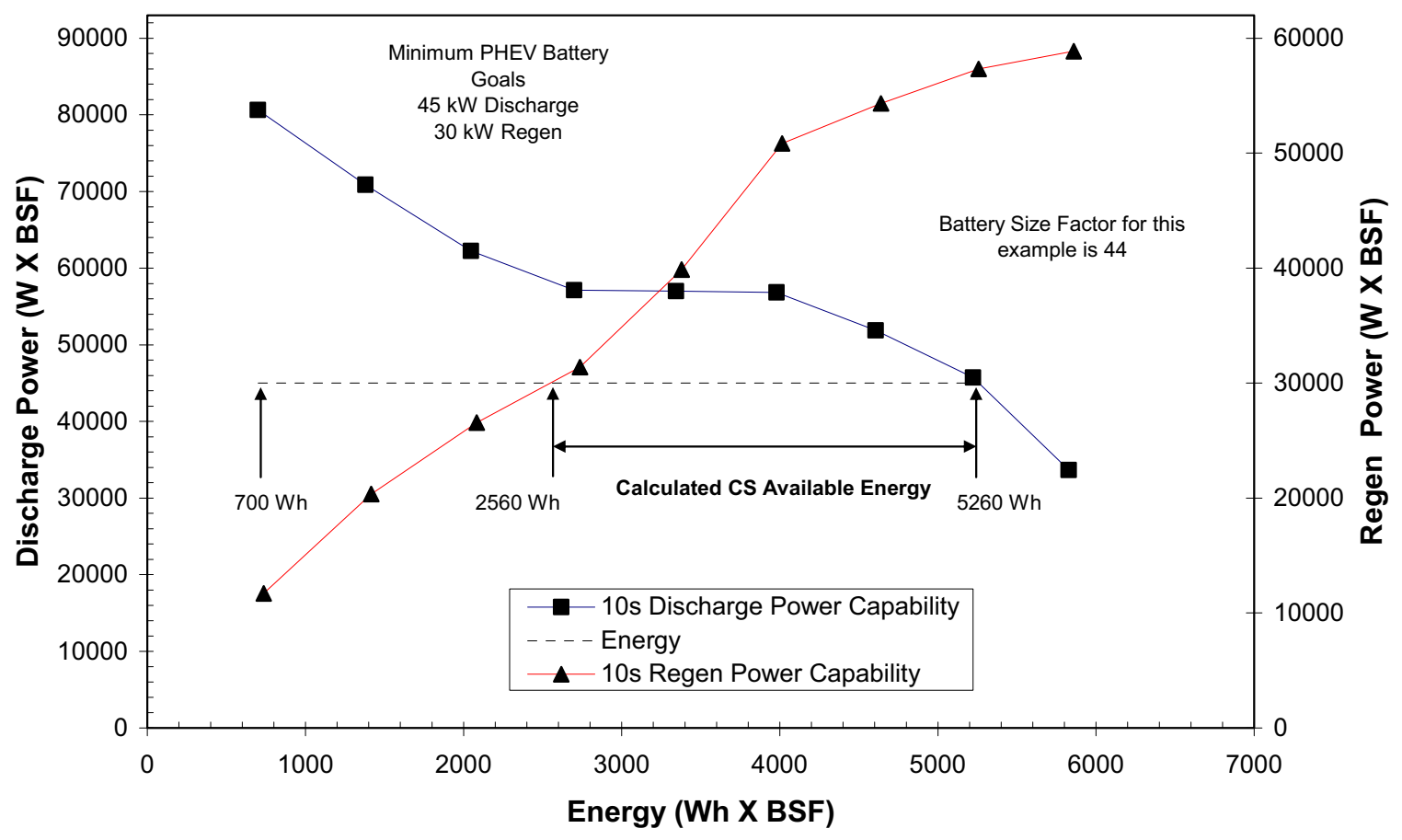

Figure 16. CS Available Energy Determination.

\subsubsection{Available Energy}

The CS Available Energy calculated above is over the operating region of the battery where both discharge and regen power targets are precisely met (i.e. where Charge-Sustaining mode is possible). This is similar to the customary method to calculate Available Energy for conventional hybrid electric vehicles. However, for Plug-In Hybrid Electric Vehicles the regen targets do not have to be met over the entire Available Energy range for Charge-Depleting operation. This is represented by the extension of the dashed Energy line to the left of the Regen Power Capability line. Thus the associated energy calculation methodology for CD operation is somewhat different. As mentioned earlier, allows the CD energy to be measured starting from 10\% DOD. A composite energy line is depicted in Figure 17. If this line were extended, the Y-axes intercepts would pass through the Discharge and Regen Power targets. First, all the $3.4 \mathrm{kWh}$ of CD Energy Target is plotted starting at the $10 \%$ DOD point (which, in this example, corresponds to an X-axis energy value of about 700 $\mathrm{Wh}$ ). Referring to both Figures 16 and 17, a portion of the $3.4 \mathrm{kWh} C D$ energy is regen limited, (i.e., $2560 \mathrm{Wh}-700 \mathrm{Wh}=1860 \mathrm{Wh}$ ) while the remaining portion of the CD energy is capable of meeting the prescribed regen targets, (i.e., $3400 \mathrm{Wh}-1860 \mathrm{Wh}=1540 \mathrm{Wh}$ ). The CS Energy Target is contained in the last $500 \mathrm{Wh}$ of the CD Energy. The last segment of the energy line which terminates at the intersection with the Pulse Power Discharge curve (in this example, an X-axis energy value of about $5260 \mathrm{Wh}$ ) is the energy margin. The total length of the composite energy line (i.e. the ChargeDepleting Available Energy) is thus the energy between 10\% DOD point and the point where the energy line intersects the Pulse Discharge Power Curve, i.e., $5260 \mathrm{Wh}-700 \mathrm{Wh}=4560 \mathrm{Wh}$.

In this example, the result indicates an energy margin of $1160 \mathrm{Wh}(4560 \mathrm{Wh}-3400 \mathrm{Wh}=1160 \mathrm{Wh})$ beyond the Minimum PHEV Battery CD Available Energy Target of $3.4 \mathrm{kWh}$. Some margin is necessary at beginning-of-life to allow for the degradation of power capability and CD and CS 
Available Energy that occurs over both life cycling and calendar life. Because the power and energy targets are required to be met at end-of-life for both the Charge-Sustaining mode and Charge-

Depleting modes, the point in life where this energy margin decreases to zero is the end-of-life, unless some other target criterion has already failed to be met (for example, the self-discharge rate might become unacceptably high). Another complicating condition is that, unlike the CD Energy, the CS Energy is simultaneously regen- and discharge-limited, while also allowing adequate energy to meet the CD Available Energy Target. All of the CS Energy line must lie between the Pulse Power Discharge Curve and the Pulse Power Regen curve.

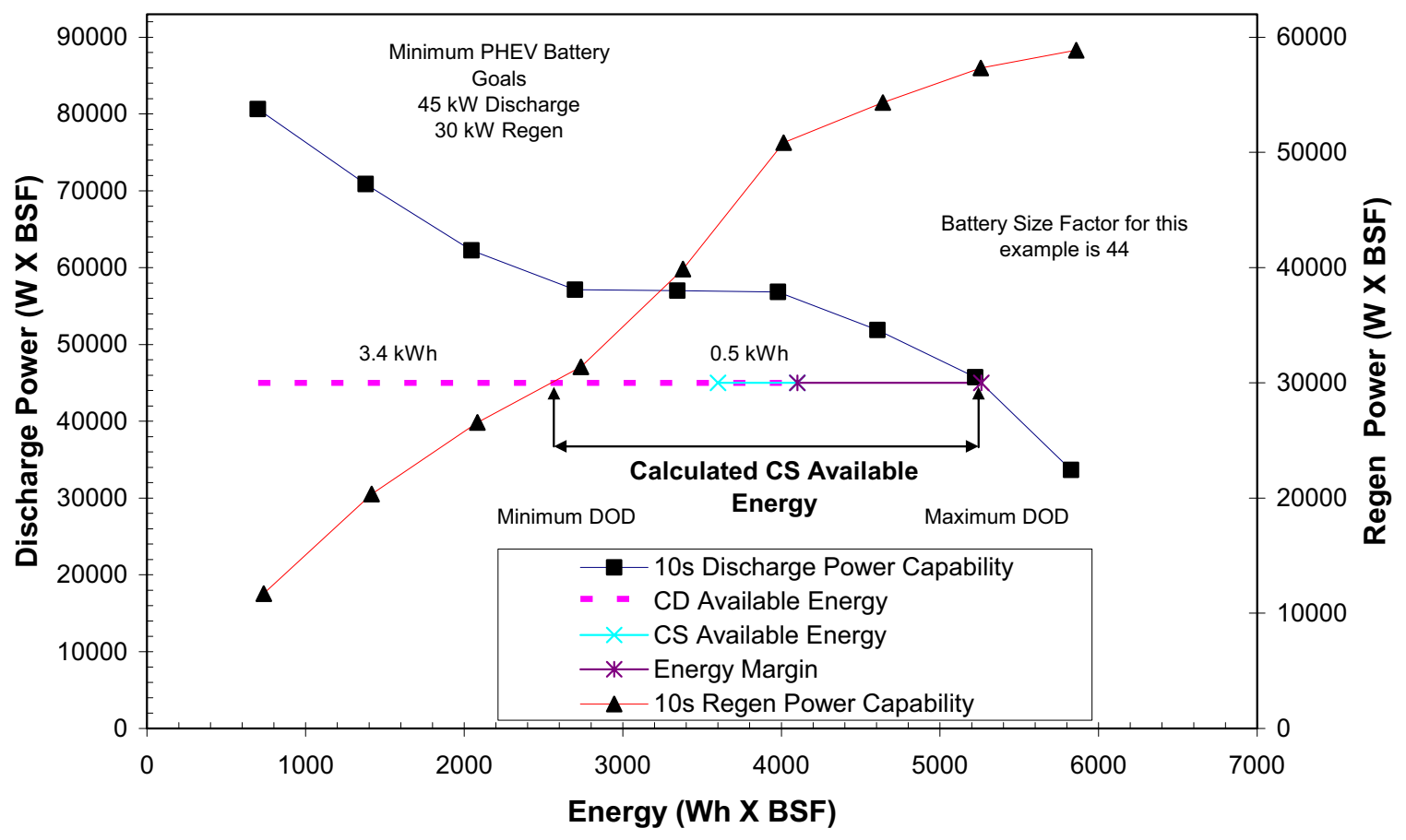

Figure 17. Charge-Depleting and Sustaining Available Energy Determination.

The variation of energy margin over life is illustrated in Figure 18. This figure shows the energy margin and power margin at beginning-of-life, how they change over life, and that these margins are zero (by definition) at end-of-life. ${ }^{32}$ Thus, it is conceivable that the battery may reach a condition in which it can only satisfy the CD targets or the CS targets, but not both simultaneously. These are all possible end-of-life conditions.

32 These end-of-life data are theoretical; in practice, test data are seldom available exactly at the point in life where power and energy margins are zero because reference tests are performed only at periodic intervals. Thus this point normally occurs between two sets of reference tests. See Section 4.9 regarding the implications of this behavior on reported life. 


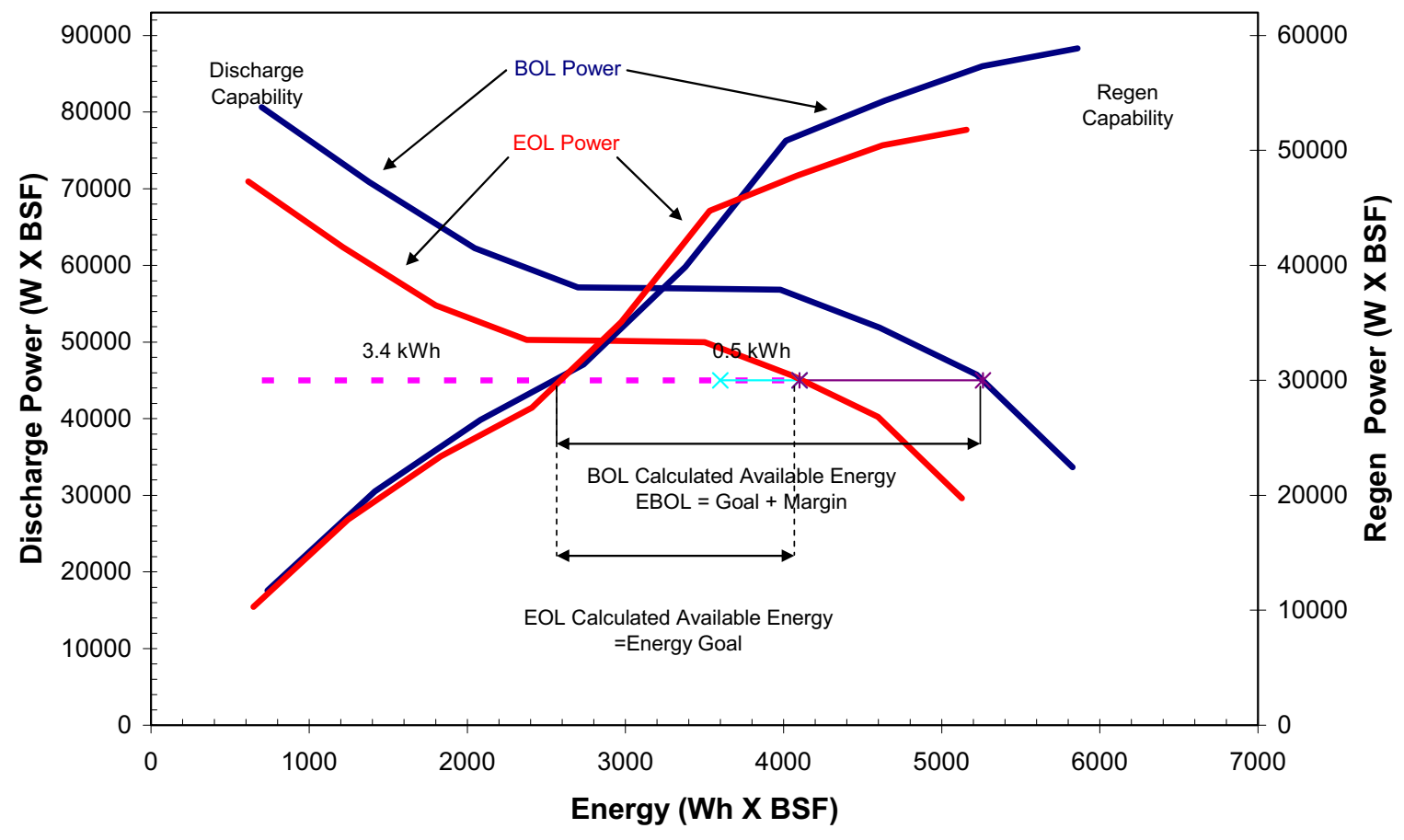

Figure 18. CD and CS Available Energy Margins Over Life.

\subsubsection{CS Available Power}

CS Available Power (only applicable to the CS Energy Target), is the discharge power capability at which usable energy is equal to the Charge-Sustaining Available Energy target for a given mode. In effect it is the maximum discharge power capability at which the Charge-Sustaining Available Energy target is precisely met. CS Available Power is illustrated at both beginning-of-life (BOL) and end-oflife (EOL) conditions in Figure 19. CS Available Power at EOL is precisely equal to the discharge target power. This parameter is defined primarily for reporting battery degradation over life. In fact, Charge-Sustaining Available Power and Available Energy represent two complementary aspects in the performance of a battery at any point in time. Additionally, the Charge-Depleting Available Energy must also be tracked and reported over life.

A more complete representation of the energy and power behavior is represented by the example of the Usable Energy versus Power curve illustrated in Figure 20. The Figure also illustrates the CD Available Energy at the 10-kW power level, the CS Available Energy and the CS Available Power. The usable energy is calculated as the energy between the discharge and regen power capability curves as a function of the associated discharge pulse power. In this context, Figure 17 illustrates one such specific energy value (CS Available Energy) which happens to be calculated at a power equal to the discharge pulse power target. 


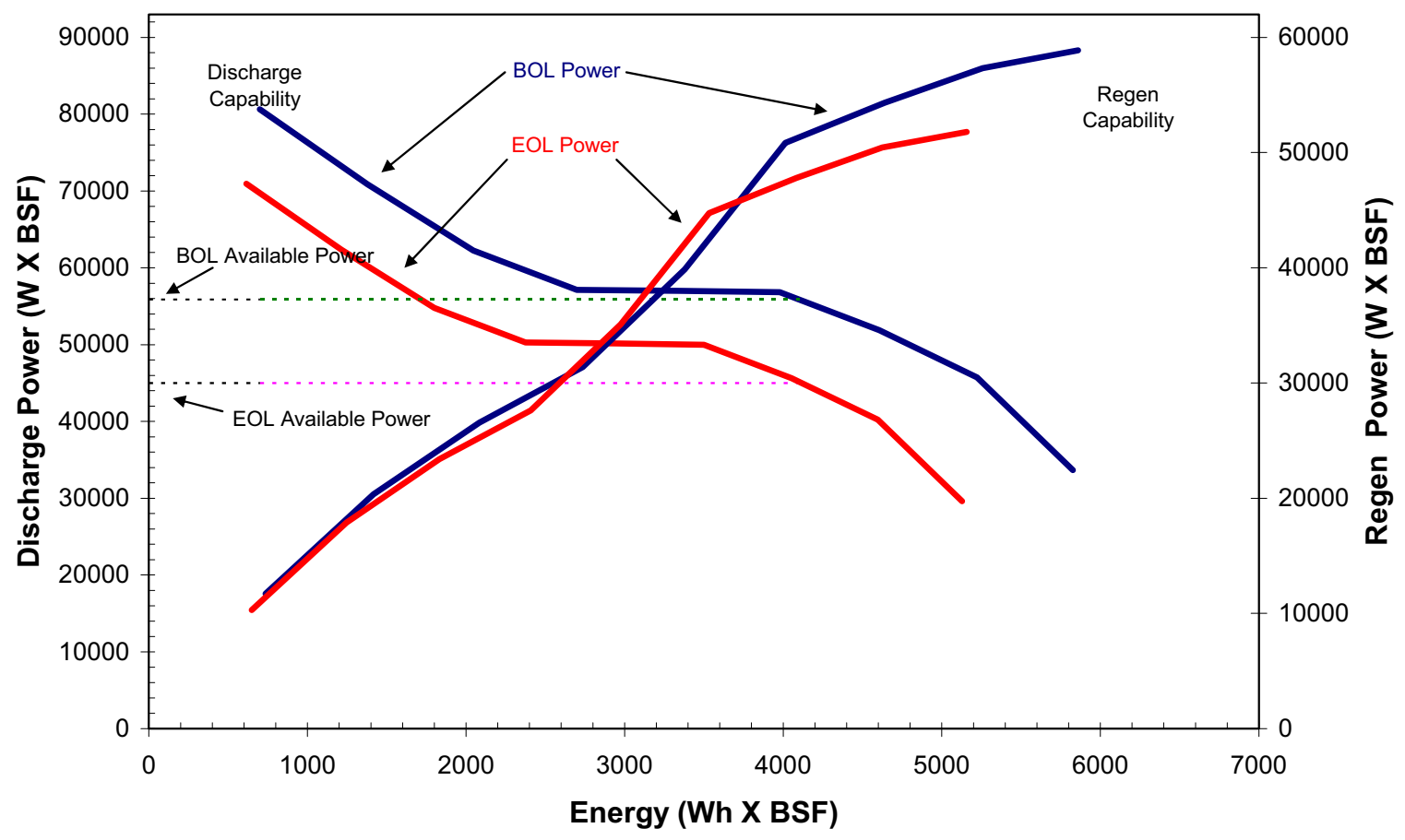

Figure 19. CS Available Power Over Life.

\subsubsection{Power and Energy Fade}

For devices subjected to life testing, the change in CS Available Power and CS and CD Available Energy from the beginning-of-life values (measured just prior to the start of life testing) to some later point in time are to be reported periodically as Power Fade and Energy Fade, both expressed as percentages of the original (BOL) values as shown in Equations 7 and 8.

$$
\begin{aligned}
& \text { Power Fade }(\%)=100 \times\left(1-\frac{{\text { Available } \text { Power }_{t 1}}_{\text {Available } \text { Power }_{t 0}}}{\text { Avo }}\right) \\
& \text { Energy Fade }(\%)=100 \times\left(1-\frac{\text { Available Energy }_{t 1}}{\text { Available Energy }_{t 0}}\right)
\end{aligned}
$$

In both cases $t 0$ refers to the time of the initial (BOL) RPT and $t 1$ refers to the time of the later RPT where power and energy fade are to be determined. 


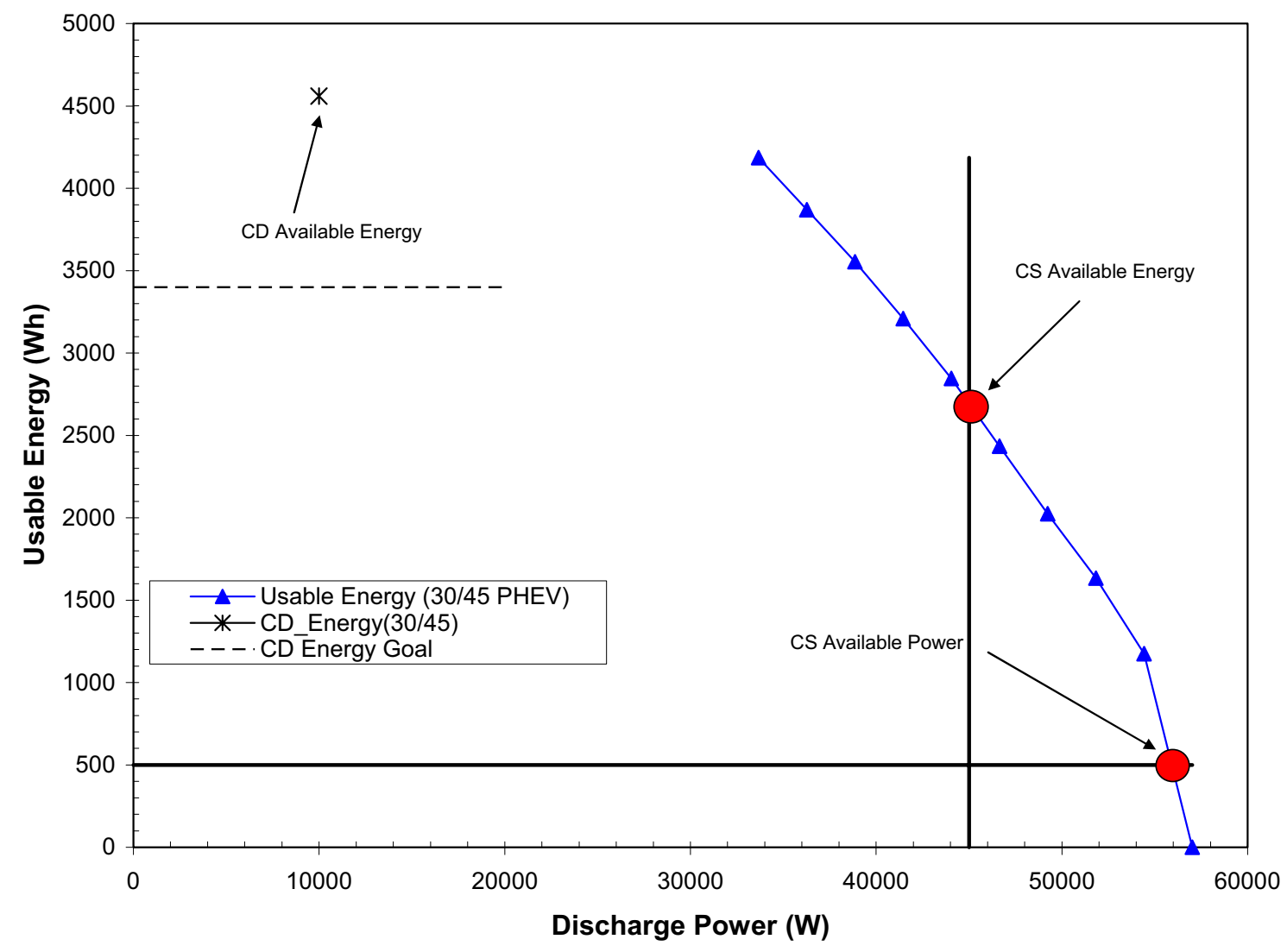

Figure 20. Usable Energy versus Power Curve.

\subsubsection{Minimum and Maximum DOD Values}

Minimum and maximum DOD values where the power targets can be met may be needed for other test purposes. These values can be determined by using the same HPPC data and scaling factors as in Figure 16, but plotted against the original DOD values from the HPPC Test (i.e., DOD values are not converted to the $10-\mathrm{kW}$ equivalent energy values). Figure 21 shows the results of this scaling applied to the same example data as previously shown. This graph shows that the minimum and maximum DOD values where the targets can be met are approximately 39 and $81 \%$, respectively.

The Cold Cranking Test DOD value can be determined by adding the energy removed at $10 \%$ DOD from full charge (or whatever value specified by the manufacturer as the minimum operating DOD) and the Available Energy Target for the Charge-Depleting mode, $3.4 \mathrm{kWh}$ and then reading the corresponding DOD value from Figure 13. This DOD is also illustrated in Figure 21. 


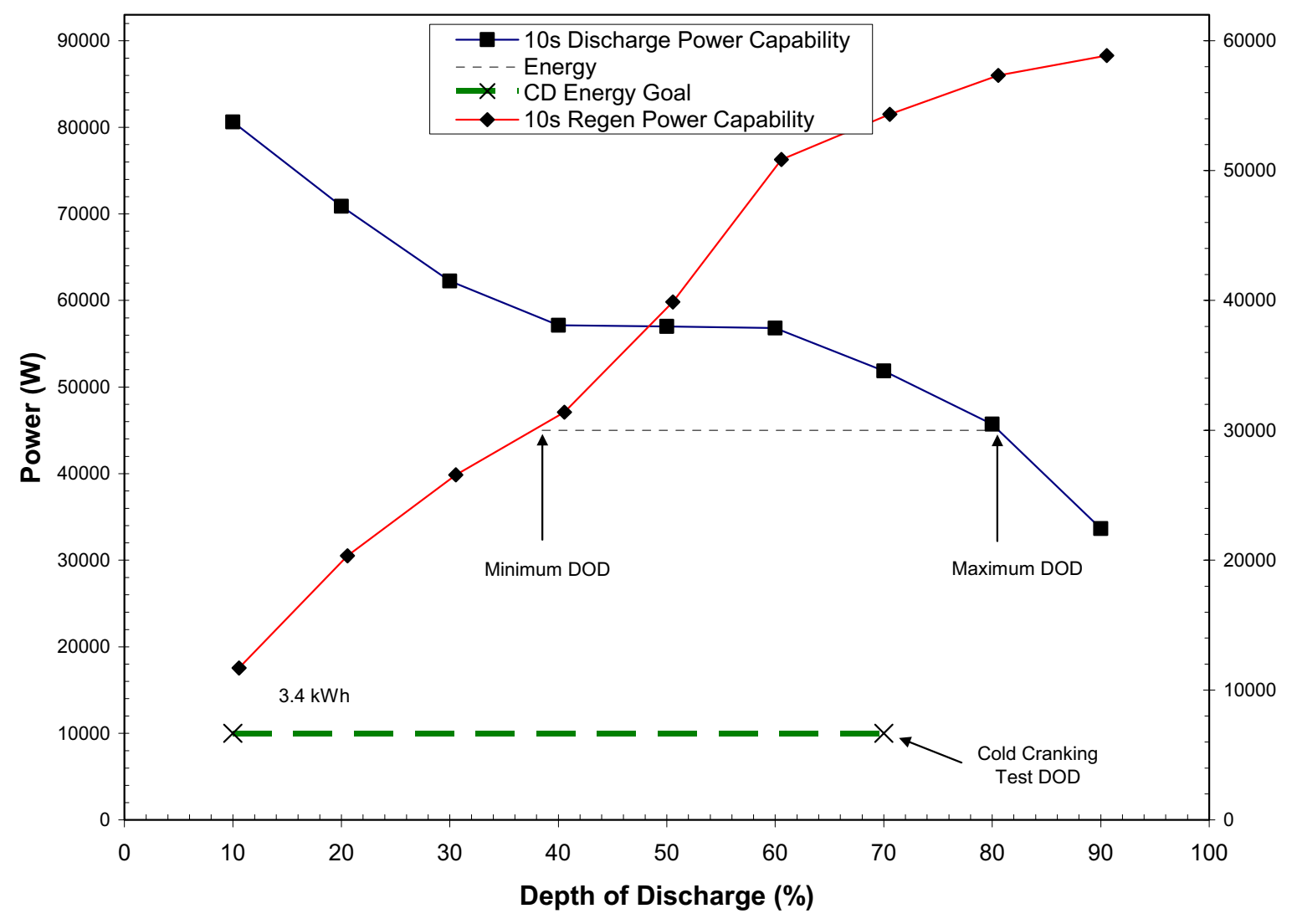

Figure 21. Minimum and Maximum DOD Values Where Targets Are Met.

\subsubsection{Two-Second Discharge Target Verification}

The 2-second discharge performance can be verified by using the voltages and currents from the same HPPC discharge pulses, but after 2 seconds into the pulse instead of the 10 -second values that are normally used. The rest of the analysis is the same as previously discussed.

\subsubsection{Pulse Power Characterization Profile Voltage Response}

Voltage response to the associated current stimulus may be shown by graphing the measured voltage and current as functions of time during one or more executions of the HPPC pulse profile or for the entire HPPC Test sequence.

\subsubsection{Other Laboratory Cell Performance Characteristics}

Other laboratory cell performance characteristics can be calculated from the HPPC data to permit scale-up calculations to full-size cells. These include some or all of the following:

- Voltage response time constant estimates for discharge, regen, and rest periods derived from the current-driven HPPC Test data 
- Cell capacity and energy in area-specific, gravimetric, and volumetric units $\left(\mathrm{mAh} / \mathrm{cm}^{2}\right.$, $\mathrm{mWh} / \mathrm{cm}^{2}, \mathrm{Ah} / \mathrm{kg}, \mathrm{Wh} / \mathrm{kg}, \mathrm{Ah} /$ liter, Wh/liter)

- Cell area-specific impedance (ASI) in ohms- $\mathrm{cm}^{2}$ for discharge and for regen from HPPC data for PHEV applications. (Note: this requires specific knowledge of the active surface area of the cells).

The data acquired from HPPC cell testing are ultimately used for modeling cell characteristics and for the selection and design of full-size module and battery pack characteristics.

\subsubsection{Determining Battery Size Factor When Not Supplied By Manufacturer}

Section 3.1.2 discusses the special case where the device manufacturer is unable to supply a Battery Size Factor in advance of testing. In this case, the minimum Battery Size Factor is calculated directly from the initial Low Current HPPC Test results. The method for doing this is effectively an inversion of the CS Available Energy calculation process described in Section 4.3.4, with steps as follows. ${ }^{33}$

1. Establish the relationship between HPPC power and $\mathrm{C}_{1} / 1$ discharge energy, both as functions of DOD, and plot this relationship as shown in Figure 14.

2. Rescale the regen power by the ratio of the regen power and discharge power targets and re-plot the results as in Figure 16, but without a Battery Size Factor applied.

3. Develop the Usable Energy versus discharge pulse power capability using the method described in Section 4.3.4 through 4.3.6 and depicted in Figure 20, again without applying a Battery Size Factor multiplier to the results. Figure 22 illustrates such a graph along with the results of the following steps.

4. On the Usable Energy graph, draw a line from the origin having a slope equal to the ratio of the CS energy target to the 10 -sec discharge power target with a $30 \%$ power margin. For Minimum PHEV Battery, this slope would be $8.55 \mathrm{Wh} / \mathrm{kW}$ (500 Wh CS Available Energy Target $) \div[45 \mathrm{~kW} \times 1.3] .^{34}$

5. Determine the value of energy at the point where this line intersects the Usable Energy curve. This is about $10.5 \mathrm{Wh}$ in this example.

6. Divide this energy value into the energy target. The result (normally rounded to the next larger integer) is the Battery Size Factor. For the graph shown in Figure 22, the resulting BSF would be about 48 cells.

\footnotetext{
33 This process is most accurately done using an automated analysis tool. However, it is described graphically here for an understanding of the calculational method, and the graphical result may be accurate enough if done carefully.

34 Note that this $30 \%$ power margin will not necessarily increase the available energy margin at beginning-of-life by $30 \%$, due to the accompanying increase in power capability of the larger size device. The power-to-energy $(\mathrm{P} / \mathrm{E})$ ratios corresponding to exactly meeting the targets are fixed (90 for Minimum PHEV Battery, 126.7 for Maximum PHEV Battery), but the $\mathrm{P} / \mathrm{E}$ function for a given device is highly nonlinear. Thus, the effect of this $30 \%$ power margin may be a change of much more or much less than $30 \%$ in available energy, depending on where the resulting device powers fall on the $\mathrm{P} / \mathrm{E}$ curves.
} 


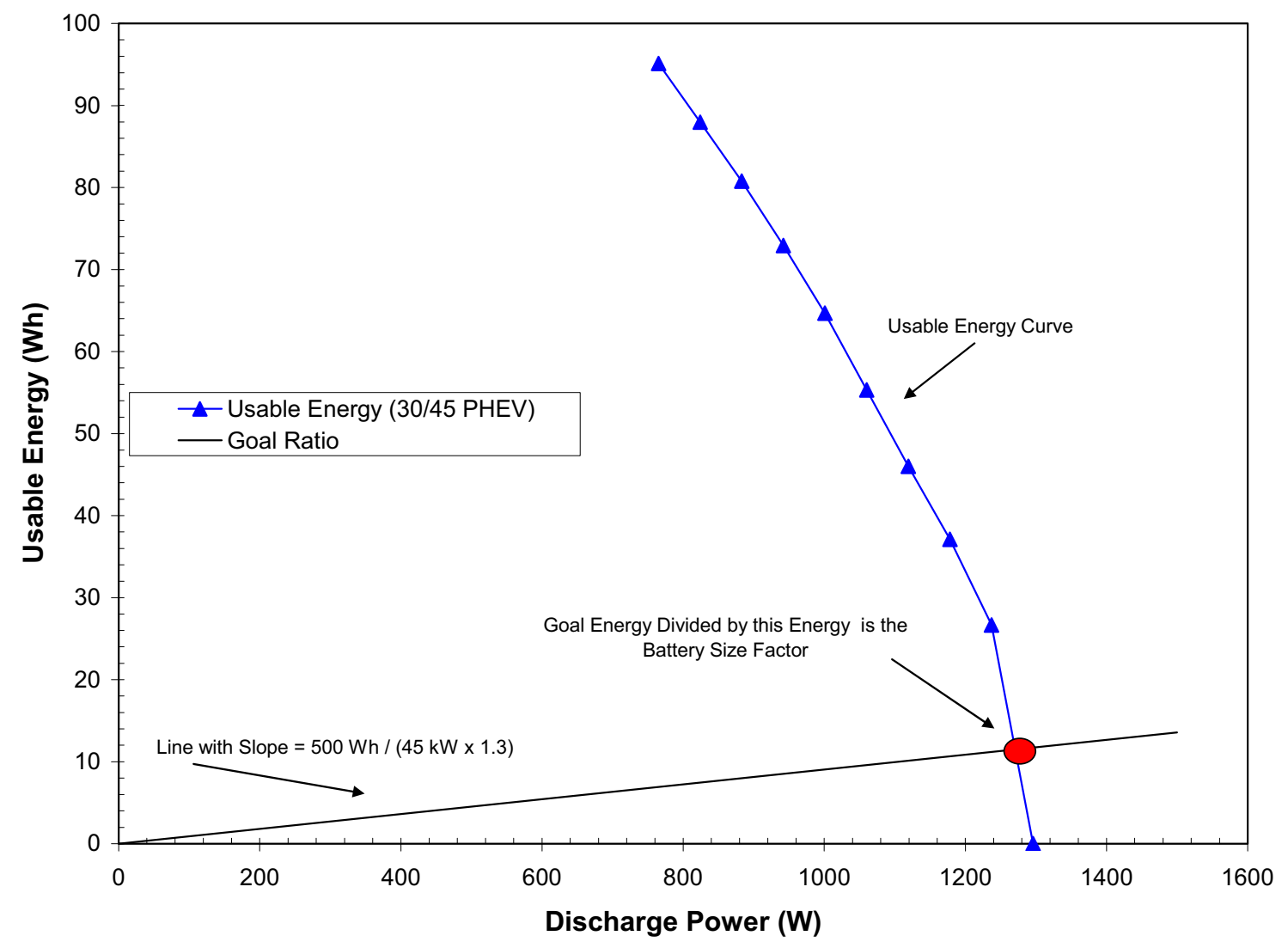

Figure 22. Finding a Battery Size Factor Using Device-Level Results.

7. Verify that this Battery Size Factor is still expected to give round-trip efficiency values within the targets at end-of-life. This can be done by executing the Efficiency Test at a power level scaled at $130 \%$ of the normal value (i.e., test power $=$ full system power divided by Battery Size Factor and multiplied by 1.3). ${ }^{35}$ If the applicable efficiency target(s) are not met using this scaling factor, the multiplier must be increased appropriately.

8. Verify that the BSF provides an adequate BOL energy margin for $\mathrm{CD}$ operation, e.g. $\mathrm{CD}$ $\mathrm{AE}$ should be at least $3.4 \mathrm{kWh} \times 1.3=4.42 \mathrm{kWh}$. If it doesn't, the BSF will need to be increased.

9. The BSF resulting from this process is used for all future testing. (A single typical or average value can be used for testing a group of identical devices).

35 The logic behind this approach is to increase the testing "stress level" (power) by a percentage equal to the BOL power margin, to give results that approximate those expected at end-of-life when the power margin has declined to zero. 


\subsection{Self-Discharge Test}

Self-discharge rate is determined over a fixed period (nominally 7 days) at one or more intermediate DOD conditions. The difference between the energy (watt-hours) capacities measured prior to the test and during the test is considered to be the energy loss reflecting self-discharge during the stand period. This energy loss is computed as the difference between the pretest HPPC-Current energy and the sum of the energies in the partial HPPC-Current discharges before and after the stand period. This value is then divided by the length of the stand period in days and multiplied by the appropriate Battery Size Factor for the applicable mode, as shown in Equation 9.

$$
\text { Self Discharge }=\frac{W h_{\text {before test }}-\left(W h_{\text {part } 1}+W h_{\text {part } 2}\right)}{\text { Stand Time in Days }} \times B S F
$$

The result of this calculation is reported for comparison with the target of no more than $50 \mathrm{Wh}$ per day.

\subsection{Cold Cranking Test}

The fundamental result of the Cold Cranking Test is the power capability at the end of the third 2-s pulse at $-30^{\circ} \mathrm{C}$, which is to be multiplied by the Battery Size Factor and compared to the target of 7 $\mathrm{kW}$. The actual power achieved does not necessarily represent the maximum power capability; it merely shows whether the device was able to meet the target. (Some batteries may be capable of higher power than this). The maximum power capability may be calculated in a manner analogous to the normal pulse-power capability results, as follows:

1. Calculate discharge pulse resistance values using the voltage and current values at three pairs of time points $[(\mathrm{t} 0, \mathrm{t} 1),(\mathrm{t} 2, \mathrm{t} 3)$, and $(\mathrm{t} 4, \mathrm{t} 5)$, illustrated in Figure 23], using the same $\Delta \mathrm{V} / \Delta \mathrm{I}$ calculation (Equation 3 ) used for discharge resistance in Section 4.4.2.

2. Calculate the discharge pulse power capability for each of the Cold Cranking Test pulses using Equation (5) as in Section 4.3.3. The current limitations must also be observed here. If the manufacturer specifies a minimum discharge voltage specifically for cold cranking, this voltage must be used for the calculation in place of the normal Minimum Discharge Voltage.

3. Multiply each of these three pulse power capability values by the Battery Size Factor and report the resulting power values for comparison with the target of $7 \mathrm{~kW}$. 


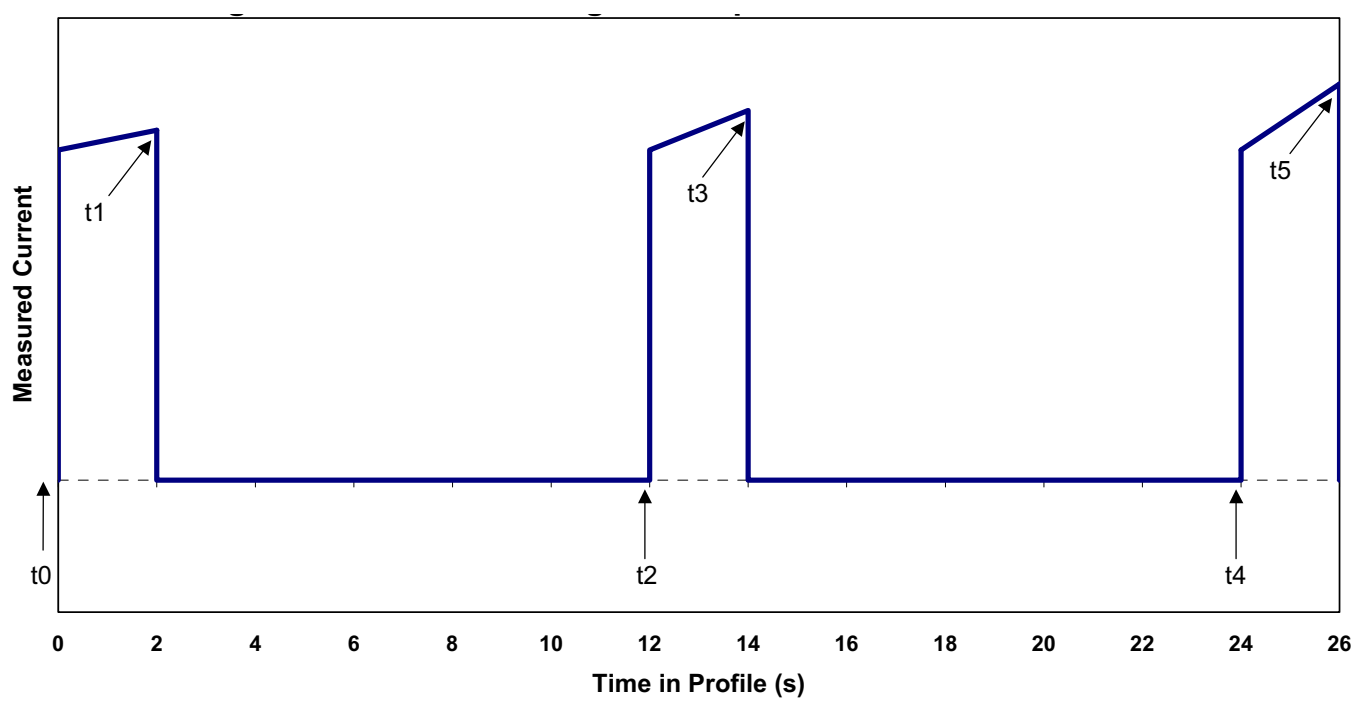

Figure 23. Cold Cranking Test Resistance Calculation Points.

\subsection{Thermal Performance Tests}

Measured capacity at the HPPC-Current rate is reported over the range of temperatures at which the Static Capacity Test is performed. Results of HPPC Testing at temperatures other than nominal are reported in the same formats defined in Section 4.3 except that the test temperature must accompany all data and graphs.

\subsection{Energy Efficiency Test}

Round trip energy efficiency is calculated from an integral number of test profiles of the Efficiency Test. The preferred approach is to use a group of 10 or more consecutive test profiles, both to reduce the impact of small profile-to-profile variations and to minimize numerical round-off effects. The calculation is performed as follows:

1. From an examination of the Efficiency Test data, choose a group of consecutive test profiles where the cell average SOC (as implied by temperature and peak voltage behavior) is stable, normally at the end of the cycling period. The amount of time to reach this condition varies but will commonly be an hour or more after the start of cycling.

2. Integrate both the current and power for the discharge and regen intervals of these profiles (separately). Verify that the discharge ampere-hours and the regen ampere-hours are equal (within $1 \%$ or less). If this condition is not satisfied, either (a) cycling conditions were not sufficiently stable or (b) the cell is not $100 \%$ coulombically efficient at the cycling conditions. In the first case, the test must be repeated using additional test profiles. In the second case, if a review of the data indicates that voltage and temperature conditions were stable, the results are reported but the charge imbalance must be noted.

3. Calculate round-trip efficiency as the ratio of discharge energy removed to regen energy returned during the profiles, expressed in percent as shown in Equation (10). 


$$
\text { Round }- \text { trip efficiency }=\frac{\text { watt } \cdot \text { hours }(\text { discharge })}{\text { watt } \cdot \text { hours }(\text { regen })} \times 100(\%)
$$

Round-trip efficiency may also be calculated if desired over a longer period of time (e.g., during life cycling) using any integral number of repeated test profiles for which the state-of-charge is stable, e.g., an entire block of several thousand profiles may be used instead of a small group. ${ }^{36}$

\subsection{Operating Set Point Stability Test}

No results are reported specifically from this test. The current, voltage, and residual capacity data are reviewed to determine that state-of-charge and other conditions are stable (and at their target values) for continuous cycle life testing, but otherwise this test is treated as part of cycle life testing.

\subsection{Cycle Life Tests}

For the selected life test profile, the cumulative number of test profiles executed prior to the most recent Reference Performance Tests is reported, along with any performance changes measured by these Reference Performance Tests. If testing is terminated due to the inability of the cell to perform the programmed test profile within the voltage limits or some other end-of-test condition, this is reported. However, the number of profiles performed is not necessarily the cycle life and should not be reported as such. Detailed results of the reference tests are reported over life as described under these specific tests, including the magnitude of adjustments made (if any) due to the measured temperatures being above or below the nominal temperature. In addition, degradation of capacity, pulse power capability, CD and CS Available Energy, and Cold Cranking Power capability as a function of life (i.e., number of test profiles performed) should be reported graphically.

The value of cycle life to be reported for a device subjected to cycle life testing is defined as the number of test profiles performed before end-of-life is reached. In general an end-of-life condition is reached when the device is no longer able to meet the targets (regardless of when testing is actually terminated). The ability to meet the targets is evaluated based on the periodic Reference Performance Tests, particularly the HPPC Test results. When the power and energy performance of the device (scaled using the Battery Size Factor) degrades to the point that there is no power and energy margin (i.e., CS or CD Available Energy is less than the target value at the target power), the device has reached end-of-life. In addition, the inability to meet any of the other technical targets (e.g., the cold cranking power, efficiency or self-discharge target) also constitutes end-of-life. The basis for the reported cycle life value (i.e., the limiting target condition) should also be reported. ${ }^{37}$ If the cycle life based on power and energy performance is very near the target, the end-of-life point may need to be interpolated based on the change in HPPC performance from the previous reference test.

36 The Efficiency Test and CS Cycle Life Test profiles are identical, so the Cycle Life Test data are directly usable for efficiency calculations if cycling is done at a constant SOC.

37 Efficiency and Self-Discharge are not necessarily measured at regular intervals during life testing, so the point during life cycling where such an end-of-life condition is reached cannot always be determined with high accuracy.

Typically the test results showing that the targets are not met would be reported, without attempting to interpolate an end-oflife point using two test results widely separated in time. 


\subsection{Calendar Life Test}

The raw data from calendar life testing are the periodic reference performance parameter measurements for all the batteries under test. The objective of this data analysis is to estimate battery calendar life under actual usage in a specified customer environment. Typically, the environmental specification will include a cumulative distribution of expected battery temperature over its 15 -year life in, for example, the $90^{\text {th }}$ percentile climate among the target vehicle market regions. These temperatures will vary, and will generally be substantially lower than the elevated temperatures used for (accelerated) calendar life testing. Note that for most $(>90 \%)$ of its 15 -year life, the battery will typically be in a non-operating, vehicle-parked state.

Predicting battery life is a desired outcome of testing. There are various approaches to constructing a battery life model. One is theoretical, using various physical and chemical processes that may occur in the battery, which degrade its performance. A second is fitting a curve to the data. The following discussion is limited to the latter approach and is meant to illustrate a general approach to construct a reasonable, data-based model. For a more advanced treatment of life test results, refer to the Technology Life Verification Test (TLVT) manual, Reference (4).

Curve fitting may be applied to resistance, power, energy, and capacity data and is transparent to battery chemistry and technology. Curve fitting is an interpretative, deductive approach to understanding the performance degradation process. Assuming that the battery test was performed with a number of different temperatures over a number of reference performance tests, the most general curve fit allows for a linear combination of temperature and time dependencies, as given in Eq. 11,

$$
Q=f(T) g(t)
$$

where $Q$ is the property of interest, $f(T)$ is the temperature-dependent part of the degradation process and $g(t)$ is the time-dependent part of the degradation process. An important assumption in constructing a curve-fit model is that there was no important change in mechanism of the degradation process with temperature and time. Temperature- and time-based changes can be accommodated, but the exact treatment of these cases is beyond the scope of this discussion.

Temperature. The two main approaches for describing temperature dependence of the degradation process, are linear and Arrhenius. Linear-with-temperature processes are very rare in battery testing. They usually occur in the early part of a longer test and are not truly indicative of the actual degradation process.

Arrhenius-like temperature dependence is common. It occurs when there is an activation energy barrier which must be overcome for the process to occur. The activation energy barrier, in this case, is a thermally activated process. The temperature-dependent part of Eq. 10 above then can be written as given in Eq. 12,

$$
f(T)=A e^{-E_{a} / R T},
$$

where $\mathrm{A}$ is a constant, $E_{a}$ is the activation energy for the process in $\mathrm{J} / \mathrm{mol}, R$ is the universal gas constant, $8.314 \mathrm{~J} / \mathrm{mol}-\mathrm{K}$, and $T$ is the absolute temperature in Kelvin. 
Time. Many life-limiting processes in a battery depend on either $\left(t^{Z}\right)$ or $\ln (t)$, depending how fast the property of interest, such as cell resistance, changes. The exponent $\mathrm{z}$ is a constant that is determined by curve fitting. Which form of the time-dependent part of Eq. 10, $g(t)$, is germane is determined by curve fitting. The simpler forms of the fit are usually preferable if the values of $r^{2}$ are approximately the same.

For example, if $Q=A e^{-E_{a} / R T} t^{z}$, the data may be fit to the linearized form of $Q$, Eq. 13, using the Microsoft Excel function LINEST.

$$
\ln (Q)=\ln (A)+\left(-E_{a} / R T\right)+z \ln (t),
$$

Care must be taken when $t=0$. These data points should be excluded from the initial fit. If the process depends on $\ln (t)$, as shown in Equation 13, the data at $t=0$ cannot be used.

\subsection{Reference Performance Tests}

Results to be reported from the periodic Reference Performance Tests are defined in the previous sections on Cycle Life and Calendar Life Tests.

\subsection{Module Controls Verification Tests}

Testing and analysis at the module level is similar to that employed for cells. However, standard tests are not defined in this manual for module control behavior, so analysis and reporting requirements for such tests must be detailed in device-specific test plans, as needed. Typically, these may include an understanding of the logic employed for electrochemically balancing the cells within the modules, and also understanding the thermal issues.

\subsection{System-Level Testing}

In general, the analysis and reporting of test results for complete battery systems is conducted similarly to comparable cell tests. Additional reporting requirements (e.g., detailed cell or module performance) should be specified in a battery-specific test plan that accounts for the specific design features of such a system.

Test procedures and the associated reporting requirements are not defined in this manual for systemlevel thermal management load testing. 


\section{REFERENCES}

1. USABC Electric Vehicle Battery Test Procedures Manual, Revision 2, DOE/ID-10479, January 1996.

2. PNGV Battery Test Manual, Revision 3, DOE/ID-10597, February 2001.

3. FreedomCAR Battery Test Manual for Power-Assist Hybrid Electric Vehicles, DOE/ID11069, October 2003

4. Advanced Technology Development Program for Lithium-Ion Batteries: Battery Technology Life Verification Test Manual, INEEL/EXT 0401986, February 2005 


\section{APPENDIX A}

Sample Test Plan

\section{VEHICLE TECHNOLOGIES PROGRAM PHEV TEST PLAN FOR TBD CELLS}

1.0 Purpose and Applicability

The intent of this test plan is to characterize the performance, of TBD cells supplied by TBD for the TBD Battery mode. This testing will support the proposed program and provide baseline data for comparison with previous technologies and future cell developments. This testing is under the oversight of the Department of Energy, Office of Vehicle Technology. These Articles will be subjected to the performance test procedures defined for the PHEV Program.

\section{$2.0 \quad$ References}

2.1 Battery Test Manual for Plug-In Hybrid Electric Vehicles, INL/EXT-0712536, Rev 0, March 2008

\subsection{Equipment}

3.1 All testing is to be performed on test channels with current and voltage capabilities adequate for the specific test procedures to be performed.

3.2 Except where specifically noted otherwise, all tests will be performed within a temperature chamber capable of controlling the chamber temperature to within $\pm 3{ }^{\circ} \mathrm{C}$.

\subsection{Prerequisites and Pre-Test Preparation}

4.2 Actual weights and open circuit voltages of the Articles as delivered shall be recorded. 
5.0 Cell Ratings, Test Limitations and Other Test Information

$5.1 \quad$ Ratings

Rated Capacity:

Application:

TBD A-h $\left(\mathrm{C}_{1} / 1\right.$ rate $)$

Battery Size Factor:

TBD Battery

HPPC Pulse Power Voltage Calculation Ranges:

Vmin

TBD V

Vmax

TBD V

5.2 Temperature Ratings

Operating Temperature Range:

Discharge Temperature Range:

TBD

Charge Temperature Range:

TBD

Storage Temperature Range:

TBD

Cold Cranking Temperature

TBD

TBD

5.2 Nominal Values

Nominal Capacity:

TBD A-h

Nominal Weight:

TBD kg

Nominal Volume:

TBD L

5.4 Discharge Limits

Minimum Discharge Voltage

$\leq 10$ second pulse:

TBD

$\leq \mathrm{C}_{1} / 1$ rate:

TBD

$\leq 10$ second pulse and temp $\leq 0^{\circ} \mathrm{C}$ : TBD

Maximum Discharge Current:

TBD

5.5 Charge and Regen Limits

Maximum Regen Voltage for $\leq 10 \mathrm{~s}$ :

TBD

Continuous rates $\leq \mathrm{C}_{1} / 1$ rate:

TBD

Maximum Regen Current $(10 \mathrm{sec})$ :

TBD

$\leq 10$ second pulse and temp $\leq 0^{\circ} \mathrm{C}$ :

TBD

5.6 Other Test Info:

Charge Procedure:

5.6 End-of-Testing Criterion:

1. Completion of a number of properly scaled life cycle test profiles adequate to meet the PHEV life cycle 
target (as appropriate for the technology) or scheduled testing; or

2. Inability to perform the life cycle test profile at the programmed values at the required DOD without exceeding the voltage limits; or

3. Inability to give valid data from the HPPC Reference Performance Test; or

4. Inability to meet the PHEV power and energy targets or

5. When directed by the Vehicle Technologies Program Manager.

\subsection{Safety Concerns and Precautions}

In general the safety issues with these cells are similar to those encountered previously with other similar technology tested for the Vehicle Technologies

Program. Care is warranted due to the high power capability of these cells, as noted below.

\subsection{Cell Handling}

TBD

\subsection{Other Safety Precautions}

TBD 


\subsection{Tests to be Performed Under this Test Plan}

The Cells to be tested under this test plan will be subjected to the performance test sequence in Table 1. The depth of discharge is to be established by discharging at a rated HPPC current for a fixed period of time from full charge. Unless otherwise specified, the test temperature shall be $30 \pm 3{ }^{\circ} \mathrm{C}$. These Articles will be tested in a temperature chamber

\subsection{Performance Testing}

\section{Table 1. Performance Test Sequence}

\begin{tabular}{|c|c|c|}
\hline Item & Sequence of Initial Performance Tests for the Cells & $\begin{array}{c}\text { No. } \\
\text { Iterations }\end{array}$ \\
\hline 1 & $\begin{array}{l}\text { Static Capacity Test (See Reference 2.1, Section 3.2) } \\
\text { Conduct this test on TBD cells at a constant rated } \mathrm{C}_{1} / 1 \\
\text { discharge current. } \\
\text { Note: Test is to be terminated at manufacturer-specified } \\
\text { cutoff voltage, NOT rated capacity } \\
\text { * Repeat discharge until measured capacity is stable within } \\
2 \% \text { for } 3 \text { successive discharges (maximum } 10 \text { discharges) }\end{array}$ & $*$ \\
\hline 2 & $\begin{array}{l}\text { Hybrid Pulse Power Characterization Test (Reference } \\
\text { 2.1, Section 3.4) } \\
\text { Perform the Low test on TBD cells. The Low Current Test } \\
\text { is performed at a peak discharge current of TBD. HPPC } \\
\text { Current = TBD. } \\
\text { For all Articles, the HPPC Current discharge will be } \\
\text { included in the same data file as the HPPC test for } \\
\text { calculation purposes. }\end{array}$ & 1 \\
\hline 3 & $\begin{array}{l}\text { Constant Power Discharge Test (Reference 2.1, Section } \\
\text { 3.3) } \\
\text { Conduct this test on TBD cells at a BSF-scaled 10-kW } \\
\text { discharge rate. } \\
\text { Note: Test is to be terminated at manufacturer-specified } \\
\text { cutoff voltage, NOT rated capacity }\end{array}$ & 1 \\
\hline 4 & $\begin{array}{l}\text { Self-Discharge Test (Reference 2.1, Sections 3.5) } \\
\text { Conduct this test on TBD cells }\end{array}$ & 1 \\
\hline
\end{tabular}




\begin{tabular}{|c|c|c|}
\hline 5 & $\begin{array}{l}\text { Cold Cranking Test (Reference } 2.1 \text {, Sections 3.6) } \\
\text { Conduct this test on TBD cells at }-30^{\circ} \mathrm{C} \text { at the maximum } \\
\text { DOD value where the targets can be met. For this test plan, } \\
\text { the cold soak time at }-30^{\circ} \mathrm{C} \text { prior to pulse testing shall be } \\
\text { four hours. }\end{array}$ & 1 \\
\hline 6 & $\begin{array}{l}\text { Thermal Performance Test (Reference 2.1, Sections 3.7) } \\
\text { Perform a Constant-Power Discharge Test and the Low- } \\
\text { Current HPPC Test (see } 2 \text { above) at } 0,-10,-30 \text {, and } 50^{\circ} \mathrm{C} \\
\text { on TBD of the cells. } \\
\text { Recharging for these tests is to be done at } 30^{\circ} \mathrm{C} \text { ambient } \\
\text { temperature. A soak period of nominally four hours or } \\
\text { longer is required at each temperature for all tests. }\end{array}$ & 1 \\
\hline 7 & $\begin{array}{l}\text { Cycle Life Test (Reference 2.1, Sections } 3.9 \& 3.10 \text { ) } \\
\text { As directed. }\end{array}$ & \\
\hline 8 & $\begin{array}{l}\text { Calendar Life Test (Reference 2.1, Sections 3.11) } \\
\text { As directed. }\end{array}$ & \\
\hline
\end{tabular}




\section{APPENDIX B}

\section{Gap Analysis}

\begin{tabular}{|c|c|c|c|}
\hline Min PHEV & Target & $\overline{B O L}$ & Present \\
\hline $\begin{array}{l}\text { Peak Discharge Pulse Power }(10 \mathrm{sec}) \\
{[\mathrm{kW}]}\end{array}$ & 45 & & \\
\hline Peak Regen Pulse Power $(10 \mathrm{sec})[\mathrm{kW}]$ & 30 & & \\
\hline $\begin{array}{l}\text { Available Energy for CD (Charge- } \\
\text { Depleting) Mode, } 10-\mathrm{kW} \text { Rate [kWh] }\end{array}$ & 3.4 & & \\
\hline $\begin{array}{l}\text { Available Energy for CS (Charge- } \\
\text { Sustaining) Mode, } 10-\mathrm{kW} \text { Rate [kWh] }\end{array}$ & 0.5 & & \\
\hline $\begin{array}{l}\text { Minimum Round-trip Energy Efficiency } \\
\text { (CS } 50 \mathrm{Wh} \text { profile) }[\%]\end{array}$ & 90 & & \\
\hline $\begin{array}{l}\text { Cold cranking power at }-30^{\circ} \mathrm{C}, 2 \mathrm{sec}, 3 \\
\text { Pulses }[\mathrm{kW}]\end{array}$ & 7 & & \\
\hline CD Cycle Life (cycles) & 5,000 & & \\
\hline $\begin{array}{l}\text { CS HEV Cycle Life, } 50 \text { Wh Profile } \\
\text { (cycles) }\end{array}$ & 300,000 & & \\
\hline Calendar Life, $35^{\circ} \mathrm{C}$ [yr] & 15 & & \\
\hline Maximum System Weight $[\mathrm{kg}]$ & 60 & & \\
\hline Maximum System Volume [L] & 40 & & \\
\hline Maximum Operating Voltage [Vdc] & 400 & & \\
\hline Minimum Operating Voltage [Vdc] & $>0.55 \times$ Vmax & & \\
\hline Maximum Self-discharge [Wh/day] & 50 & & \\
\hline $\begin{array}{l}\text { Maximum System Recharge Rate at } \\
30^{\circ} \mathrm{C}[\mathrm{kW}]\end{array}$ & $1.4(120 \mathrm{~V} / 15 \mathrm{~A})$ & & \\
\hline $\begin{array}{l}\text { Unassisted Operating \& Charging } \\
\text { Temperature Range } \\
52^{\circ} \mathrm{C} \quad>45 \mathrm{~kW} \text { Discharge Power } \\
0^{\circ} \mathrm{C} \quad>22.5 \mathrm{~kW} \text { Discharge Power } \\
-10^{\circ} \mathrm{C} \quad>13.5 \mathrm{~kW} \text { Discharge Power } \\
-30^{\circ} \mathrm{C} \quad>4.5 \mathrm{~kW} \text { Discharge Power }\end{array}$ & -30 to +52 & & \\
\hline Survival Temperature Range & -46 to +66 & & \\
\hline $\begin{array}{l}\text { Maximum System Production Price @ } \\
100 \mathrm{k} \text { units/yr }\end{array}$ & $\$ 1,700$ & & \\
\hline
\end{tabular}

